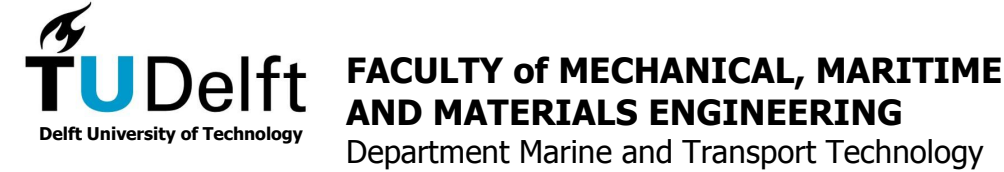 \\ Mekelweg 2 \\ 2628 CD Delft \\ The Netherlands \\ Phone +31 (0)15-2782889 \\ Fax +31 (0)15-2781397 \\ www.mtt.tudelft.nl
}

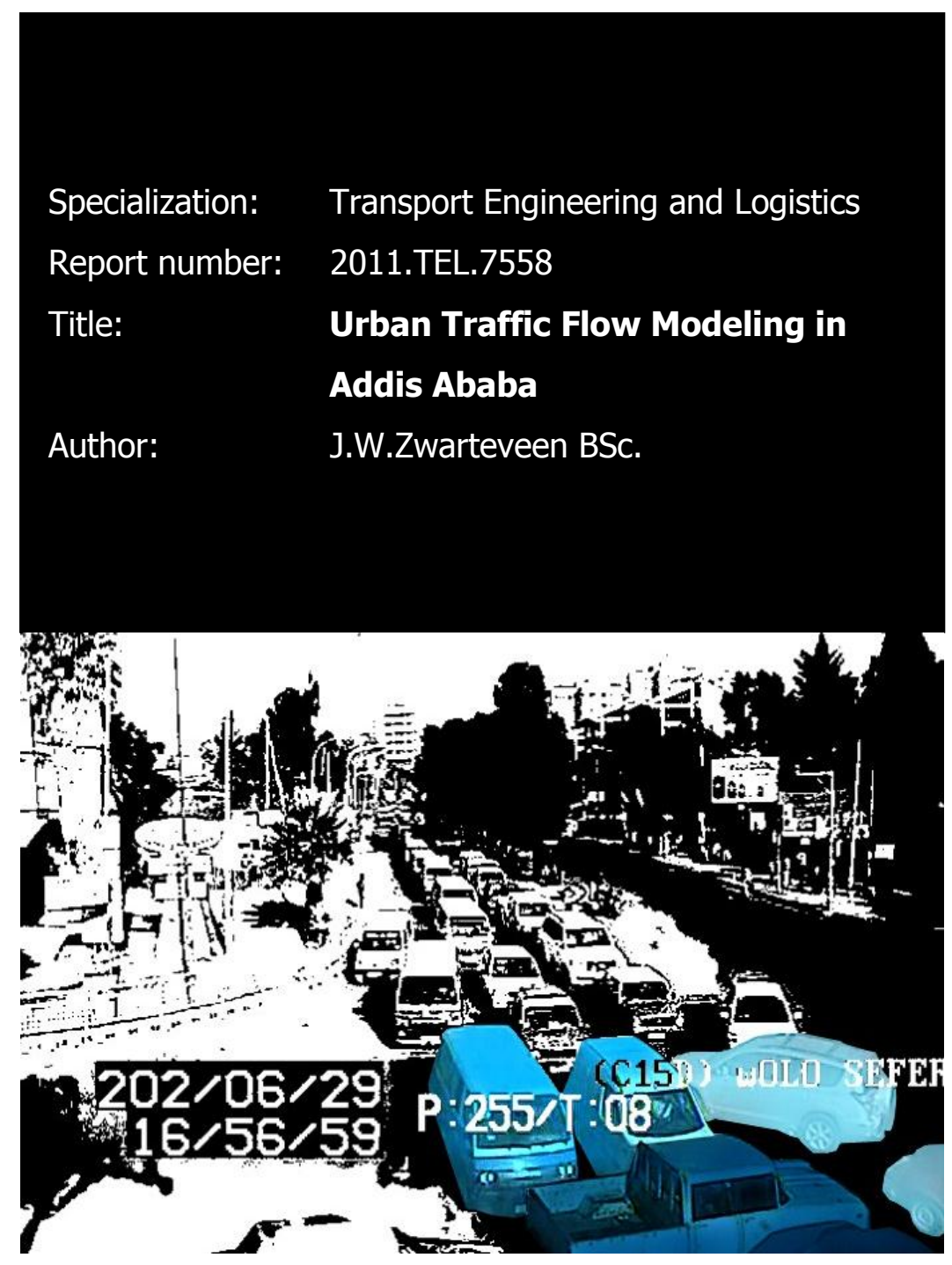

Title in Dutch: Modelleren van verkeersstromen in

Addis Ababa

Type: $\quad$ Master of Science thesis

Confidential: No

Initiator: $\quad$ Prof.dr.ir. J.Hellendoorn

Supervisor: $\quad$ S.K.Zegeye MSc.

Date: March 24, 2011 

Mekelweg 2

2628 CD Delft

the Netherlands

Phone +31 (0)15-2782889

Fax +31 (0)15-2781397

$\underline{\text { www.mtt.tudelft.nl }}$

Student: J.W.Zwarteveen BSc. Type: Master of Science thesis

Supervisor: S.K.Zegeye MSc. $\quad$ Creditpoints (EC): 36

Specialization: Transport Engineering and Logistics

Report number: 2011.TEL.7558

Confidential: $\quad$ No

\section{Subject: $\quad$ Urban traffic flow modeling in Addis Ababa}

Sub Saharan Africa has the highest urban growth worldwide. Directly related to the urban growth is the growth in traffic demand. A very low road density in cities in this region causes severe congestion. This study considers Addis Ababa, the capital city of Ethiopia. Improving the current use of infrastructure at intersections is the focus.

The research objectives of this thesis are the following:

- Determine the different factors that significantly influence the traffic flow rate at the intersections of Addis Ababa

- Build a model of the traffic flow rate at the intersections of Addis Ababa

- Assess different strategies to improve the traffic flow rate at one specific intersection in Addis Ababa

The report should comply with the guidelines of the section. Details can be found on the website given above.

The professor,

Prof. dr. ir. J.Hellendoorn

This report consists of 69 pages and 11 appendices. Copyright (c) 2011 Jan Willem Zwarteveen. It may only be reproduced literally and as a whole. For commercial purposes only with written authorization of the author. Requests for consult are only taken into consideration under the condition that the applicant denies all legal rights on liabilities concerning the contents of the advice. 



\section{Acknowledgments}

The work reported in this thesis was executed under the responsibility of Prof. Hans Hellendoorn. First of all, I would like to express my gratitude towards him for making this research possible. It was as a result of his willingness to help and his network that he found a match to my large list of requirements for an MSc thesis assignment. During the process he stayed involved by sending me in the right direction, assuring a narrow scope of the research. Without the guidance, I would probably have tried to explain the whole world and to solve all its problems. I appreciate it very much that he even took the time to help me during my job orientation.

My direct supervisor was Solomon Zegeye. During the process I was impressed by the effectiveness of all meetings, the into-dept discussions we had and the time and effort he put into my thesis. I am very thankful he was able to supervise this assignment even during the end phase of his own PhD research. His personal touch during all meetings made the process highly pleasurable: we discussed the cultural differences between Ethiopia en the Netherlands, the challenges of the Dutch society and the opportunities of the Ethiopian economy.

Furthermore, I would like to thank everybody who is involved with ITEAM in addition to Solomon Zegeye: Alemgena Araya, John Seiffers and Martin Seiffers. Their comments from an entrepreneurial point of view resulted in a study not only with scientific contributions, but also with economic relevance. I wish them good luck with their Ethiopian intelligent traffic engineering and management consultancy business.

I am grateful for the support of Abraham Belay and Mekonnin Tadessa of INSA in Addis Ababa. Without their contribution, this research would not have been possible. They supplied large amounts of video data of the Addis Ababa intersections that formed the backbone of this thesis.

I also would like to thank the Civil Engineering Transport and Planning department of Delft University of Technology - and in particular Hans van Lint - for sharing their knowledge of traffic systems and contributing to the formulation of the problem statement.

Further, general words of thanks for Prof. Peter Wieringa for stimulating me to attend the MA track of Excellence, the Honourstrack. It enabled me to study the relation between technology, entrepreneurship and developing countries, with the topic of this thesis as a final result.

Finally, a special word of thanks for my girlfriend, Anne-Sophie van der Spek, for her comments on the used English language, for her vital lay-out advice and the patience during the period in which I assumed the whole world consisted of intersection control, vehicle flows and traffic modeling. 


\section{Summary}

World's largest urban growth is taking place in Sub Saharan Africa. As a result, the demand for mobility is increasing. However, the supply of urban infrastructure is low. This is causing mobility problems, such as congestion. Improvements are possible by building new infrastructure. This is a long term, complex and expensive solution. A short term solution is to improve the traffic management to maximize the use of existing infrastructure. Intersections can be considered as the bottlenecks of the urban traffic flows. In order to maximize the use of existing infrastructure, it is useful to quantify the influences of the different factors on the intersection flow. Numerous scientists have studied the traffic flow at intersections in both developed countries and developing countries; however, no study about a city in Sub Saharan Africa could be found. The goal of this research is the development of a simulation model that describes the traffic flows at the intersections of Africa Avenue in Addis Ababa, Ethiopia. The aim of the model is to perform ex ante assessment of different flow improvement strategies.

Lanes at three traffic intersections (both officer controlled and signal controlled) were studied during times of congestion. 6573 vehicles were observed, from which $76 \%$ were passenger cars, $21 \%$ were minibuses and $2 \%$ were heavy vehicles. The average queue discharge flow for the straight through traffic was significantly lower than the saturation flow for the same conditions. These were 1358 Passenger Car Units per hour per lane (PCU/h/ln) and $1522 \mathrm{PCU} / \mathrm{h} / \mathrm{ln}$ respectively. It appeared that the total flow at the studied interfering lanes at the intersection depends on the share of minibuses, the share of slow vehicles, the number of lanes per approach and the productivity of the type of control.

An officer controlled intersection was used as a case study for to flow improvement. Installing traffic responsive signals showed the potential to increase the interference flow. To reach a high productivity with signal control, thorough studies by specialists are needed. However, as a result of the chaotic traffic behavior it is not sure whether the signal settings can be tuned such that signal control results in an improvement compared to officer control. Simple, low-cost and effective solutions with a high certainty appears possible to improve the productivity of officer control. The flow at the studied interfering lanes is expected to increase with $6.4 \%$ compared to the current $2275 \mathrm{PCU} / \mathrm{h}$.

To cope with a large expected growth in traffic demand, maximizing the use of existing infrastructure will not be enough. A combination with broader solutions - such as extra infrastructure and coordinated traffic control - is difficult to realize but essential. Further research is needed to determine what the effects of broader solutions will be and how these measures can be implemented successfully. 


\section{Summary in Dutch}

De grootste stedelijke groei ter wereld vindt plaats in Sub-Sahara Afrika. Het gevolg hiervan is dat de vraag naar mobiliteit toeneemt. Dit, in combinatie met het lage aanbod van infrastructuur zorgt voor mobiliteitsproblemen, zoals verstoppingen. Extra wegen zorgen voor een oplossing. Dit is een kostbare, complexe oplossing voor de lange termijn. Een korte termijn oplossing is het maximaliseren van het gebruik van het huidige netwerk. Kruispunten kunnen als de bottlenecks van de verkeersstromen beschouwd worden. Om het gebruik van het huidige netwerk te maximaliseren is het nuttig om de invloeden van verschillende factoren op de doorstroom te kwantificeren. Er zijn veel studies gedaan naar de doorstroom in ontwikkelde en ontwikkelende landen, maar publicaties over Sub-Sahara Afrika werden niet gevonden. Het doel van deze studie is het modeleren van de voertuigstromen op kruispunten van de Africa Avenue in Addis Ababa, Egypte. Het model zal gebruikt worden voor ex ante beoordeling van verschillede doorstoom verbeteringsstrategieën.

Rijbanen van drie verschillende verkeerskruispunten (zowel met verkeerslichten als met menselijke verkeersregelaars) zijn bestudeerd tijdens de spits. 6573 voertuigen zijn geobserveerd, waarvan $76 \%$ personen auto's, $21 \%$ minibusjes en $2 \%$ zware voertuigen. De gemiddelde verzadigingsstroom voor verkeer rechtdoor was 1522 personen auto eenheden per uur per rijbaan (PCU/h/ln), de gemiddelde stroomsnelheid van auto's die uit een rij bij een verkeerslicht vertrokken was significant lager, namelijk $1358 \mathrm{PCU} / \mathrm{h} / \mathrm{ln}$. Het bleek dat de totale doorstoom bij interfererende rijbanen op de bestudeerde kruispunten afhankelijk was van het percentage minibusjes, het percentage trage voertuigen, het aantal rijbanen per rijrichting en de productiviteit van het type verkeersregeling.

Een manueel geregelde kruispunt functioneerde als case studie voor het verbeteren van de doorstroom. Het installeren van verkeerslichten heeft de potentie om voor verbeteringen te zorgen. Ten gevolge van het chaotische verkeer is het niet zeker of de verkeerlichten door specialisten kunnen worden ingesteld zodanig dat de productiviteit hoger is dan met manuele verkeersregelingen. Simpele, goedkope en effectieve oplossingen om de productiviteit van de manuele regeling te verhogen bestaan. De verwachte verbetering op het bestudeerde kruispunt is $6.4 \%$ vergeleken bij de huidige doorstroom van $2275 \mathrm{PCU} / \mathrm{h}$. Het maximaliseren van het gebruik van de huidige infrastructuur is niet genoeg om de verwachte groei te faciliteren. Een combinatie met grotere oplossingen - zoals extra infrastructuur en gecoördineerde regelingen - zijn essentieel, maar moeilijk om te realiseren. Verder onderzoek is nodig voor effectieve implementatie van deze grotere oplossingen. 


\section{Glossary}

\section{List of symbols}

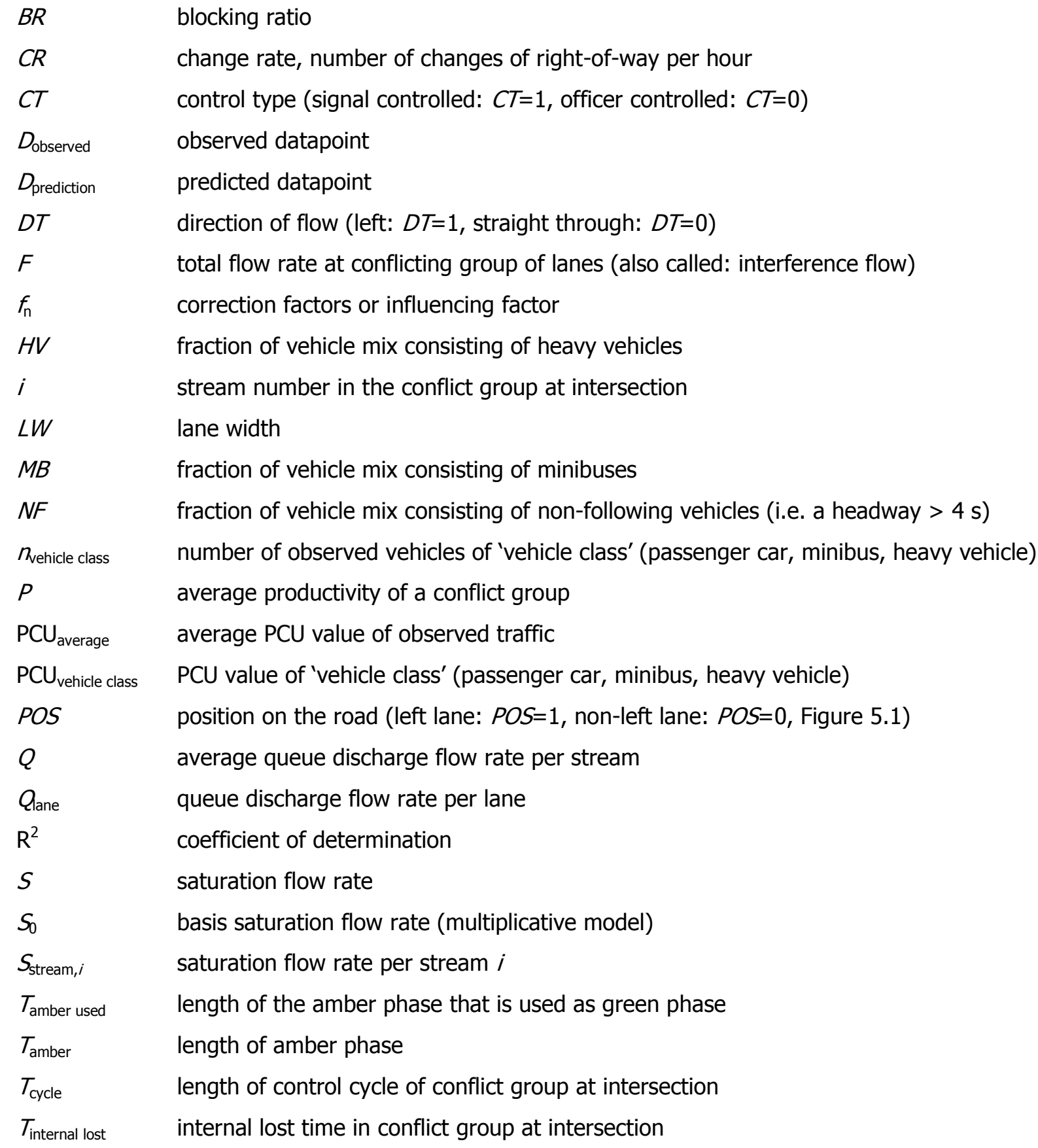




$\begin{array}{ll}T_{\text {start up }} & \text { start-up delay between start of green phase and movement of first vehicle } \\ \beta_{n} & \text { corresponding coefficient for the influencing factor } f_{n} \\ \varepsilon & \text { error } \\ \mu & \text { interference efficiency }\end{array}$

\section{Acronyms and abbreviations}

$\begin{array}{ll}\text { HCM } & \text { Highway Capacity Manual } \\ \text { PCE } & \text { Passenger Car Equivalent } \\ \text { PCU } & \text { Passenger Car Unit } \\ \text { SUV } & \text { Sports Utility Vehicle }\end{array}$




\section{Contents}

$\begin{array}{lll}\text { Acknowledgments } & \text { ii }\end{array}$

Summary iii

Summary in Dutch $\quad$ iv

Glossary $\quad$ v

$\begin{array}{lll}\text { Contents } & \text { vii }\end{array}$

1. Introduction 2

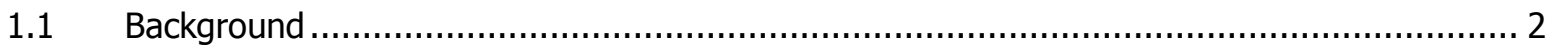

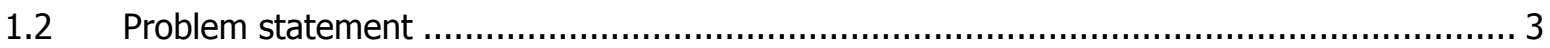

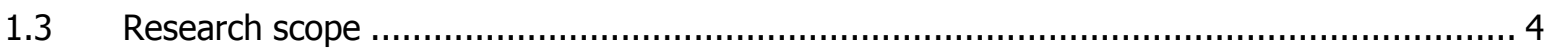

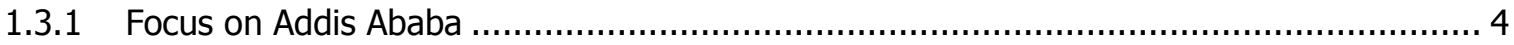

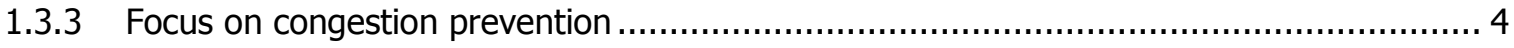

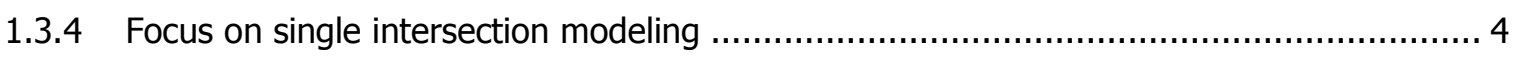

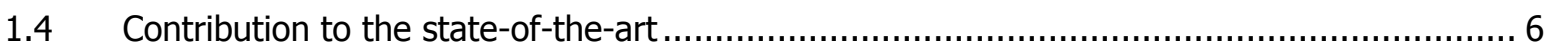

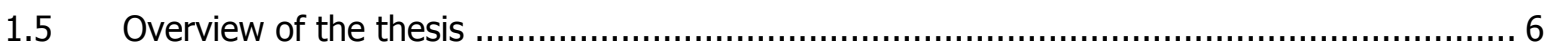

2. Literature review $\quad 8$

$2.1 \quad$ Urban traffic congestion in developing countries ....................................................... 8

2.1.1 Mobility characteristics of cities in developing countries .......................................... 8

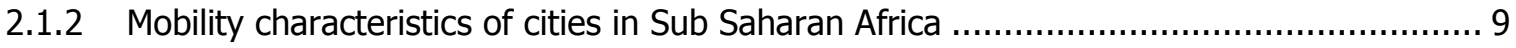

2.1.3 Mobility characteristics Addis Ababa ................................................................. 9

2.1.4 Mobility improvement, economic growth and sustainable development..........................10

2.2 Traffic flow at urban intersections in developing countries........................................11

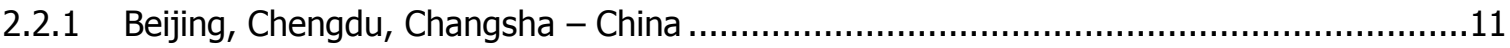

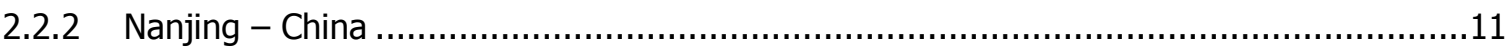

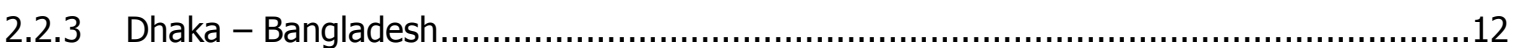




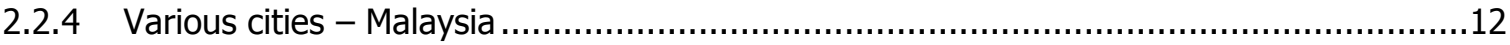

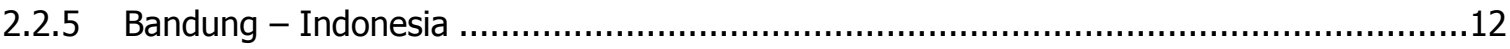

2.2.6 Comparison developing and developed countries ...................................................12

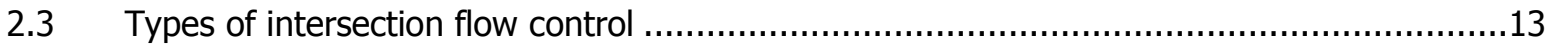

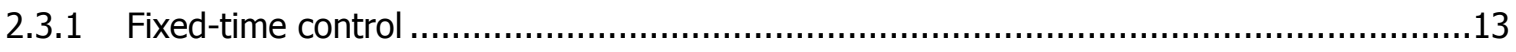

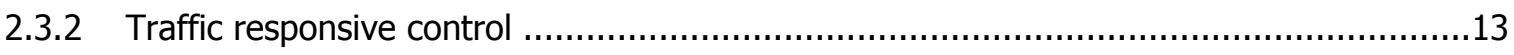

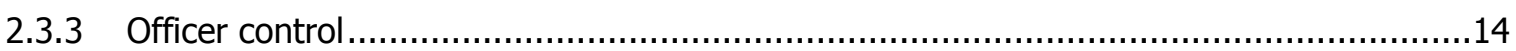

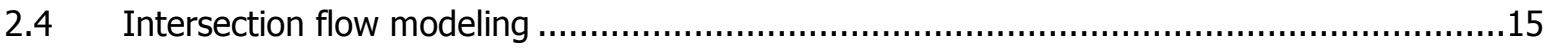

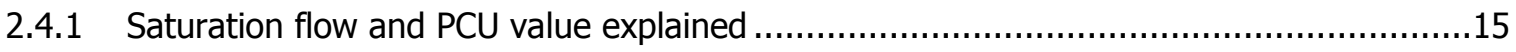

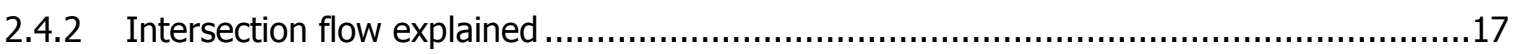

2.4.3 Macroscopic intersection flow modeling ............................................................ 18

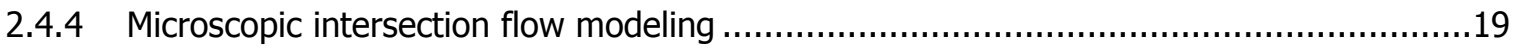

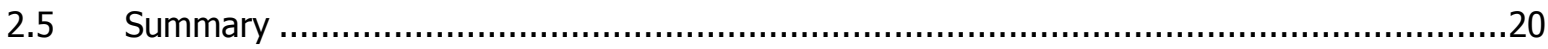

3. Research approach and methodology 22

3.1 Analysis of traffic flow at the intersections of Addis Ababa...........................................22

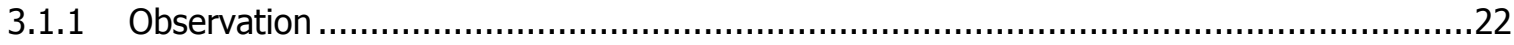

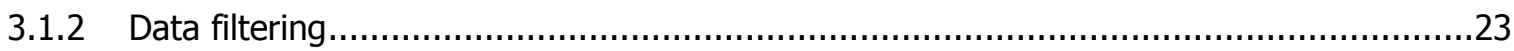

3.1.3 Saturation flow and PCU value calculation method …...........................................2

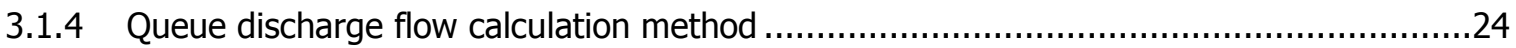

3.1.5 Interference flow and interference efficiency calculation method................................24

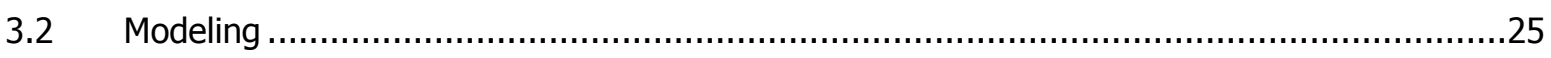

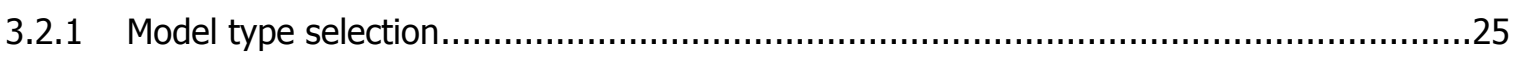

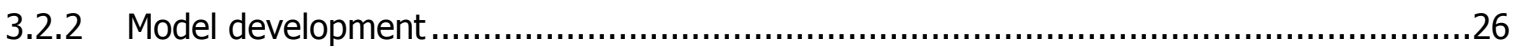

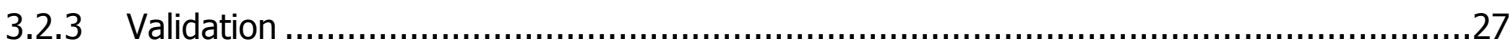

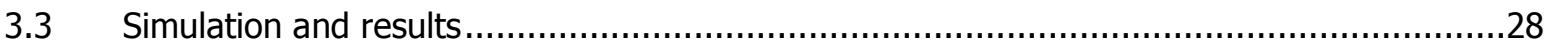

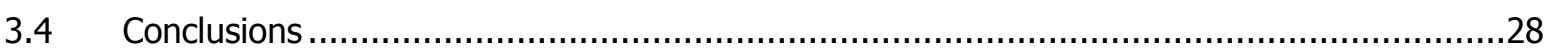

4. Traffic flow analysis intersections Addis Ababa $\quad 30$

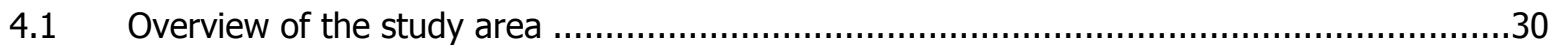

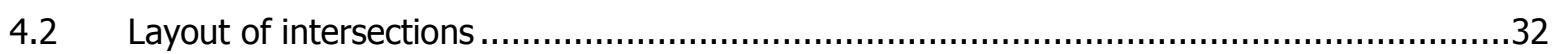

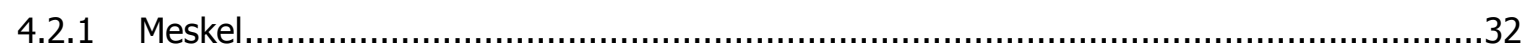

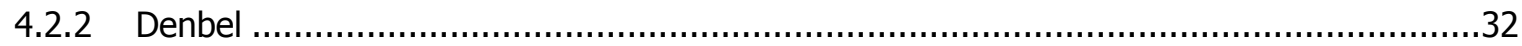

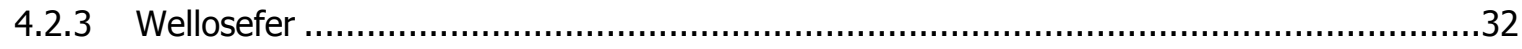

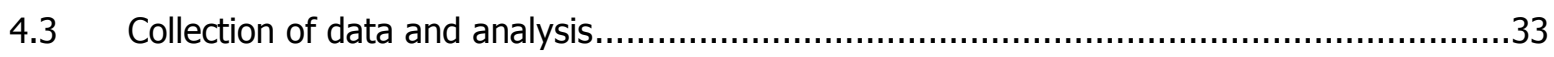

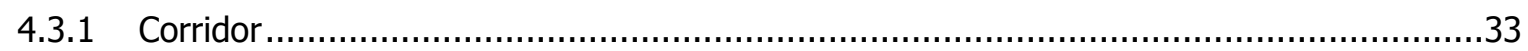

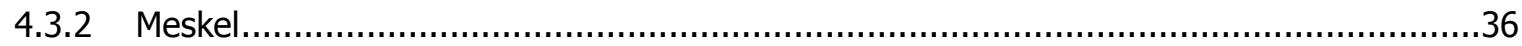

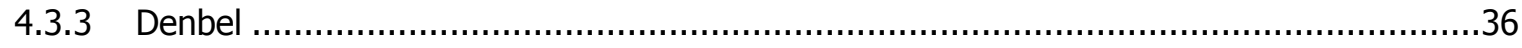

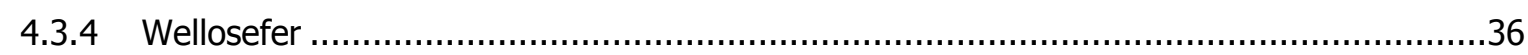




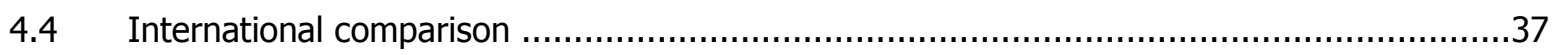

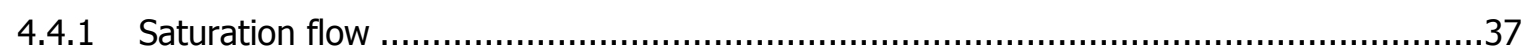

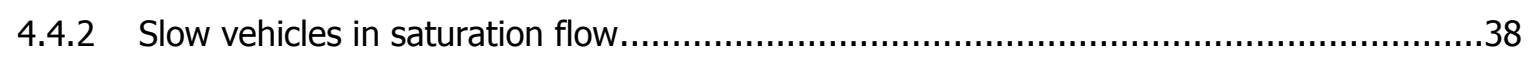

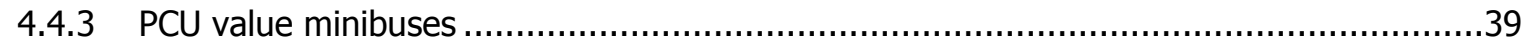

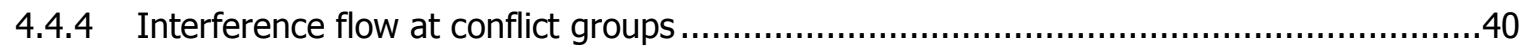

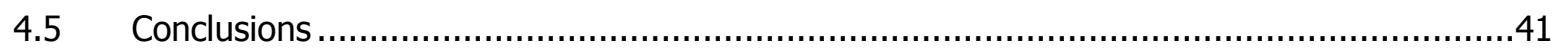

5. Modeling $\quad 42$

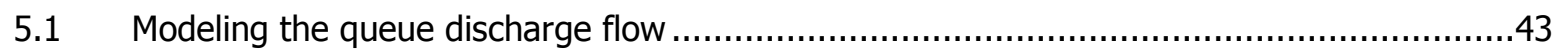

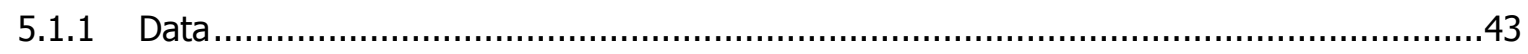

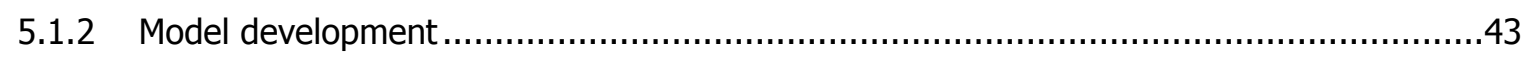

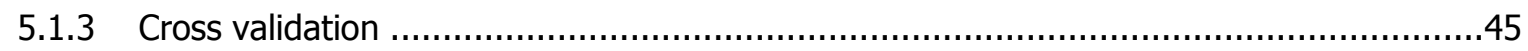

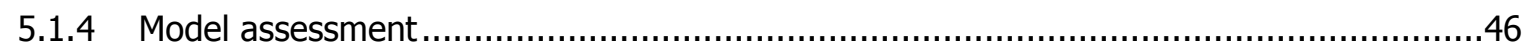

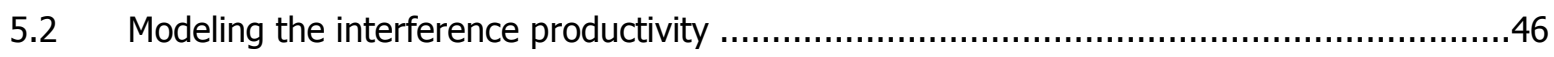

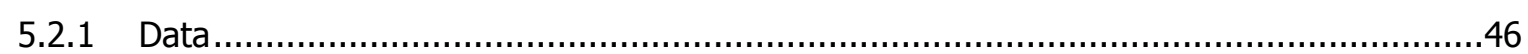

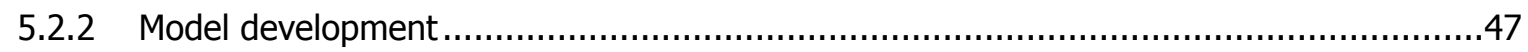

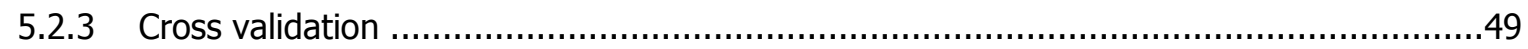

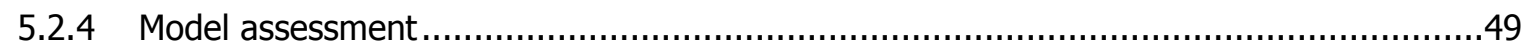

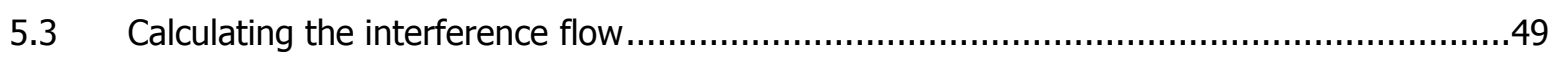

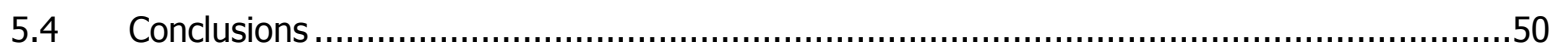

6. Simulation and results $\quad 52$

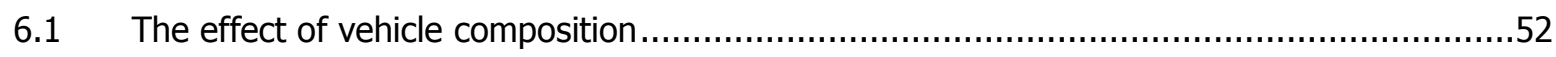

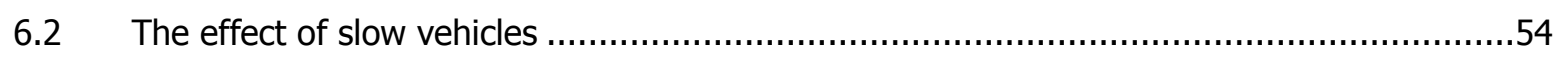

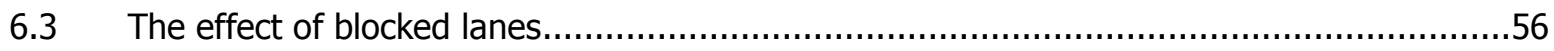

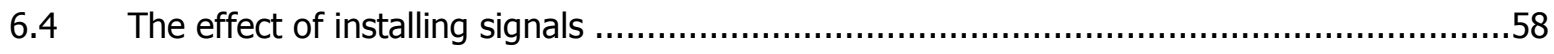

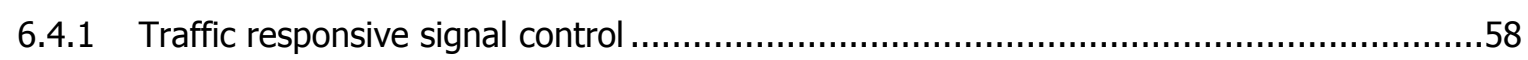

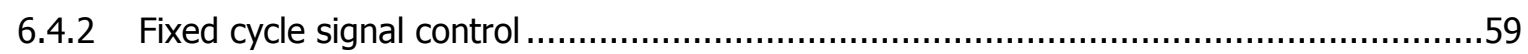

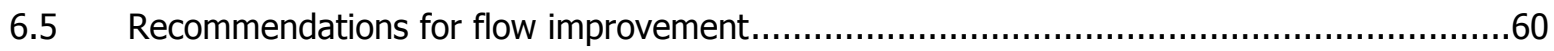

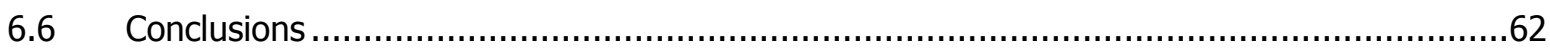

$\begin{array}{ll}\text { 7. Conclusions and further research } & 64\end{array}$

$\begin{array}{ll}\text { References } & \mathbf{7 0}\end{array}$

A. Summary in paper format $\quad 76$

$\begin{array}{lr}\text { B. Data } & 86\end{array}$

$\begin{array}{lr}\text { C. Measurement error } & 88\end{array}$ 
$\begin{array}{ll}\text { D. Saturation flow model comparison } & 90\end{array}$

E. Model calculations versus observations $\quad 92$

F. Prediction of queue discharge flow by HCM method 94

G. Cross-validation of the models $\quad 96$

H. Calculation of specifications simulation $\quad 98$

$\begin{array}{ll}\text { I. Traffic modes } & 100\end{array}$

$\begin{array}{ll}\text { J. Significance and power } & 102\end{array}$

K. Definitions of frequently used words $\quad 104$ 


\section{Chapter 1}

\section{Introduction}

This chapter describes the background of the research, the problem statement, the research scope and presents an overview of the thesis.

\subsection{Background}

Worldwide urbanization is stimulating a new global economy and vice versa. This interactive process will literally change the face of the planet (Cohen, 2004). More than half of world's population is currently living in cities. This share is expected to grow to almost 70 percent in 2050. The total world population growth in the same period (2010-2050) is estimated to be 33 percent; therefore, the prognosis for the absolute urban growth is 86 percent over the next 40 years (United Nations, 2008). A significant share of the urban growth is taking place in large cities. Especially the number of conglomerates with more than 5 million inhabitants will grow. Middle and low income countries show the highest urban population increase, especially in Sub Saharan Africa (Gwilliam, 2003). Despite some economic benefits, the rapid urban growth in these developing countries ${ }^{1}$ is outstripping the capacity of most cities to provide adequate services for their citizens (Cohen, 2004). A high urbanization rate in combination with the intense desire for car ownership in developing countries causes a rapid growth of motorization (Gakenheimer, 1999). In other countries where public transport plays a dominant role, urban population growth goes hand in hand with a significant increase in public transport trips (The World Bank, 2002). On the other hand, a lack of infrastructure and weak maintenance put extra stress on these growing traffic flows with congestion, pollution and a low road safety level as a result (Rust et al., 2008, Cohen, 2004, Gakenheimer, 1999, Gwilliam, 2003). Improved mobility in urban areas in developing countries is possible by building new infrastructure. However, this is a long term and expensive solution. A short term solution is to improve the traffic

\footnotetext{
${ }^{1}$ There is not a general definition for developing and developed countries in literature. As far as possible, this report uses the classification of the UN. The developing regions are Africa, Caribbean, Central America, South America, Asia (excluding Japan), Oceania (excluding Australia and New Zealand). Within these regions, both developing and transitional countries can be distinguished. Other regions are classified as developed (UN, 2010).
} 
management to rationalize the use of existing infrastructure (Gakenheimer, 1999). The current traffic control and management in developing cities is underdeveloped (Gwilliam, 2003).

Urban traffic flows interfere at intersections. The intersections can be considered as the bottlenecks of the urban traffic flows. Severe congestion takes place when the demand of traffic outnumbers the supply of infrastructure. Optimizing the flow at intersections would result in reduced congestion. In order to maximize the use of existing infrastructure, the influences of the different factors on the intersection flow have to be quantified. This can be done by modeling. Simulation can be used to assess flow-improving concepts. Commonly used intersection flow models are developed for Western traffic conditions, or are tailor made for specific cities in developing countries. The different characteristics of chaotic urban traffic in developing countries result in different models per city.

Numerous scientists have studied the traffic flow at intersections in both developed countries and developing countries (see Section 2.2). However, no intersection flow study about a city in Sub Saharan Africa could be found. Since the largest urban growth worldwide is taking place in this area (Gwilliam, 2003), significant mobility related problems are to be expected. According to forecasts, African society will be predominantly urban by 2025 (United Nations, 2004). Research on the urban intersection traffic flow in Sub Saharan Africa is needed in order to prevent large scale congestion problems. This research will study several intersections of the Africa Avenue in Addis Ababa, Ethiopia, as a start to fill this gap in scientific literature and to be able to quickly respond to the emerging mobility problems.

\subsection{Problem statement}

The goal of this research is the development of a simulation model that describes the traffic flows at the road intersections of Addis Ababa. The aim of the model is to perform ex ante assessment of different flow improvement strategies. The research objectives of this thesis are the following:

\section{Determine the different factors that significantly influence the traffic flow rate at the intersections of Addis Ababa}

\section{Build a model of the traffic flow rate at the intersections of Addis Ababa}

\section{Assess different strategies to improve the traffic flow rate at one specific intersection in Addis Ababa}

The research objectives are specified into four different research questions:

1. What are the saturation flow rates and queue discharge flow rates of different lanes at different intersections during congestion in Addis Ababa?

2. What are the differences between the saturation flow rate at the intersections of Addis Ababa compared to developing and developed cities?

3. What are the significant factors that influence the flow rate at the intersections of Addis Ababa and what are the quantitative contributions of these factors?

4. Case study: how can the traffic flow at one specific intersection in Addis Ababa be improved?

Question 1-3 will cover the objectives 1 and 2; question 4 will cover the third objective. The scope of the research questions is explained in the following section. 


\subsection{Research scope}

As explained in Section 1.1, the significant population growth has a negative effect on urban mobility. The problems are expected to grow in magnitude as urban population continues to grow, especially in urban areas in Sub Saharan Africa. The Sub Saharan mobility problem is very wide and complex as a result of the large study area, the numerous factors that are related to mobility and the multifaceted field of traffic management. The focus of this thesis is introduced in the following sections.

\subsubsection{Focus on Addis Ababa}

The Sub Sahara African region is expected to have five cities larger than 5 million by 2015 (Gwilliam, 2003): Abidjan, Addis Ababa, Lagos, Luanda and Kinshasa. To be able to study the different effects on the intersection flow rate into detail, one of these cities will be considered. This study will focus on Addis Ababa, the capital of Ethiopia, as a result of both its numerous similarities with other Sub Saharan cities (Kumar and Barret, 2008, The World Bank, 2002) and the availability of video images of three intersections.

\subsubsection{Focus on demand larger than supply}

A demand of vehicles larger than the supply of infrastructure results in congestion. The limitations of the supply are essential in order to suggest solutions to maximize the use of existing infrastructure. Therefore, the demand limited by the supply has to be studied. By measuring the free flow of traffic outside congestion hours, one will measure a flow based on the demand of traffic. By measuring the flow of traffic during queue discharge, one will measure a flow limited by the supply of the infrastructure. To be sure to measure the limitations of the supply, the flow of traffic at intersections is only measured during queue discharge and not during free flow.

\subsubsection{Focus on congestion prevention}

Safety, pollution and traffic congestion are in numerous cases interrelated. For example, long queues at signals cause pollution and unexpected upcoming congestion can decrease the safety level due to potential head-tail collisions. This research focuses exclusively on the reduction of traffic congestion. However, an optimization towards traffic congestion reduction is likely to positively influence both safety and pollution related challenges.

Congestion can be measured in the average delay experienced per vehicle. On the other hand, to be able to measure the delay, individual vehicle tracking is needed. Since the available data does not support this method, this research focuses on maximizing the throughput at intersections. Assuming a demand larger than the supply, an increase of vehicle throughput at the intersection causes a decrease in (local) congestion.

\subsubsection{Focus on single intersection modeling}

Improved traffic management architecture can solve city-wide congestion problems. Examples of successful improvements can be found in cities of some developing Asian countries (Wang, 2003, Nelson et al., 2001, Lo et al., 2001). Most of these cities can be considered as rapidly industrializing 
transitional cities, such as Hong Kong, Beijing and Seoul. However, Sub Sahara African cities have not solved their mobility problems yet.

Redesigning the whole traffic management architecture of Addis Ababa to find a long term, city-wide solution would be essential. However, traffic management architecture is extensive and complex: it comprises different levels of architecture, such as the control architecture, the application architecture, architecture of the technical infrastructure, the information architecture and the institutional architecture (see also (Westerman et al., 2001)). As a result of the institutional weaknesses of political instability, corruption and chronic mismanagement of economic resources in Sub Saharan African Countries (Cohen, 2006), a large-scale, complex and holistic solution for the architecture in Addis Ababa is difficult to realize.

The current state of infrastructure is very weak in Addis Ababa (Kumar and Barret, 2008). However, the basic state of the economic development and the institutional challenges will make a development of infrastructure a complex and long term solution. To be able to maximize the use of the current infrastructure on the short term, the poor road traffic management (Kessides, 2007) has to be improved. This research will focus on a specific aspect of traffic control architecture, the redesign of the traffic management at a single intersection. Such a small solution can either be implemented in networks, or be used to build a basic traffic management architecture from bottom-up.

\subsubsection{Focus on simulation of flow improvement strategies}

Urban traffic flows interfere at nodes. When the volume of the traffic flow reaches a certain maximum (e.g., calculated by using the criterion of Slop (Slop, 1972, Slop, 1975)) the interference has to be regulated. Different control types have different effects on the overall intersection flow rate. The current state of traffic control in Addis Ababa is basic: main intersections are controlled either by fixed time signal control or manually by police officers.

Besides control type, other factors, such as the vehicle composition, might influence the overall flow rate at intersections. The Addis Ababa traffic composition has a uniquely large share of minibuses. By solely focusing on the control, other significant flow improvements might be overlooked. Therefore, this research first identifies factors that significantly influence the intersection flow before it formulates the conceptual improvement strategies.

Ex ante assessment of different improvement strategies in real life is expensive, time consuming and as a result of natural disturbances inaccurate. Simulation models can be used to prevent trial-anderror testing in the field and to prevent unsafe real life situations (May, 1990). Different urban simulation models exist, both macroscopic and microscopic. None of these models is calibrated and validated in Addis Ababa yet. The development of a fitting model to describe the flow of the Addis Ababa traffic at a single intersection is therefore one of the focus areas of this thesis.

\subsubsection{Focus on saturation flow and queue discharge flow}

The saturation flow at intersections is an indication of the maximum flow of a junction during green phase when operating under ideal conditions (Turner and Harahap, 1993). The saturation flow is a 
well described performance indicator for intersections worldwide. However, when one wants to improve the actual flow at an intersection, not the flow under ideal conditions, but the flow under actual conditions is needed. This study considers both the saturation flow and the actual occurring queue discharge flow.

\subsection{Contribution to the state-of-the-art}

The main contribution of this thesis is that it describes the traffic flow at intersections in a SubSaharan city. No traffic flow model specifically developed for or calibrated at intersections in cities in this region could be found yet. The detailed contributions to the state-of-the-art are listed below:

- The study provides a comparison of saturation flow rates between the Addis Ababa intersections and other urban intersections worldwide.

- The study creates insight in the quantitative influences of different factors on the queue discharge flow rate at intersections of Addis Ababa during congestion. Sub Saharan city traffic has unique characteristics. For example, manual officer control at intersections and a vehicle mix consisting of a large share of minibuses are common. Among more, the influence of these phenomena on the flow rate at intersections is studied.

- The study provides a case study on urban intersection performance improvement in a developing country (Ethiopia), using a limited amount of data.

\subsection{Overview of the thesis}

In Chapter 2, a state-of-the-art overview of literature relating to traffic flow at intersections is given. In Chapter 3, the research method is explained. The video data analysis to determine the intersection performance of Addis Ababa intersections is discussed in Chapter 4. In the same chapter, the international comparison of intersection performance is addressed. Based on the intersection analysis, a flow model is developed, stated in Chapter 5. Successively, the developed model is used to assess different improvement strategies, as described in Chapter 6. Chapter 7 encloses the thesis with conclusions and recommendations for further research. An overview of the relation between the different chapters is shown in Figure 1.1.

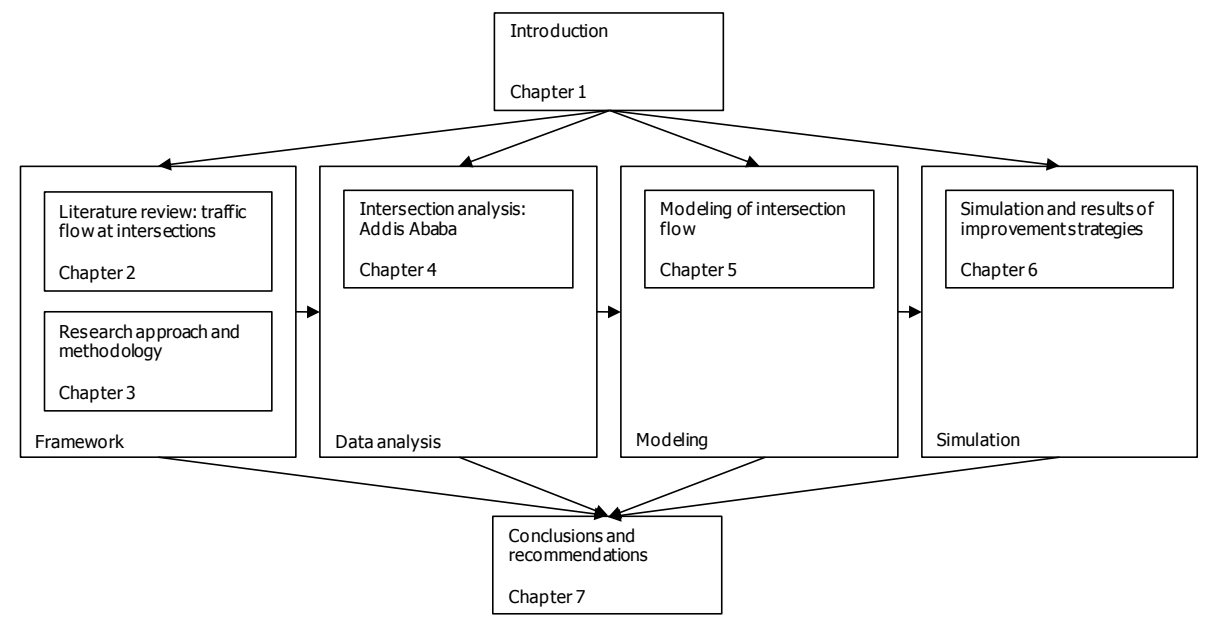

Figure 1.1: Overview of the relation between the different chapters 


\section{Chapter 2}

\section{Literature review}

This chapter gives an overview of the state-of-the-art of literature related to traffic flow at intersections. The trend of urban congestion in developing countries is described, followed by the flow characteristics at urban intersections in developing countries. The third section explains different types of intersection flow control. Finally, different methods to model the flow at urban intersections are presented.

\subsection{Urban traffic congestion in developing countries}

This section describes the mobility characteristics of cities of developing countries in general, the more specific mobility characteristics of cities of Sub Saharan Africa and the detailed mobility characteristics of Addis Ababa.

\subsubsection{Mobility characteristics of cities in developing countries}

Concerning the field of mobility, a study by (Gakenheimer, 1999) states numerous unique characteristics of cities in developing countries:

- Rapid growth of motorization

- Intense desire for car ownership

- Travel demand that far exceeds the supply of facilities

- High share of trips by public transit

- Urban structure incompatible with motorization

- Greater differences in vehicle performance

- Inadequate street and highway maintenance

- Irregular response to impacts of new construction

- Fewer legal constraints on the use of new technologies

- Weak driver discipline in many countries

- Very limited agreement on planning approaches

- Scarcity of capital and operating subsidies are difficult to sustain

- Local transportation development is more centralized in the hands of a few elite players 
Developing countries are characterized by a high travel demand, chaotic traffic behavior and a low supply of networks and means. Although fewer legal restraints exist for the use of new technologies, the transport sector as a whole is not likely to be innovative: capital is scarce and the number of involved stakeholders is limited. The lack of adequate and accessible transportation options causes a high share of non-motorized transport. This stressed mobility situation in developing countries results in premature congestion, a deteriorating environment and a high incident rate (Gwilliam, 2003).

It has to be noted that these characteristics concern the average of the whole group of developing countries. Individual exceptions of countries that have different mobility characteristics exist. The next section describes the characteristics of Sub Saharan Africa.

\subsubsection{Mobility characteristics of cities in Sub Saharan Africa}

Within the group of developing countries, the subgroup of Sub Saharan African countries distinguishes themselves on a number of characteristics. While other regions in developing countries are industrializing rapidly as a result of the new global economy, the African cities remain economically marginalized. However, the population in African cities is growing despite poor macroeconomic performance and without significant foreign direct investment. Even more, Sub Saharan Africa has globally the highest urban population growth in percentages (Gwilliam, 2003). By 2025, African society is expected to become predominantly urban (United Nations, 2004). The institutional weaknesses of political instability, corruption and chronic mismanagement of economic resources (Cohen, 2006) put extra stress on the level of services in cities. It can be concluded that world's challenges concerning urban mobility will be particularly significant in Sub Saharan Africa.

\subsubsection{Mobility characteristics Addis Ababa}

By 2015, the Sub Sahara African region is expected to have five cities larger than 5 million inhabitants: Abidjan, Addis Ababa, Lagos, Luanda and Kinshasa (Gwilliam, 2003). This thesis will focus on Addis Ababa, the capital city of Ethiopia, a city with numerous similarities with other Sub Saharan cities (Kumar and Barret, 2008, The World Bank, 2002). The mobility problems in Addis Ababa are emergent, since the recent state of road traffic management is considerably poor (Kessides, 2007).

Table 2.1 shows a benchmark of Addis Ababa with the average urban area in Africa, the developing world, Europe and the US. It can be seen that Addis Ababa has a relatively high population density and a high urban population growth; both facts combined with a low GDP per capita put high stress on the quality of mobility services. This stress is reflected by the very low supply of infrastructure: the current road density measured in kilometer of road per 1000 habitant in Addis Ababa is significantly lower than the average of developing countries, moreover, it is only one third of the African average.

The public transport plays a dominant role in urban mobility in Ethiopia. The current average number of cars per 1000 habitants in whole Ethiopia is only 1 (The World Bank, 2011). In Addis Ababa, the car ownership has not gone up corresponding to the population growth. However, the number of trips per public transport is directly related to the urbanization. In general, for every additional 1000 people in developing world cities, an increase of 350-400 public transport trips will be realized per day. Similarly, 
Table 2.1: Benchmarking Addis Ababa, Africa average, Developing average, Europe average and US average

\begin{tabular}{|c|c|c|c|c|c|}
\hline City & $\begin{array}{l}\text { Addis } \\
\text { Ababa }\end{array}$ & $\begin{array}{l}\text { Africa } \\
\text { average }\end{array}$ & $\begin{array}{l}\text { Developing } \\
\text { average }\end{array}$ & $\begin{array}{l}\text { Europe } \\
\text { average }\end{array}$ & $\begin{array}{l}\text { US } \\
\text { average }\end{array}$ \\
\hline Urban density & $12400^{[1]}$ & $8200^{[2]}$ & $9200^{[2]}$ & $3050^{[2]}$ & $1150^{[2]}$ \\
\hline \multicolumn{6}{|l|}{ habitants $/ \mathrm{km}^{2}$} \\
\hline Annual national urbanization rate & $4.3^{[3]}$ & $3.6^{[4]}$ & $2.7^{[4]}$ & $0.3^{[4]}$ & $1.3^{[3]}$ \\
\hline \multicolumn{6}{|l|}{$\%$} \\
\hline National GDP per capita & $700^{[5]}$ & $3700^{[5]}$ & $2926^{[6]}$ & $28700^{[5]}$ & $46300^{[5]}$ \\
\hline \multicolumn{6}{|l|}{ USD } \\
\hline Road density & $0.13^{[7]}$ & $0.32^{[7]}$ & $1.0^{[7]}$ & $3.3^{[8]}$ & $6.4^{[8]}$ \\
\hline \multicolumn{6}{|l|}{ km/1000 habitants } \\
\hline \multicolumn{6}{|c|}{$\begin{array}{l}\text { [1](Demographia, 2010) } 2003 \text { estimation, only urban areas included with }>500000 \text { habitants } \\
\text { [2](Demographia, 2006) } 2006 \text { estimation, only urban areas included with }>500000 \text { habitants } \\
\text { [3](CIA, 2010) 2005-2010 estimation } \\
\text { [4](United Nations, 2002) 2005-2010 estimation } \\
\text { [5](CIA, 2010) 2009 estimation, retrieved from (IndexMundi, 2010) } \\
\text { [6](The World Bank, 2010) 2009 estimation } \\
\text { [7](Kumar and Barret, 2008) The African average is based on } 12 \text { large Sub Saharan African cities } \\
\text { [8](Vivier and Mezghani, 2001) The US average is based on US and Canada }\end{array}$} \\
\hline
\end{tabular}

for every square kilometer of urban growth, an increase of 500 public transport trips will be realized per day (The World Bank, 2002). It can be concluded that the current supply of infrastructure is significantly below average and the demand is significantly increasing. An extension of infrastructure is necessary; however, the basic state of the economic development and the institutional challenges will make a development of infrastructure a complex and long term solution. To be able to maximize the use of the current infrastructure on the short term, the poor road traffic management has to be improved.

\subsubsection{Mobility improvement, economic growth and sustainable development}

The impact of congestion reduction on the economy has different short term and long term effects (Van Lint, 2009). On the short term, improved travel times will reduce the costs of travelling. Therefore, the number of consumers that is able to purchase the service of transportation for the price that is less or equal to the amount they would be willing to pay increases. Not only the number of trips will increase, also the length of trips is likely to increase when traveling time decreases. Historical research by (Schafer and Victor, 1999) and (Filarski, 2004) indicate that travelers have a constant travel time budget. This means that when the speed of travel increases, the traveler will increase its travel distance to reach its original travel time budget. On the long term, traffic congestion is likely to occur when the demand reaches the supply. The economic difference however is the realized value by the increased number of trips. Therefore, reducing the congestion is economically justifiable, both on the long term and on the short term.

Economic growth in developing countries is an important subject. However, economic growth has both positive and negative effects. Therefore, the economic development has to be evaluated from a global sustainable development point of view. Many argue that global economic growth is unsustainable (e.g., (Meadows, 1972, Durning, 1992)). However, economic growth has significant benefits concerning the quality of life, an important aspect of social sustainability. Considerable benefits are occurring in premature economic development. For example when the GDP per capita is below 10000 USD, an 
increase in GPD per capita generally results in a significant increase in the life expectancy. Economic development in cases where the GDP per capita is over 10000 USD results generally in a minimal increase of life expectancy (CIA, 2010). Similar correlation can be found concerning literacy. Ethiopia is in a very early state of economic development, its GDP per capita is 700 USD (Table 2.1), therefore economic development is likely to have significant benefits. Congestion prevention to cause economic growth has considerable benefits from a sustainable development point of view.

\subsection{Traffic flow at urban intersections in developing countries}

A parameter to describe the traffic performance at intersections is the saturation flow during green phase. The saturation flow expresses how much traffic the infrastructure can process. It is an indication of the maximum flow of a junction during this green phase when operating under ideal conditions (Turner and Harahap, 1993). Therefore, it is an important performance indicator. However, no unique definition or calculation method for the saturation flow exists. The flow of traffic can be expressed in vehicles per hour or in Passenger Car Unit per hour (PCU/h or PCE/h). Similar to saturation flow, different definitions and calculation methods concerning the PCU exist. Section 2.4.1 will elaborate about the different methods to determine the saturation flow and PCU values.

Numerous studies have described the saturation flow at intersections in developing countries. A large share of these studies reports the situation in Asia. No research was found describing the traffic flow at intersections in Sub Saharan Africa. The next sections will briefly discuss the different studies per location.

\subsubsection{Beijing, Chengdu, Changsha - China}

This study, described by both (Lu, 2008) and (Li et al., 2009), presents a comparison of driver behavior between four Dutch intersections and three Chinese intersections. Each intersection was studied for 30 to 90 minutes. The PCU value and the saturation flow are calculated by means of multiple linear regression, based on vehicle counts per time interval of 5 seconds. All studied intersections are controlled by signals. The saturation flow measured per direction was between 1280 and $1430 \mathrm{PCU} / \mathrm{h}$ in China and between 1710 and 1880 PCU/h in the Netherlands. The saturation flow in China is therefore 20-30\% lower than the Dutch saturation flow. This confirms an earlier study with the same results ( $\mathrm{Li}$, 2008). A better driving discipline is expected to eliminate the very large gaps and improve the saturation flow at intersections; however, the quantitative influence of this factor is not calculated.

\subsubsection{Nanjing - China}

(Righolt and Berkhout, 2009) studied the traffic performance at one signalized intersection during four days for 90 minutes per day. The PCU values and the saturation flow were determined by means of multiple linear regression based on vehicle counts per time interval of 5 seconds. The measured saturation flow per direction was 1430 to $1610 \mathrm{PCU} / \mathrm{h}$. An auxiliary lane and a better separation of non-motorized and motorized vehicles is expected to result in an improved saturation flow, however the quantitative influence of these factors is not calculated. 
Table 2.2: Overview of saturation flow rate per country

\begin{tabular}{llll}
\hline Study & Country & $\begin{array}{l}\text { Mean saturation flow } \\
\text { [PCU/h] }\end{array}$ & $\begin{array}{l}\text { Sample size } \\
\text { (number of sites) }\end{array}$ \\
\hline (Kimber et al., 1986) & UK & 2080 & 64 \\
(Branston, 1979) & UK & 1778 & 5 \\
(Webster and Cobbe, 1966) & UK & 1800 & 100 \\
(Miller, 1968) & Australia & 1710 & unk. \\
(Huzayyin and Shoukry, 1986) & Egypt & 1617 & 18 \\
(Hussain, 1990) & Malaysia & 1945 & 50 \\
(Bhattacharya and Bhattacharya, 1982) & India & 1232 & 20 \\
(De Andrade, 1988) & Brazil & 1660 & 125 \\
\hline unk. = unknown & & & \\
\hline
\end{tabular}

\subsubsection{Dhaka - Bangladesh}

A research by (Hadiuzzaman et al., 2008) focused on modeling the non-lane based traffic behavior at five signalized intersections in Dhaka. Normal streams consist of different defined lanes. Non-lane based streams do not have defined lanes, the number of lanes depends on the vehicle density. Each intersection was studied for 90 to 120 minutes. By means of linear regression, based on vehicle counts per green phase, a saturation flow between 3100 and 4100 PCU/h was measured for streams between 6 and 13 meter. A saturation flow per lane was not calculated, as a result of the frequent change of number of lanes per stream. The conclusion was that the saturation flow increases with increasing stream width. No suggestions for improvement are stated.

\subsubsection{Various cities - Malaysia}

(Vien et al., 2006) performed a traffic performance study at 64 signalized intersections in Malaysia. Each single lane was observed for about one hour. Different sets of standard PCU values per vehicle type were used to turn the observations into a saturation flow. Using the standard PCU values determined for Malaysia, the saturation flows per intersection were between 1100 and 2000 PCU/h. This study does not contain suggestions for flow improvement.

\subsubsection{Bandung - Indonesia}

The study by (Turner and Harahap, 1993) describes the vehicle flow at four signalized intersections in Bandung. In total, 57 cases of 100 signal cycles were studied. Based on vehicle counts per 6 seconds, the saturation flow and PCU values were determined using multiple linear regression. The overall saturation flow equals $1922 \mathrm{PCU} / \mathrm{h}$. No explanation was given for the exceptional high saturation flow. In the same study, a model was developed to quantify the influences of different factors on the saturation flow. However, the model was not used to suggest improvements.

\subsubsection{Comparison developing and developed countries}

(Turner and Harahap, 1993) also provide an extensive overview of different saturation flow values for both developed and developing countries. Table 2.2 shows the saturation flow rate of different countries for straight ahead traffic on a 3.5 meter wide lane at level gradient without opposed flow. It 
is not clear whether the intersections are signal controlled. Also, the used calculation methods are unknown. The mean saturation flow of developing countries (1230-1950 PCU/h) is lower than the mean flow of developed countries (1710-2080 PCU/h). Besides the lower mean, the range of saturation flows of developing countries is larger than the range of flows in developed countries. The variations in saturation flow are likely to be influenced by the geometric characteristics of the junction, as well as extraneous factors like the level of pedestrian interference. The previously described studies in this chapter confirm the range of developing countries, despite the fact that the research by (Turner and Harahap, 1993) was performed some decades earlier. It must be noticed that the used datasets for developing countries are generally relatively small compared to developed countries.

Comparing all described studies, it appears that the following aspects are not well-studied:

- The application of flow models to propose a plan of improvement with quantitative results for the relative low flow rates in most of the developing countries

- The influence of a human traffic controller on the intersection flow

- The characteristics of the traffic at intersections in Sub Saharan Africa

\subsection{Types of intersection flow control}

(Papageorgiou et al., 2003) provide a useful overview of two different intersection control strategies. Based on the description in this study, both strategies will be discussed in the following sections. An old type intersection control is officer control. In developed countries, this strategy is hardly applied. However, in developing countries, where wages are low, officer control is very common. As a result of its unique character, officer control will be considered as a separate control strategy. Not all types of control are applicable to all traffic modes. Under saturated traffic flow can be controlled in many ways, while oversaturated flow is hard to control. Definitions of the different traffic modes are given in Appendix I.

\subsubsection{Fixed-time control}

Fixed-time control for an isolated intersection is the most basic non-human type of control. Each of the involved lanes receives the right-of-way for a fixed-time. No sensors are needed. Based on different optimization methods, the length of the right-of-way periods are set to minimize the delay at each approach. A maximum cycle and a minimum-green constraint are taken into account. Different phases of the day can have different fixed-time strategies.

By optimizing the fixed-time settings of multiple intersections and taking travel times in between the intersections into account, green waves can be created. During green waves, a vehicle will not encounter a red signal. This type of control can only be applied to under-saturated conditions.

\subsubsection{Traffic responsive control}

Traffic-responsive strategies make use of real-time measurements provided by inductive loop detectors. Different strategies within this class exist. Most of the responsive control strategies for a single intersection function according to the same basis principle. Minimum green phases are assigned to each approach. These minimum green phases can be extended as a result of a higher traffic 
demand. The green phases are limited by the maximum-green value. At the end of the green phase, either caused by a decreased traffic demand or by the maximum-green value, the right-of-way will change. In case of oversaturated conditions at all streams of an intersection, the length of the greenphases equals the maximum-green value.

Traffic responsive control can also be applied to networks. A central system will measure the demand and supply in the network and will calculate the optimal lengths of green phases. This type of control can handle oversaturated traffic demand by limiting the number of vehicles entering a network.

(Sutandi, 2008) compared the use of simple fixed time control and advanced traffic responsive control in Indonesia by means of simulation. The conclusion was that only in specific cases the application of a more advanced responsive system would result in a better traffic performance. Officer control was not considered in this study.

\subsubsection{Officer control}

Officer control can be considered as single intersection traffic responsive control. Intersection control by traffic officers has numerous advantages compared to signal control (Marsh, 1927):

- Officer control can deal with variations in the volume of traffic

- Officer control can give each street the right proportion of time needed at that exact moment

- Officer control can give a special treatment of specific vehicles

- Officer control can aid turning traffic to weave it through the traffic from the opposite direction without entirely stopping either line

- Officer control can deal with any unusual condition or emergency

However the advantages of officer control will decrease at the more complicated intersections as the number, volume, and regularity of different kinds of movements increase. The disadvantages of officer control are (Marsh, 1927):

- No coordination or communication with other intersections possible

- Disobedience of traffic due to bad visibility of officer

- Distraction of officers as a result of answering questions, social chatting or law enforcement

- Leaving of officers in case of emergency

- Learning time of an officer how to control efficiently

- Personal differences between officers

- High costs of officer control

In the beginning of the $20^{\text {th }}$ century, Marsh expected that the amount of signals in urban areas would increase as a result of an increase in the costs of traffic controllers and in the need of coordinated traffic control systems to secure continuous traffic flow. However, he argues that thorough research by traffic experts is needed before and during installation to secure a high efficiency.

Some of the previously mentioned disadvantages are not always applicable. For example, in developing countries, the costs of officer control are relatively low. In numerous cases, the advantages of officer control outweigh the disadvantages. (De Jongh Schreuder and Venter, 2005) describe the recent successful implementation of officer control for highway entering in South Africa. 
According to this study, highway entering control by officers is an excellent example of a First World practice, implemented with Third World restrictions.

Upcoming countries tend to replace their officer control for automated intersection control. However, a study by (Khan, 2007) shows that such a redesign of the control system will not necessary result in better performance. The traffic congestion in Dhaka city has become worse after the introduction of automated lights. Khan argues that it is a formidable task for an automated traffic system, even with an extensive sensor system, to match the decision making capacity of a human traffic controller.

\subsection{Intersection flow modeling}

This section starts with a description of the saturation flow and the intersection flow. Furthermore two types of flow modeling are explained: macroscopic and microscopic flow modeling.

\subsubsection{Saturation flow and PCU value explained}

The saturation flow is frequently used as a performance measure of a lane at intersections and is applied extensively in intersection and control design. It is an indication of the maximum flow of a junction during green phase when operating under ideal conditions (Turner and Harahap, 1993). (Branston and van Zuylen, 1978) argue that it is a well-know property of signals that when the light turns green on a stream gaining right-of-way, the flow across the stop line quickly rises to a steady value, the saturation flow, of the stream. An idealistic representation of the saturation flow is shown in Figure 2.1. Simply removing the begin and end lag will result in the saturation flow.

However, in some cases the queue discharge flow does not reach a steady value. Even during queue discharge large gaps between vehicles can occur as a result of significant differences in acceleration behavior and slow responding traffic (as explained by the study of (Gakenheimer, 1999), presented in Section 2.1.1). The distance between vehicles is usually referred to as the headway. In this thesis, the
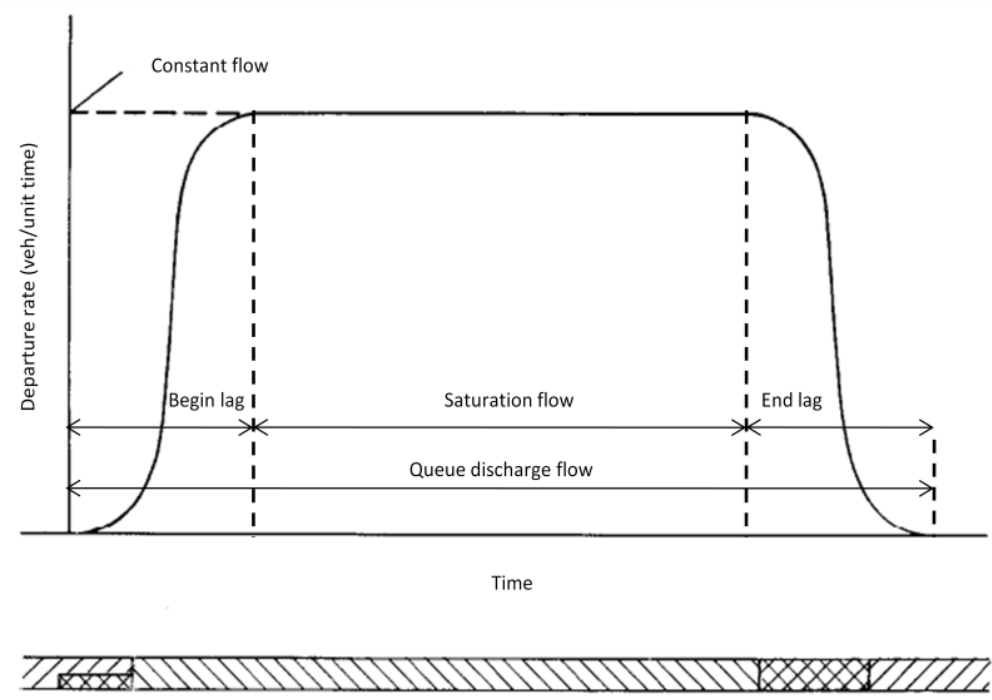

Z7Z Red Q8X Amber DIV Green

Figure 2.1: Idealistic representation of the saturation flow, based on (Kimber et al., 1985) 
headway of a vehicle is defined as the moment in time when the front axis of the preceding vehicle crosses the stop line minus the moment in time when its own front axis crosses the same stop line. The time difference is the headway. In case of an unsteady flow, removing only a begin and end lag will not result in a proper indication of the saturation flow. ( $\mathrm{Lu}, 2008)$ therefore uses a different method to determine the saturation flow. In this study, the saturation flow is defined as the vehicles with a headway time within plus and minus two $\sigma$ (i.e., standard deviation) from the mean. In the study of Lu, this resulted in a maximum time headway of 6 seconds. All traffic with headways lower than 6 seconds was considered as being part of the saturation flow. However, including such large headway times, it is not likely to get a proper indication of the maximum flow of a junction when operating under ideal conditions.

The third method is to introduce a fixed threshold for the saturation flow, either measured by a maximum headway distance or a minimum number of vehicles per time interval. The latter was applied by (Minh et al., 2009). A minimum number of vehicles per time interval will result in a lower boundary for the saturation flow (illustrated by Figure 2.2). The problem with the study by Minh et al. (2009) is that the threshold is defined for non-lane based traffic. This cannot be compared to the lane based traffic of Addis Ababa. The selection of the definition used in this thesis is presented in Section 3.1.3.

To compensate for vehicle differences, the saturation flow is commonly expressed in Passenger Car Units (PCU) per hour. The PCU value is the ratio between the time headway of a vehicle of a specific type and the time headway of a passenger car. As a result of different traffic behavior, the PCU values differ heavily for vehicle classes worldwide. Therefore, it is preferred to determine the PCU values in the same area where the saturation flow is measured. Different methods to calculate the saturation flow and the PCU values exist. Three common methods to calculate the saturation flow are:

- The average headway method (e.g., applied by (Greenshields et al., 1947, Scraggs, 1964) (Miller, 1968, Webster, 1964))

- The Road Note 34 method (developed by (Transport and Road Research Laboratory, 1963))
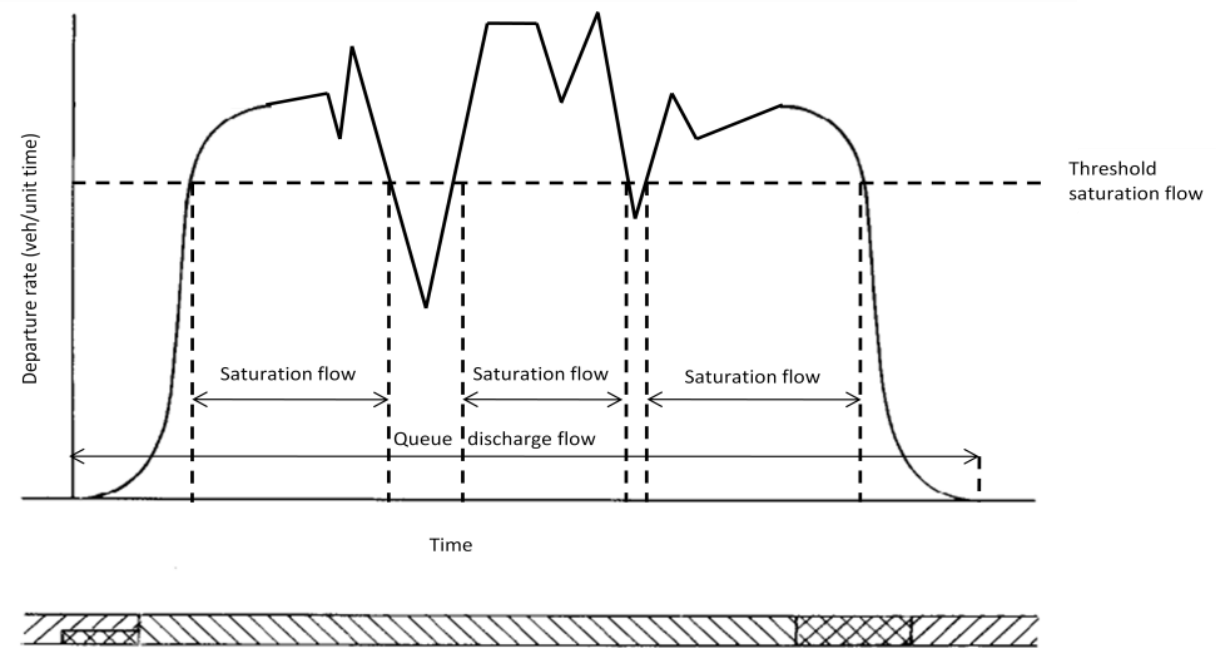

$$
\text { Z7Z Red Q8X Amber DIV Green }
$$

Figure 2.2: Representation of the saturation flow definition with a minimum threshold. A saturation flow defined as a minimum number of passing vehicles per time unit (Minh et al., 2009) results in a minimum threshold for the departure rate. 
- The multiple linear regression method (e.g., applied by (Branston and van Zuylen, 1978, Branston and Gipps, 1981, Holroyd, 1963))

The selection of the calculation method of the saturation flow and the PCU value for this study is described in Section 3.1.3.

\subsubsection{Intersection flow explained}

This thesis focuses on the flow at interfering streams (also called conflicting streams, see Appendix $\mathrm{K}$ for definitions of commonly used words) at intersections. The total flow at the interfering streams is measured in PCU per hour or in vehicles per hour. Conflicting streams from which only one stream at the time can have the right-of-way form a conflict group (more thoroughly described by (Taale, 2008)). An intersection can have multiple conflict groups. The total flow realized at one conflict group at an intersection depends on two factors:

- The average queue discharge flow per involved lane

- The internal lost time during the transition of the right-of-way

The lost time is the sum of the clearance time, the start-up delay and the share of unused amber phase (Taale, 2008, Hegyi, 2008).

$$
T_{\text {internal lost }}=\sum_{i}\left(T_{\text {amber }}-T_{\text {amber used }}\right)+\sum_{i} T_{\text {clearance }}+\sum_{i} T_{\text {start up }}
$$

Where:

$$
\begin{array}{ll}
T_{\text {internal lost }} & \text { internal lost time in conflict group at intersection, } \\
T_{\text {amber }} & \text { length of amber phase, } \\
T_{\text {amber used }} & \text { length of the amber phase that is used as green phase, } \\
T_{\text {start up }} & \text { start-up delay between start of green phase and movement of first vehicle, } \\
i & \text { stream in the conflict group at intersection. }
\end{array}
$$

The total flow of the conflict group at an intersection during heavy to oversaturated traffic modes can be determined based on the average queue discharge flow, according to the following formula:

$$
F=\frac{T_{\text {cycle }}-T_{\text {internal lost }}}{T_{\text {cycle }}} \times Q
$$

Where:

$F$

$T_{\text {cycle }}$

$Q$

total flow of conflict group at intersection (also called: interference flow), length of control cycle of conflict group at intersection,

The first part of Equation 2.2 defines the productivity $(P)$ of a conflict group at a signalized intersection:

$$
P=\frac{T_{\text {cycle }}-T_{\text {internal lost }}}{T_{\text {cycle }}}
$$

It must be noticed that Equation 2.2 is only applicable to situations in which continuous queue discharge is taking place during green phase, i.e., heavy to saturated traffic conditions (Appendix I). Numerous intersection flow models focus on predicting the saturation flow during the green phase. The most common definition of the saturation flow is illustrated in Figure 2.1. After a begin lag, the 
flow rate is assumed to be constant. This constant flow is described as the saturation flow. Different methods exist to calculate the size of the begin lag and end lag. However, the average queue discharge flow will be lower than the saturation flow, since the begin and end lag are not included in the saturation flow. Therefore, an intersection flow based on the saturation flow, corrected by the lost time, is likely to result in an overestimation.

\subsubsection{Macroscopic intersection flow modeling}

Traffic models can be categorized by their levels of detail. The two most common groups are macroscopic models and microscopic models. This section describes the principles behind the model groups. Based on these principles, a choice is made in Section 3.2.1 for a model group to form the basis of the intersection flow modeling for this study. (Hegyi, 2004) defines the main model groups the as follows:

- Macroscopic models use a high level of aggregation without distinguishing between individual vehicle actions such as a lane change. Instead traffic is described in aggregate terms as average speed, average flow, and average density.

- Microscopic models describe the behavior of vehicles individually. Important aspects of microscopic models are the so-called car-following, lane changing and gap acceptance behavior.

Numerous macroscopic intersection flow models focus on the modeling of the saturation flow (e.g., (Kimber et al., 1986, Turner and Harahap, 1993, Hadiuzzaman et al., 2008, Hossain, 2001)). No models could be found that directly predict the total flow of conflict groups. However, as explained in Equation 2.2 , by using the lost time, the cycle time and the saturation flow, the intersection flow can be estimated.

Two basic types of macroscopic saturation flow models will be discussed. The first type is the multiplicative model.

$$
S=S_{0} \times f_{1} \times f_{2} \times . . \times f_{n}
$$

Where:

$S \quad$ saturation flow,

$S_{0}$ basis saturation flow,

$f_{\mathrm{n}} \quad$ correction factors.

The basis saturation flow is corrected for factors like lane width, traffic composition and type of area. Based on extensive traffic measurements - however, not in Sub Saharan countries - the Highway Capacity Manual (TRB, 2000) presents values of the correction factors.

The second type of models is the additive model.

$$
S=S_{0}+\beta_{1} \times f_{1}+\beta_{2} \times f_{2}+. .+\beta_{n} \times f_{n}
$$

Where:

$S$ saturation flow, 
Table 2.3: Macroscopic saturation flow model overview

\begin{tabular}{llll}
\hline Study & $\mathbf{R}^{\mathbf{2}}$ & $\begin{array}{l}\text { Standard error } \\
\text { (PCU/h) }\end{array}$ & $\begin{array}{l}\text { Number of data points } \\
\text { for linear regression }\end{array}$ \\
\hline (Turner and Harahap, 1993) & $0.49-0.97$ & unk. & 57 \\
(Hadiuzzaman et al., 2008) & 0.998 & unk. & 6 \\
(Hossain, 2001) & 0.92 & 270 & 106 \\
(Tarko and Tracz, 2000) & unk. & $90-93$ & 69 \\
& & & \\
\hline unk.=unknown & & \\
\hline
\end{tabular}

$S_{0}$ basis saturation flow,

$f_{\mathrm{n}} \quad$ influencing factor $\mathrm{n}$ (such as the share of heavy vehicles),

$\beta_{n} \quad$ corresponding coefficient for the influencing factor $f_{n}$.

The additive model is frequently used to build fitting models to specific situations (e.g., by (Kimber et al., 1986, Turner and Harahap, 1993, Hadiuzzaman et al., 2008, Hossain, 2001)), since it can easily be developed. Using simple vehicle counts per unit of time, the saturation flow per lane is calculated. Based on saturation flows at different streams, linear regression is then applied to build the model. An overview of additive models with their corresponding data size and model-fit is shown in Table 2.3. Data points exist of observed saturation flow of one lane during a period of time, mostly larger than half an hour to prevent large fluctuations. The number of studied lanes for the models in Table 2.3 varies between 6 and 106. Nearly all the developed models predict the saturation flow rather accurate, as illustrated by the high coefficient of determination $\left(R^{2}\right)$ and the low standard error. Multiplicative and additive models can also be combined (Akcelik, 1981, Teply, 1984). A comparison of the models can be found in (Tarko and Tracz, 2000).

Previous studies have shown numerous factors that influence the saturation flow. These factors can be categorized into four different groups: driver behavior, intersection characteristics, vehicle flow characteristics and externalities. Table 2.4 shows factors that appeared to have significant influence in the corresponding studies, organized per category. A discussion on the applicability of the use of macroscopic modeling for this study can be found in Section 3.2.1.

\subsubsection{Microscopic intersection flow modeling}

Microscopic models are capable of describing the individual behavior of vehicles in complete networks. The flow at a conflicting group can directly be determined based on individual vehicle tracking. No calculations based on saturation flows or queue discharge flows of involved lanes are needed.

Decades of research on traffic behavior resulted in numerous models (for an extensive overview, see (Vanderschuren, 2007)). The use of a popular simulation model has the advantage that comparable case studies are more likely to be found in literature. According to (Park and Won, 2006), the most popular, commercially available microscopic simulation models are: 
Table 2.4: Factors with significant influence on the saturation flow

\begin{tabular}{lll}
\hline Category & $\begin{array}{l}\text { Factor with significant influence } \\
\text { on saturation flow }\end{array}$ & Study \\
\hline \multirow{2}{*}{ Driver behavior } & - Age & (Evans and Wasielewski, 1983, Wu et al., 1999) \\
& - Gender & (Evans and Wasielewski, 1983) \\
Intersection & - Direction (turning or straight) & (Tarko and Tracz, 2000) \\
characteristics & - Location of the lane (near curb or in middle) & (Tarko and Tracz, 2000) \\
& - Signal settings & (Turner and Harahap, 1993, Hadiuzzaman et al., 2008) \\
& - Lane width & (Turner and Harahap, 1993, Hadiuzzaman et al., 2008, \\
Vehicle flow & - Share of turning traffic on mixed lanes & Hossain, 2001) \\
characteristics & - Composition of the traffic mix: & (Hadiuzzaman et al., 2008, Hossain, 2001) \\
& - Share of heavy vehicles & (Cuddon and Ogden, 1992) \\
& - The share of light trucks & (Kockelman and Shabih, 2000) \\
& - Share of motorcycles & (Vien et al., 2006, Oktech, 2003) \\
& & (Hossain, 2001)
\end{tabular}

- $\quad$ AIMSUN (Barcelo, 2003)

- CORSIM (FHWA, 2003)

- INTEGRATION (Van Aerde, 2005)

- $\operatorname{MITSIM}$ (Yang, 1997)

- PARAMICS (Quadstone Limited, 2002)
- SimTraffic (Trafficware, 2003)

- TRANSIMS (Barrett et al., 1995)

- $\operatorname{VISSIM}(P T V, 2003)$

- WATSIM (KLDassociates, 1996)

Microscopic models are based on lane changing models, car following models and gap acceptance models. The interference flow is mainly described by the car following models. Different car following models exist (overviews can be found in (Brackstone and McDonald, 1999, Panwai and Dia, 2005, Hoogendoorn and Bovy, 2001)).

To be able to use these microscopic models, large amounts of parameters need to be calibrated. The use of these simulation models with the standard values for the parameters is possible; however, large errors in simulation outcome can be expected. VISSIM is a simulation package that has been calibrated worldwide, for example in China (Righolt and Berkhout, 2009, Lu, 2008), India (Mathew and Radhakrishnan, 2010) and South Africa (De Jongh Schreuder and Venter, 2005). No calibration in Ethiopia could be found. However, the general calibration procedures for new locations are well-described (Park and Won, 2006, Park and Schneeberger, 2003, Park and Qi, 2005, Fellendorf and Vortisch, 2000). Detailed data is needed to correctly calibrate microscopic simulation models. A discussion on the applicability of the use of microscopic modeling for this study can be found in Section 3.2.1.

\subsection{Summary}

The demand of traffic is significantly increasing in Addis Ababa while the current supply of infrastructure is significantly below the average of the developing world. An extension of 
infrastructure is necessary; however, the basic state of the economic development and the institutional challenges will make a development of infrastructure a complex and long term solution. A short term solution would be to maximize the use of the current infrastructure.

The saturation flow is an indication of the maximum flow of a junction during green phase when operating under ideal conditions. To compensate for the vehicle differences, it is usually measured in Passenger Car Units per hour (PCU/h). Different methods to calculate the saturation flow and PCU values per vehicle type exist. Section 3.1.3 elaborates on the applicability of the different methods for this study.

The mean saturation flow of developing countries (1200-2000 PCU/h) is lower than the mean flow of developed countries (1700-2080 PCU/h). Besides the lower mean, the range of saturation flows of developing countries is larger than the range of flows in developed countries. The variations in saturation flow are likely to be influenced by factors such as the level of pedestrian interference. Comparing different international studies on traffic flows at intersections in developing countries, it appears that the following aspects are not well-described:

- The characteristics of the traffic flow at urban intersections in Sub Saharan Africa

- The effect of a human traffic controller on the internal lost time of a control cycle

- The application of flow models to propose a plan of improvement with quantitative results for the relative low flow rates at intersections in most of the developing countries

The type of intersection control determines the amount of traffic an intersection can process. Different control types exist: fixed-time signal control, responsive signal control and officer control. The first two types of control can also be applied in networks where intersections interact with each other. As a result of unique advantages - such as the low costs - officer control is still being applied in developing countries. Upcoming countries tend to replace their officer control for automated intersection control. However, such redesigns of the control system will not necessary result in better performance.

More into detail, the total flow realized at a group of conflicting lanes at an intersection depends on two factors:

- The average queue discharge flow per involved stream

- The internal lost time during the transition of the right of way divided by the cycle length Numerous macroscopic intersection flow models focus on modeling of the saturation flow. No models could be found that directly predict the total flow of a group of conflicting lanes. However, by using the lost-time/cycle-time ratio and the saturation flow, the flow at the conflict group can be estimated. The saturation flow is larger than the actual occurring queue discharge flow; an estimation of the flow of a conflict group based on the saturation flow is therefore likely to result in an overestimation. Macroscopic flow models can be developed based on simple vehicle counts per unit of time. Microscopic models are capable of describing the individual behavior of vehicles in complete networks. The flow at a conflicting group can directly be determined based on individual vehicle tracking. Several models are commercially available. To be able to use these microscopic models, large amounts of parameters need to be calibrated. Detailed data is needed for correct calibration. Section 3.2.1 elaborates on the applicability of both macroscopic and microscopic models for this study. 


\section{Chapter 3}

\section{Research approach and methodology}

This chapter describes the research approach and methodology used in the thesis. The titles of the sections refer to the titles of the chapters from which the research approach and methodology is described.

\subsection{Analysis of traffic flow at the intersections of Addis Ababa}

This Section describes the observation method, the data filtering method and the calculation method to determine the saturation flow, the PCU value, the queue discharge flow and the interference efficiency.

\subsubsection{Observation}

At several intersections in Addis Ababa, traffic cameras are installed since March 2010 by Information Network Security Agency of Addis Ababa to both gather accurate information on traffic flow and to monitor traffic accidents (Alemu, 2010). The cameras provided by China Video Surveillance Ltd. are positions well above all traffic, providing a good overview of the intersections. The traffic flow can be clearly seen, vehicles can be easily distinguished from each other. For this study, video images of several camera positions at three intersections were available.

In total, nine lanes at the three intersections in Addis Ababa are studied. Per intersection, the geometry is determined using Google Earth. All lanes are part of conflict groups. Per vehicle, the vehicle type and the time when the front axis of the vehicle crosses the stop line are manually registered, using the data log program TrafficLog ${ }^{2}$. Computerized vehicle recognition would be hard as a result of the chaotic vehicle movements, the different colors of the vehicles and the wide range of vehicle types. The observed vehicles are grouped in three different vehicle types: passenger cars, minibuses and heavy vehicles (Table 3.1). Motorbikes and non-motorized vehicles are not considered, since preliminary observations showed that these vehicles have a negligible share of the total vehicle composition. To be sure to measure the flow of vehicles limited by the supply of the network and not

\footnotetext{
${ }^{2}$ TrafficLog is developed by the author for the specific purpose of this research. TrafficLog is available upon request.
} 
Table 3.1: Definitions of the different vehicle classes

\begin{tabular}{lll}
\hline Class & Includes & Details \\
\hline & & \\
Car & Passenger car, taxi, SUV, pick-up & $2-7$ passengers \\
Minibus & Minibus & 12 passengers \\
Heavy vehicle & Medium bus, large bus & $>12$ passengers \\
& Light truck, heavy truck, trailer & Freight transport \\
\hline [1] In Ethiopia a minibus is allowed to carry up to 12 passengers (Gebeyehu and Takano, 2007) & \\
\hline
\end{tabular}

the flow of vehicles limited by the demand of the traffic, only queue discharging flows are studied. The output of TrafficLog consists of a list with vehicle types and their corresponding times of crossing the stop line. The estimated measurement error, calculated by means of repetitive observing of the same data sample, is $2.8 \%$ for determining the time headway (explained in Section 3.1.2) and $1.7 \%$ for determining the vehicle counts per 5 seconds (Appendix $\mathrm{C}$ ). The total flow of a conflict group is measured as the total amounts of vehicles leaving the zone of interference per unit of time.

One of the considered intersections is fully controlled by policemen another intersection is party officer controlled. As a result, the stop position of vehicles before crossing the intersection differs heavily. In most cases, the stop line is ignored since it is located far away from the intersection or simply because a stop line does not exist. Therefore, a virtual stop line is defined as the front of the last stop position of the first vehicle in a queue before it crosses the intersection.

\subsubsection{Data filtering}

The data is filtered for manual measurement errors, such as vehicles with a headway time that would not be realistic (lower than 0.4 seconds). In this thesis, the headway of a vehicle is defined as the moment in time when the front axis of the preceding vehicle crosses the stop line minus the moment in time when its own front axis crosses the same stop line. The time difference is the headway.

\subsubsection{Saturation flow and PCU value calculation method}

The saturation flow is an indication of the maximum flow of a junction during green phase when operating under ideal conditions (Turner and Harahap, 1993). Section 2.4.1 states an overview of different methods to determine the saturation flow. The most simple method is to remove a begin and end lag of a queue discharge flow (Figure 2.1). However, preliminary analysis showed that the queue discharge flow in Addis Ababa does not reach a steady value. The flow is heavily fluctuating, as illustrated in Figure 2.2. Therefore, removing only a begin and end lag will not result in an indication of the maximum flow of a junction when operating under ideal conditions. The method used by (Lu, 2008) is also not likely to give a proper indication of saturation flow since it includes large headway times. Therefore, this research uses a method similar to (Minh et al., 2009), in which the saturation flow is based on a minimum flow threshold. However, the method by (Minh et al., 2009) was developed for non-lane based traffic. Therefore, the minimum flow threshold has to be redefined to be applicable to the Addis Ababa lane based traffic. 
Traffic flows consist of both car following vehicles and non-following vehicles. Non-following vehicles have such a large distance to the preceding vehicle that the driving behavior is not depending on the preceding vehicle. A study by (Wasielewski, 1979) concluded that vehicles with a time headway of larger than 4 seconds cannot be described as car-following vehicles. Concerning the traffic in Addis Ababa, this thesis assumes that a queue discharging flow consisting only of vehicles in a car-following state will give a proper indication of the maximum flow of a junction when operating under ideal conditions. Therefore, the upper limit of the time headway of 4 seconds is used as a threshold to define the saturation flow. Each vehicle with a time headway larger than 4 seconds is therefore not included in the calculation of the saturation flow. An upper limit of the time headway will result in a lower boundary for the saturation flow. As a result, in this thesis the saturation flow is not a constant value as assumed by (Branston and van Zuylen, 1978), but consists of a range of values with a minimum threshold, as illustrated in Figure 2.2. A maximum headway of 4 seconds result in a minimum departure rate (larger than $900 \mathrm{veh} / \mathrm{h}$ ).

The saturation flow is usually expressed in PCU/h to compensate for the different vehicle types and can be calculated in different ways (see Section 2.4.1). This research will use the multiple linear regression method since a combined calculation of the saturation flow and PCU value is possible. It makes the results also comparable to numerous studies worldwide ( $\mathrm{Lu}, 2008$, Li et al., 2009, Righolt and Berkhout, 2009, Hadiuzzaman et al., 2008, Turner and Harahap, 1993). Based on vehicle counts per vehicle type per time interval of 5 seconds, the PCU values and saturation flow value are determined by means of linear regression. An explanation of the working of the considered models and a more detailed motivation of choice can be found in Appendix D.

\subsubsection{Queue discharge flow calculation method}

In this study, the saturation flow is determined to enable international comparison and to be able to calculate the PCU values. However, the queue discharge flow is needed to model the actual flow at conflicting streams at intersections. The difference between the saturation flow and the queue discharge flow is illustrated in Figure 2.2. The queue discharge flow is based on the overall amount of observed vehicles of a discharging flow during green phase per unit of time; therefore, it does include vehicles with a headway time of larger than 4 seconds. The conversion from vehicles per hour to PCU per hour is made by using the previously determined PCU values per vehicle class.

\subsubsection{Interference flow and interference efficiency calculation method}

The maximum possible flow at conflicting lanes of an intersection is limited by the highest saturation flow of the involved conflicting streams. Under ideal conditions, closing down all lanes except from the one with the highest flow would result in the saturation flow.

Where:

$$
F \leq \max \left(S_{\text {stream }, 1} ; S_{\text {stream }, 2} ; \ldots ; S_{\text {stream }, i}\right)
$$

$F \quad$ total flow rate of conflict grouping of lanes (also called: interference flow),

$S_{\text {stream, } i}$ saturation flow per stream $i$. 
To measure the relative performance of the total flow of the interfering lanes compared to the maximum potential flow, this thesis introduces the interference efficiency. The efficiency of conflicting lanes, expressed as follows:

$$
\mu=\frac{F}{\max \left(S_{\text {stream }, 1} ; S_{\text {stream }, 2} ; \ldots ; S_{\text {stream }, i}\right)} \times 100 \%
$$

Where:

$\mu \quad$ interference efficiency.

The interference efficiency depends on the combination of traffic behavior and the available infrastructure, expressed in the saturation flow. Generally, the efficiency is influenced by the following aspects:

- The difference between the queue discharge flow and the saturation flow of the involved streams. A low queue discharge flow causes a low flow of interfering lanes; but a high saturation flow causes high denominator in Equation 3.2; therefore, the efficiency will be low.

- The lost time due to change of right-of-way. A long lost time causes a low flow of interfering lanes, but does not influence the maximum saturation flow; therefore, the efficiency will be low. More conflicting lanes per conflict group will result in more changes of right-of-way and is therefore likely to result in more losses and a lower efficiency.

- The unbalance in queue discharge flow per stream. One stream with a low queue discharge among other high queue discharge flows will cause a lower flow of interfering lanes; however, it does not influence the maximum saturation flows. Therefore the efficiency will be low.

Based on the available data, the saturation flow of the involved streams can be calculated according to methods as described in Section 3.1.3. The interfering flow can be calculated based on vehicle counts of all vehicles on the conflicting lanes over a period of time. By using the previously determined PCU values, this can be translated into a total PCU per hour.

\subsection{Modeling}

In this section, the type of model that will be used is chosen, the method of model development is described and validation method is explained.

\subsubsection{Model type selection}

To be able to suggest throughput improvements for intersections, a simulation model of the flow at conflicting lanes will be developed. As described in Sections 2.4.3 and 2.4.4, macroscopic and microscopic flow models exist. Both can be applied to describe urban traffic flows.

Macroscopic intersection flow models focus on modeling of aggregated flows. These models can be developed based on simple vehicle counts per unit of time. Microscopic models are capable of describing the individual behavior of vehicles. The flow at a conflicting group can directly be determined based on individual vehicle tracking. Numerous models are commercially available. To be able to use these microscopic models, large amounts of parameters need to be calibrated. Detailed data is needed for correct calibration. 
The available data from Addis Ababa consists of video images from several intersections. The information that can be extracted would not be enough to track individual vehicles, needed to calibrate complex microscopic models. However, macroscopic models can be developed based on basic data. Therefore, the model to be developed is based on macroscopic traffic behavior. A disadvantage of macroscopic modeling is that it only calculates average values. It cannot deal with stochastic behavior, while microscopic models can. In cities, stochastic models can be used to calculate for example the chance on intersection overflow. However, limited by the data, the development of macroscopic models is the only option. Since no models that describe the total flow of a group of conflicting lanes could be found, a new model is developed. The method is described in the following section.

\subsubsection{Model development}

The objective of the model is to quantify the different factors that influence the traffic flow of a conflict group at an intersection in order to suggest improvements. The total flow of a conflict group $(F)$ equals the average queue discharge flow of the involved lanes minus losses (for example due to transition of the right-of-way). The losses are expressed in the productivity factor.

$$
F=Q \times P
$$

Where:

$P \quad$ average productivity factor of the conflicting group,

$Q \quad$ average queue discharge flow rate per stream.

It must be noticed that Equation 3.3 is only applicable to situations in which continuous queue discharge is taking place during green phase, i.e., heavy to saturated traffic conditions (Appendix I). For signal controlled intersections, the productivity can be calculated based on the internal lost time that is a result of the signal settings (see Equation 2.3). However, in case of officer control, it is more complicated to determine the productivity. Both the productivity factor of officer control and the queue discharge flow rate are functions of different influencing factors. Therefore, the productivity of officer control and the queue discharge rate will be modeled separately. Both models together result in a model to predict the total flow rate of a conflict group at an officer controlled intersection.

Nine different lanes at three different intersections are studied. As explained in Section 2.4.3, two macroscopic model types can be used: the multiplicative model and the additive model. The standard HCM method (TRB, 2000) does not include the influence specific Addis Ababa characteristics (such as officers control and African minibuses) on the flow rate. Adapting the HCM model would be necessary. However, a more common method is to build a completely additive model by using of linear regression (method also be used by e.g., (Kimber et al., 1986, Turner and Harahap, 1993, Hadiuzzaman et al., 2008, Hossain, 2001)). The frequent use of the additive model for developing countries shows that this model can easily be developed and results in well fitting models (Table 2.3). Therefore, this study will also use the additive model. Based on the average observed queue discharge flow rate per lane, the additive model is developed to quantify the influence of different factors on the queue discharge flow rate. As a result of differences between the studied lanes, 
numerous factors can be studied. Examples of factors are: lane width, type of control (officer or signals) and traffic composition (such as share of minibuses).

Furthermore, two hours of flow at a conflicting group at an officer controlled intersection during heavy to oversaturated traffic conditions (definition of traffic conditions, see Appendix I) was studied. Based on these observations, the total flow rate of the conflict group $(F)$ can be determined. Combining this with the average queue discharge flow rate of the involved lanes enables the modeling of the productivity factor of an officer controlled conflict group. The dataset is split into several groups and multiple linear regression is applied to determine the influence of different factors, such as the transition rate of the right-of-way and the amount of time the intersection is blocked.

To develop both models, backwards multiple linear regression is used to determine which factors have significant influence. The first step is to include all factors in the regression, followed by removing the least significant factor. The regression process is repeated, until the factors with significant influence remain. A level of significance of 0.01 is considered. The model fitness is measured in the coefficient of determination $\left(R^{2}\right)$, illustrating the amount of variance in the depending variable that can be explained by the predictors, and the standard error. If the linear regression model does not result in a sufficient fit, non-linear regression is applied. Post hoc analysis using GPOWER (Erdfelder et al., 1996) is applied to determine whether the sample size is large enough for sufficient power (for a detailed explanation of significance and power, see Appendix J).

Both the queue discharge model and the productivity model can only be applied to predict the interference flow during comparable conditions, such as season, location and traffic mode, since the data is not rich enough to describe all possible traffic phenomena.

\subsubsection{Validation}

The accuracy of a model can be determined by validating the model on another dataset. However, since the video datasets from Addis Ababa road intersections are not very large, all the data is used to develop a proper model. To estimate the accuracy of a model without testing it on another dataset, leave-one-out cross-validation can be applied (e.g., used by (John et al., 1994)). The model is trained on $\mathrm{n}-1$ data points. This trained model is used to predict data point $\mathrm{n}$. The error between the prediction and the observation is calculated by means of:

$$
\epsilon=\frac{\left|D_{\text {prediction }}-D_{\text {observed }}\right|}{D_{\text {observed }}}
$$

Where:

$$
\begin{array}{ll}
\varepsilon & \text { error, } \\
D_{\text {prediction }} & \text { predicted datapoint, } \\
D_{\text {observed }} & \text { observed datapoint. }
\end{array}
$$

This procedure is repeated $\mathrm{n}$ times, each time leaving out one other data point. The average error is the estimated accuracy. A disadvantage of this method is that applying it to a small dataset results in a risk of having a large error and a large variation of error (Braga-Neto and Dougherty, 2004). However, no other appropriate validation methods could be found. 


\subsection{Simulation and results}

Based on the developed model, the quantitative influence of different significant factors on the traffic flow at the conflict group at Wellosefer is simulated. Using the results of the simulations, improvements are suggested to increase the total flow at the conflict group.

\subsection{Conclusions}

The saturation flow is an indication of the maximum flow of a junction during green phase when operating under ideal conditions. In this research, it is defined as the flow of vehicles only in carfollowing state. The saturation flow and the passenger car equivalent (PCU) values are calculated using multiple linear regression based on vehicle counts per 5 seconds, a method applied in numerous comparable studies.

The total interference flow at all streams of a conflict group is modeled with a macroscopic modeling approach. The interference flow is the product of the average queue discharging flow and the productivity of the conflict group (productivity related to the losses due to, e.g., transition of right-ofway). The productivity of a signal controlled intersection can be directly calculated based on the signal settings. However, the productivity of an officer controlled intersection is harder to determine. The interference flow model therefore consists of two parts: a model of the queue discharging flow and a model of the productivity factor of a manual controlled intersection. Both models are developed by applying multiple linear regression to the data that is generated by vehicle counts. The accuracy of the models is determined by leave-one-out cross-validation. A significance level of 0.01 is considered. Post hoc analysis is applied to determine whether the sample size is large enough for sufficient power. Based on the developed models, simulation is used to suggest improvements to increase the total flow at a conflict group of the officer controlled intersection Wellosefer. 


\section{Chapter 4}

\section{Traffic flow analysis intersections Addis Ababa}

This chapter describes the analysis of the traffic flow at intersections. First, an overview of the complete study area is given, followed by a more detailed layout description per intersection. The third section presents the flow data of the study area. Finally, the flow characteristics are compared to other studies of intersections in developing and developed countries.

\subsection{Overview of the study area}

Addis Ababa consists of a basic road network. A network exists of links and nodes (or intersections). In this thesis, three intersections in one corridor of the African Avenue are considered. The Africa Avenue is the main road between the international airport and the city center and it is one of the major routes of Addis Ababa (Figure 4.1). Cameras are positioned at several intersections on this corridor. The available video images are from cameras positioned at the following intersections:

- Meskel: intersection at the Meskel Square

- Denbel: intersection with the Democratic Republic Congo Street

- Wellosefer: intersection with the Ethio-China Street

Different lanes at all the three intersections are studied to model the queue discharge flow. An overview of the specifications of the intersections is shown in Table 4.1. During 9 different days, randomly chosen in November and December 2010, the traffic flow at 9 different lanes were recorded during times of congestion for at least 30 minutes per lane, resulting in a total of 20 lane-hours. As a result of the limitations of manual data extractions from the video recordings, not more data could be generated. Further research is needed to determine whether the recorded behavior of the traffic at the intersections is representative for other intersections in Addis Ababa or in other cities in Sub Sahara Africa.

The Wellosefer intersection is particularly interesting since the traffic is completely regulated by policemen. No signals are installed. On the other hand, the Denbel and Meskel intersection are currently already (partially) controlled by signals. The Wellosefer intersection causes large delays, as illustrated by Figure 4.2. The intersection is in need for a solution to increase the flow of traffic and shows potential by simply replacing the manual controllers by signals. It offers the opportunity to 


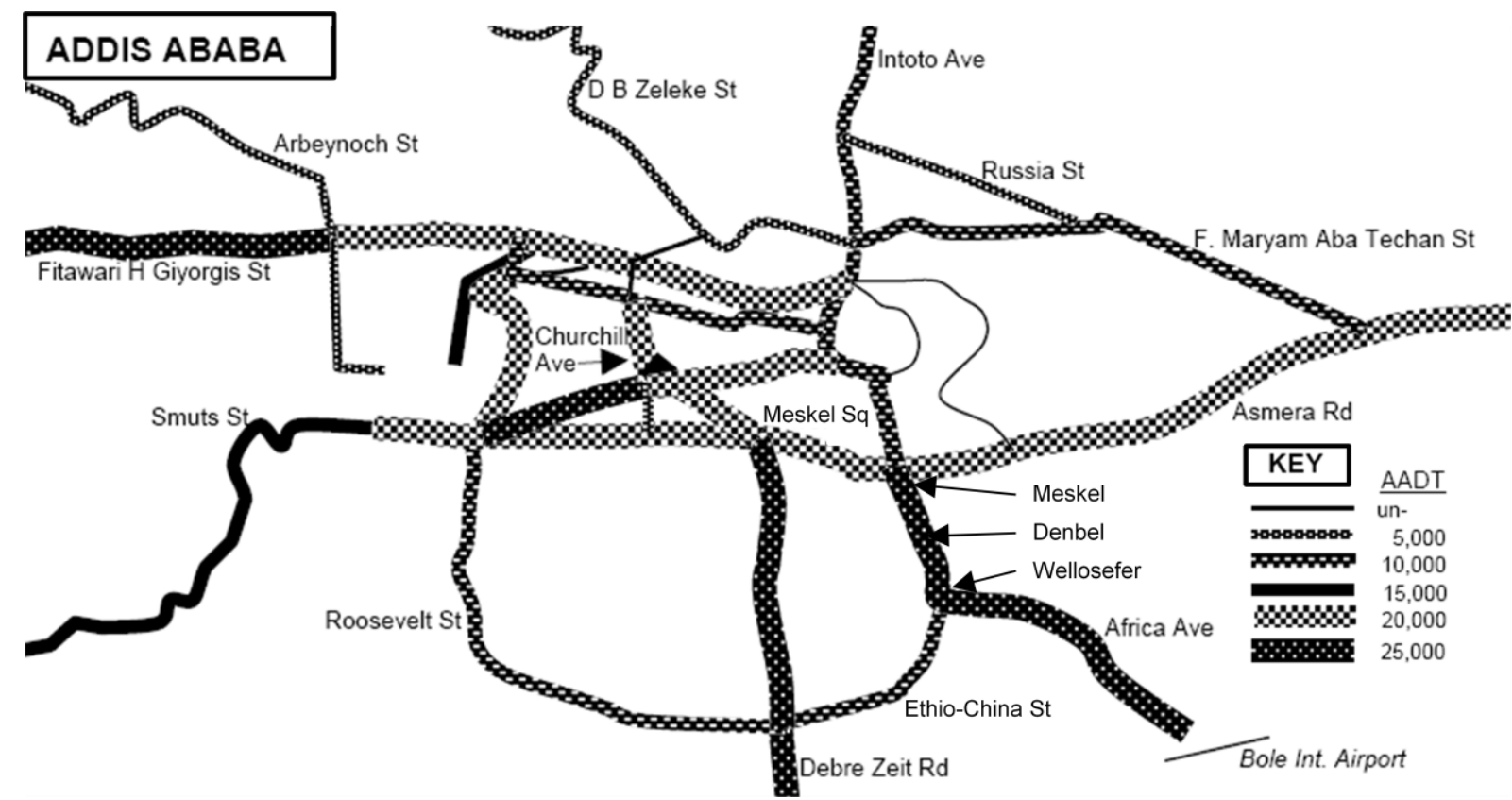

Figure 4.1: Major routes and traffic volumes in Addis Ababa, measured as Annual Average Daily Traffic (AADT), based on (The World Bank, 2002). The considered intersections are Meskel, Denbel and Wellosefer.

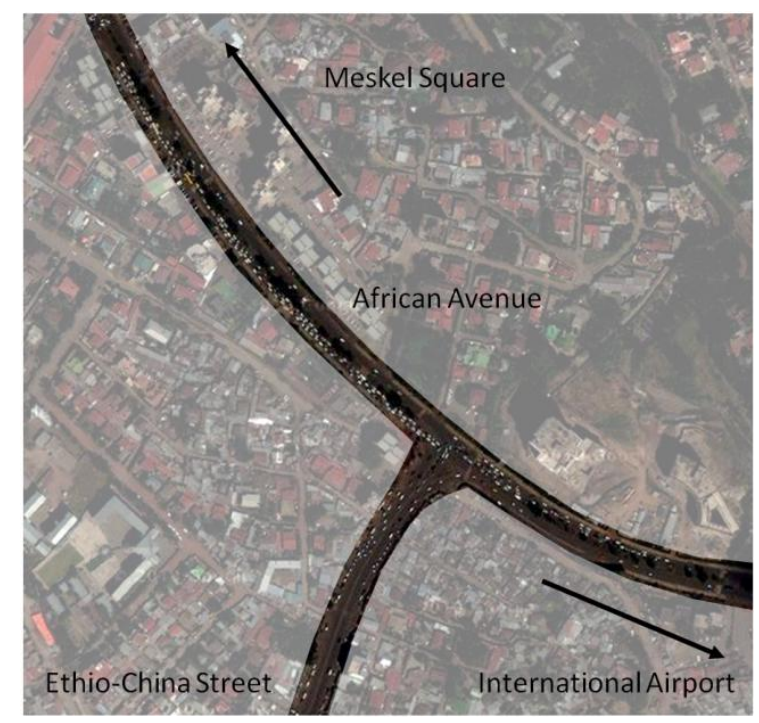

Figure 4.2: The Wellosefer intersection. A long queue can be seen at the left side of the picture, travelling from Meskel Square in the direction of the international airport (picture retrieved from Google Earth).

Table 4.1: Overview of the specifications of the studied intersections

\begin{tabular}{lllll}
\hline $\begin{array}{l}\text { Intersection } \\
\text { name }\end{array}$ & $\begin{array}{l}\text { Number of } \\
\text { studied lanes }\end{array}$ & $\begin{array}{l}\text { Control } \\
\text { type }\end{array}$ & Direction & $\begin{array}{l}\text { Lane } \\
\text { width [m] }\end{array}$ \\
\hline Meskel & 3 & signal & straight through & 3.5 \\
Denbel & 2 & human/signal & straight through & 2.7 \\
Wellosefer & 4 & human & straight through / turning & $2.7-3.0$ \\
\end{tabular}


study and model the interference flow. Wellosefer is a unique location to be able to estimate the improvements of signal control versus manual control in case of the Addis Ababa traffic situation. In addition to this, the layout of the intersection is relatively simple, enabling performance benchmarking with Dutch and Chinese intersection studies (Righolt and Berkhout, 2009, Lu, 2008, Li et al., 2009).

\subsection{Layout of intersections}

Figure 4.3 shows the layout of the studied intersections. Each intersection is described below.

\subsubsection{Meskel}

Meskel is the largest of the considered intersections (Figure 4.3, left). Three different lanes are studied, for a total of about 2 lane-hours, during traffic congestion on two different days. The lane width of all considered lanes is 3.5 meters. Lane 09 and 12 are mixed lanes for both turning and straight through traffic. As a result of a low proportion of turning traffic and the large turning radius, both are considered as straight through lanes.

\subsubsection{Denbel}

Denbel is shown in the middle of Figure 4.3. Two different lanes are studied, for a total of about 2.5 lane-hours, during traffic congestion on one day. The lane width of all considered lanes is 2.7 meters. Lane 03 is a mixed lane for both turning and straight through traffic. As a result of a low proportion of turning traffic, it is considered as a straight through lane.

\subsubsection{Wellosefer}

Wellosefer is the only intersection with three streams (Figure 4.3 , right) and is fully controlled by officers. Four different lanes are studied in detail, for a total of 16 lane-hours, during traffic congestion on six different days. Lanes 08 (left and right) are straight through lanes, lanes 06 (left
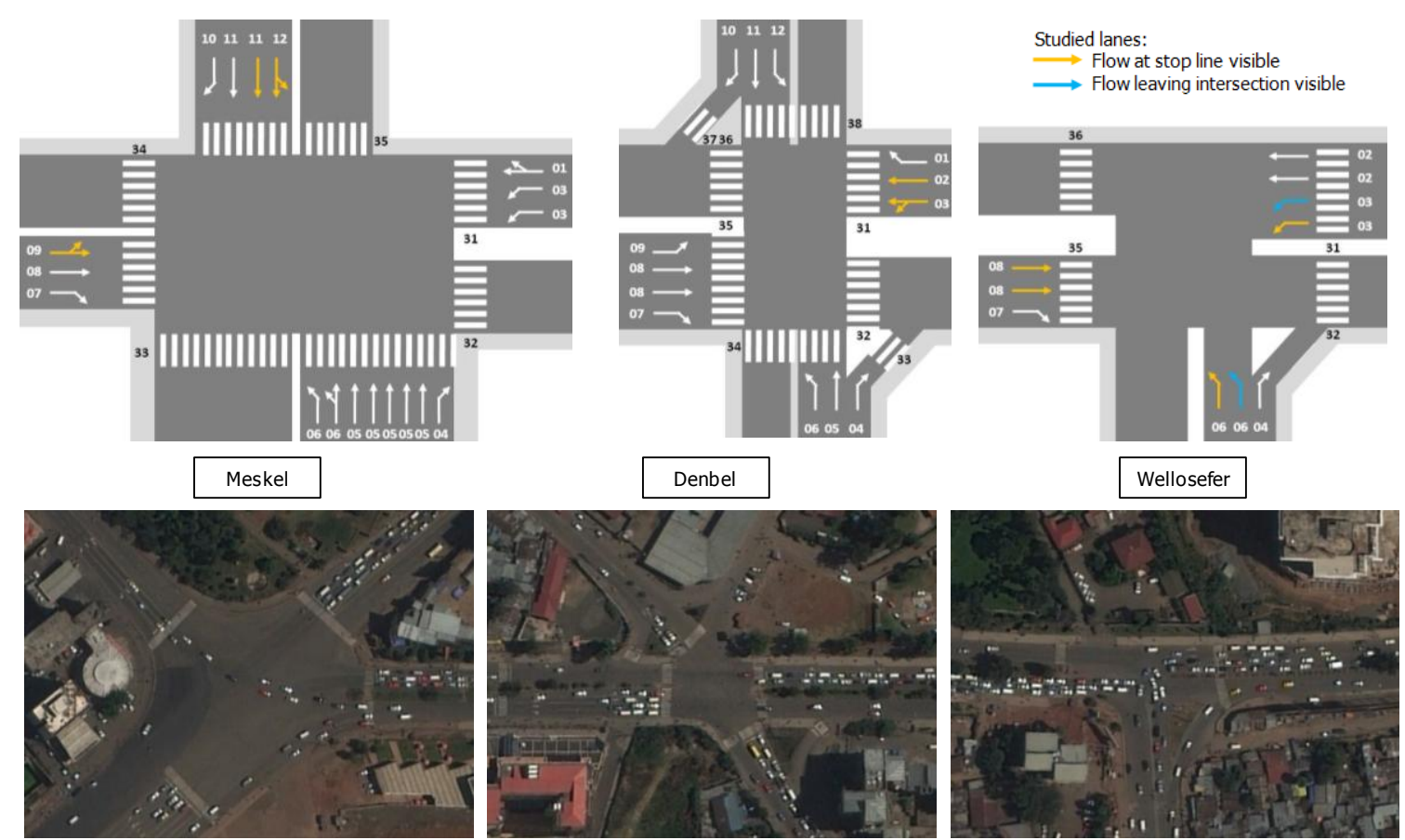

Figure 4.3: Considered intersections. Lanes are numbered according to Dutch standards. 
and right) and 03 (left and right) are turning lanes. Lanes 03, 06 and 08 are the conflicting streams, together they form a conflict group. As a result of the position of the camera, the stop line can only be seen at lanes 08, 03 left and 06 left. A flow based on vehicle counts crossing the stop line can therefore only be determined for lanes 08 and 03 left and 06 left. The flow of 03 right and 06 right can still be seen when leaving the intersection. The flow of the complete conflict group is studied for two hours. The lane width of the considered straight through lanes is 2.7 meters and of the turning lanes 3.0 meters.

\subsection{Collection of data and analysis}

In this section, the collection of data and analysis is described for the corridor as a whole and per intersection for Meskel, Denbel and Wellosefer respectively. Table 4.2, 4.3, 4.4 and 4.5 show respectively the vehicle composition, PCU values per vehicle type, the saturation flow rate and the queue discharge flow rate of the corridor. Table 4.6 shows the vehicle counts of the conflict group at the Wellosefer intersection during heavy to oversaturated traffic conditions.

\subsubsection{Corridor}

To determine the traffic performance in the corridor, all three intersections are considered: Wellosefer, Denbel and Meskel. Minibuses form a large share of the total vehicle composition (Table 4.2), however passenger cars are the dominant vehicle type. Tables 4.3 and 4.4 show respectively the PCU values per vehicle class and the corresponding saturation flow, both calculated by means of linear regression based on vehicle counts per time interval of 5 seconds (explanation in Section 3.1.3 and Appendix D).

The PCU value of a minibus is in all cases smaller than 1 . The more aggressive driving compared to passenger cars results in shorter time headways and therefore low PCU values. The PCU value of heavy vehicles is on average slightly larger than 1 . The PCU values of turning traffic appear to be lower than straight through traffic. Especially the heavy vehicles are expected to have a higher PCU value when turning, since a turning movement with a large vehicle generally takes significantly more time than with a passenger car. The low PCU value can be explained by the following:

- The small amount of observed heavy vehicles. This can result in non-representative samples.

- The category of heavy vehicles is broad. A small commercial truck that cannot be considered as a car or a minibus was also considered to be a heavy vehicle.

- The passenger cars category contained a large share of SUVs that have problems with quick turning. Since the PCU values are normalized in such a way that the PCU value of a passenger cars is always 1 , the other PCU values will decrease when passenger cars have larger headways. The saturation flow of turning traffic is lower than straight through traffic (confirming studies in Table 2.4). The queue discharge flow is shown in Table 4.5. It is significantly lower than the saturation flow, caused by the share of non-following vehicles (i.e., with a headway larger than 4 seconds) in the queue discharge flow, respectively $8.8 \%, 9.9 \%$ and $9.1 \%$ for straight through traffic, turning traffic and all traffic. For all studied data, the average number of PCUs crossing the stop line during the first 5 seconds of the green phase was 1.90, during the second 5 seconds it was 1.81 . This gives an indication of a lack of start delay. Moreover: the flow rate appears to be decreasing in the second 5 seconds. This does 
Table 4.2: Vehicle composition, grouped per location and per direction of traffic flow

\begin{tabular}{llll}
\hline Location/direction & Number of cars (\%) & Number of minibuses (\%) & Number of heavy vehicles (\%) \\
\hline $\begin{array}{l}\text { Corridor } \\
\text { Straight through }\end{array}$ & $3327(71 \%)$ & $1292(27 \%)$ & $100(2 \%)$ \\
Turning & $1681(91 \%)$ & $114(6 \%)$ & $59(3 \%)$ \\
All & $5008(76 \%)$ & $1406(21 \%)$ & $159(2 \%)$ \\
Meskel & & & $21(5 \%)$ \\
Straight through & $346(80 \%)$ & $65(15 \%)$ & $12(1 \%)$ \\
Denbel & & $311(33 \%)$ & $66(2 \%)$ \\
Straight through & $625(66 \%)$ & & $59(3 \%)$ \\
Wellosefer & & $916(27 \%)$ & \\
Straight through & $2356(71 \%)$ & $114(6 \%)$ & \\
Turning & $1681(91 \%)$ & & \\
& & &
\end{tabular}

Table 4.3: PCU values per vehicle class, grouped per location and per direction of traffic flow. The number of observed vehicles gives an indication of the datasize.

\begin{tabular}{|c|c|c|c|c|}
\hline Location/direction & Vehicle type & PCU & Standard error & $\begin{array}{l}\text { Number of } \\
\text { observed vehicles }\end{array}$ \\
\hline \multicolumn{5}{|l|}{ Corridor } \\
\hline \multirow[t]{2}{*}{ Straight through } & Minibus & 0.90 & 0.026 & 511 \\
\hline & Heavy vehicle & 1.09 & 0.11 & 27 \\
\hline \multirow[t]{2}{*}{ Turning } & Minibus & 0.82 & 0.088 & 35 \\
\hline & Heavy vehicle & 0.94 & 0.12 & 19 \\
\hline \multirow[t]{2}{*}{ All } & Minibus & 0.90 & 0.023 & 546 \\
\hline & Heavy vehicle & 1.03 & 0.082 & 46 \\
\hline \multicolumn{5}{|l|}{ Meskel } \\
\hline \multirow[t]{2}{*}{ Straight through } & Minibus & 0.64 & 0.11 & 31 \\
\hline & Heavy vehicle & 1.07 & 0.36 & 3 \\
\hline \multicolumn{5}{|l|}{ Denbel } \\
\hline \multirow[t]{2}{*}{ Straight through } & Minibus & 0.87 & 0.053 & 104 \\
\hline & Heavy vehicle & 0.98 & 0.35 & 2 \\
\hline \multicolumn{5}{|l|}{ Wellosefer } \\
\hline \multirow[t]{2}{*}{ Straight through } & Minibus & 0.92 & 0.030 & 376 \\
\hline & Heavy vehicle & 1.11 & 0.12 & 22 \\
\hline \multirow[t]{2}{*}{ Turning } & Minibus & 0.82 & 0.088 & 35 \\
\hline & Heavy vehicle & 0.94 & 0.12 & 19 \\
\hline
\end{tabular}


Table 4.4: Saturation flow rate, grouped per location and per direction of traffic flow. The flow consisted of a vehicle mix shown in Table 4.2. The flow was calculated based on vehicle counts per time interval of 5 seconds. The number of intervals gives an indication of the data size.

\begin{tabular}{llll}
\hline Location/direction & Saturation flow rate $[\mathbf{P C U} / \mathbf{h}]$ & Standard error $[\mathbf{P C U} / \mathbf{h}]$ & Number of intervals \\
\hline Corridor & & & \\
Straight & 1522 & 18.0 & 871 \\
Turning & 1507 & 21.6 & 341 \\
All & 1517 & 13.7 & 1212 \\
Meskel & & \\
Straight through & 1492 & 57.6 & 84 \\
Denbel & & & \\
Straight through & 1427 & 45.4 & 124 \\
Wellosefer & & & 663 \\
Straight through & 1538 & 20.2 & 341 \\
Turning & 1507 & 21.6 & \\
\hline
\end{tabular}

Table 4.5: Queue discharge flow rate, grouped per location and per direction of traffic flow. The flow consisted of a vehicle mix shown in Table 4.2. The flow was calculated based on vehicle counts per time interval of 5 seconds. The number of intervals gives an indication of the data size.

\begin{tabular}{lll}
\hline Location/direction & {$[\mathbf{P C U} / \mathbf{h}]$} & Number of intervals \\
\hline Corridor & & \\
Straight & 1358 & 2159 \\
Turning & 1345 & 804 \\
All & 1356 & 2963 \\
Meskel & 1406 & \\
Straight through & & 175 \\
Denbel & 1324 & \\
Straight through & & 436 \\
Wellosefer & 1361 & \\
Straight through & 1345 & 1548 \\
Turning & & 804 \\
\end{tabular}

Table 4.6: Vehicle counts at one conflict group at Wellosefer during two hours of heavy to saturated traffic mode per stream. The flow includes all vehicle types.

\begin{tabular}{lll}
\hline Stream & Direction & Number of vehicles (PCUs) \\
\hline 03 left + right & turning & $1166(1150)$ \\
06 left + right & turning & $424(418.2)$ \\
08 left + right & straight through & $2128(2095)$ \\
Total & & $3718(3663)$ \\
\hline
\end{tabular}


not fit assumptions by (Branston and van Zuylen, 1978) of the ideal profile that has been widely used (Figure 2.1). The low speed of traffic can be an explanation for the inexistence of the start lag.

\subsubsection{Meskel}

All studied lanes at the Meskel intersection are straight through lanes. Passenger cars form the largest share of the vehicle composition, followed by minibuses. Heavy vehicles form the smallest group (Table 4.2). The PCU value of a minibus is smaller than 1, the PCU value of heavy vehicles is larger than 1 (Table 4.3). However, as a result of the small number of heavy vehicles, the standard error of the PCU value for heavy vehicles is relatively large. Considering the overall flow - consisting of all types of vehicles - the saturation flow rate is $1492 \mathrm{PCU} / \mathrm{h}$ (Table 4.4). The queue discharge rate is lower, namely $1406 \mathrm{PCU} / \mathrm{h}$ (Table 4.5). This is caused by a share of $8.3 \%$ of non-following vehicles.

\subsubsection{Denbel}

All studied lanes at the Denbel intersection are straight through lanes. Passenger cars form the largest share of the vehicle composition, followed by minibuses. The share of minibuses is the highest of the considered intersections. Heavy vehicles form the smallest group (Table 4.2). The PCU values of minibuses and heavy vehicles are smaller than 1 (Table 4.3). However, as a result of the small number vehicles, the standard error of the PCU value for heavy vehicles is relatively large. Considering the overall flow - consisting of all types of vehicles - the saturation flow rate is 1427 $\mathrm{PCU} / \mathrm{h}$ (Table 4.4). The queue discharge rate is lower, namely $1324 \mathrm{PCU} / \mathrm{h}$ (Table 4.5). This is caused by a share of $10.1 \%$ of non-following vehicles.

\subsubsection{Wellosefer}

The studied lanes at the Wellosefer intersection consist of both turning lanes and straight through lanes. Passenger cars form the largest share of the vehicle composition, followed by minibuses. The share of minibuses for the turning lanes is significantly lower than for the straight through lanes. This might be explained by standard routes of the public tranport in Addis Ababa. Heavy vehicles form the smallest group (Table 4.2). Concerning straight through traffic, the PCU value of a minibus is smaller than 1, the PCU value of heavy vehicles is larger than 1 (Table 4.3). Concerning turning traffic, the PCU values of minibuses and heavy vehicles are both smaller than 1 . The low PCU value for the heavy vehicles can be explained by the small dataset, the large range of vehicles within the group of heavy vehicles and the large share of SUVs within the group of passenger cars (explained in 4.3.1). The saturation flow rate is $1538 \mathrm{PCU} / \mathrm{h}$ and $1507 \mathrm{PCU} / \mathrm{h}$ for straight through and turning traffic respectively (Table 4.4). The queue discharge rate for both straight through and turning traffic is lower, namely $1388 \mathrm{PCU} / \mathrm{h}$ and $1363 \mathrm{PCU} / \mathrm{h}$ respectively (Table 4.5). This is caused by a share of $8.5 \%$ of non-following vehicles for straight through lanes and $9.9 \%$ for turning lanes.

Furthermore, vehicles at all conflicting lanes of the Wellosefer intersection were counted for a total of 2 hours, during 3 different days. The flow of traffic was measured at the location where the vehicles leave the conflict zone. All vehicle counts were measured during heavy to oversaturated traffic condition: throughout the green phase, continuous queue discharge is taking place (traffic modes, see 
Appendix I). The vehicle counts are shown in Table 4.6. To transform the vehicle counts to PCU values, values from Table 4.3 are used. The total length of the data after filtering was 1.61 hour (1:36:31), therefore, the total flow rate of the conflict group is $3663 / 1.61=2275 \mathrm{PCU} / \mathrm{h}$.

The interference efficiency is defined in Equation 3.2. Filling in the interference flow of $2275 \mathrm{PCU} / \mathrm{h}$, the maximum saturation flow of Wellosefer straight (1538 PCU/h $\times 2$ lanes, Table 4.4) and Wellosefer turning (1507 PCU/h $\times 2$ lanes, Table 4.4) results in an efficiency of $74 \%$ :

$$
\mu=\frac{2275}{\max (1538 \times 2 ; 1507 \times 2 ; 1507 \times 2)} \times 100 \%=74 \%
$$

The interference efficiency of the Wellosefer intersection is considerably high. This might be the result of the oversaturated traffic mode and the efficient control by the officer. The effect of the officer will be studied in the next chapters.

\subsection{International comparison}

The data presented in the previous section is compared to available studies worldwide. The following aspects are subject to international comparison:

- Saturation flow

- Following and non following traffic in saturation flow

- PCU value minibuses

- Interference flow at conflict groups

\subsubsection{Saturation flow}

The saturation flow of straight through traffic at the intersections of Addis Ababa is benchmarked with different countries, as shown in Table 4.7. (Turner and Harahap, 1993) present saturation flows occurring in developing countries, including Asia, South America and North Africa, compared to saturation flows in developed countries, including Europe and Australia. The mean saturation flow of developing countries (1230-1950 PCU/h) is lower than the mean flow of developed countries (1710-2080 PCU/h). Besides the lower mean, the range of saturation flows of developing countries is larger than the range of flows in developed countries. The more recent studies presented in the table confirm the low mean and the large range of saturation flows in developing countries. No specific studies about Sub-Saharan Africa could be found. The low mean can be explained by (based on (Turner and Harahap, 1993)):

- A diverse composition of traffic, consisting of a large share of old and slow vehicles

- Motorized and non-motorized traffic use the same lanes

- High level of pedestrian interference with the vehicle flow, e.g., as a result of street vendors

- A diverse design of intersections, e.g., multilane flows

- Smaller datasets for studies performed in developing countries

- Low law compliance

Not all of these factors occur at the same locations. Large varieties can be observed. For example, in Addis Ababa, the pedestrian interference is very low. These varying conditions and small data sizes for studies in developing countries result in a large range of saturation flows. The traffic in Addis Ababa 
Table 4.7: International saturation flow benchmark of straight through flows

\begin{tabular}{|c|c|c|c|c|c|c|c|}
\hline Country & City & $\begin{array}{l}\text { Saturation } \\
\text { flow } \\
{[\mathrm{PCU} / \mathrm{h}]}\end{array}$ & $\begin{array}{l}\text { Lane } \\
\text { width } \\
\text { [m] }\end{array}$ & $\begin{array}{l}\text { Traffic } \\
\text { composition } \\
{[\%]}\end{array}$ & $\begin{array}{l}\text { Signal } \\
\text { control }\end{array}$ & $\begin{array}{l}\text { Data size } \\
\text { int./veh. }\end{array}$ & Study \\
\hline Ethiopia & Addis Ababa & 1522 & $2.8-4.0$ & $c 71 \mathrm{mb27} h v 2$ & yes / no & 3 int./3108 veh. & \\
\hline \multirow[t]{4}{*}{ China } & Chengdu & 1477 & 3.2 & c98 lb1 l1 & yes & 1 int./1957 veh. & (Lu, 2008, Li et \\
\hline & Gangsha & 1399 & 3.0 & c98 lb1 l1 & yes & 1 int./830 veh. & al., 2009) \\
\hline & Beijing & 1284 & 3.0 & c93 lb7 & yes & 1 int./182 veh. & \\
\hline & Nanjing & 1537 & 3 & c89 lb1 I10 & yes & 1 int./1806 veh. & $\begin{array}{l}\text { (Righolt and } \\
\text { Berkhout, 2009) }\end{array}$ \\
\hline Malaysia & Various & 1660 & unk. & c60 mc30 lb5 I5 & yes & 64 int. / unk. & $\begin{array}{l}\text { (Vien et al., } \\
2006 \text { ) }\end{array}$ \\
\hline $\begin{array}{l}\text { Developing } \\
\text { countries }\end{array}$ & Various & $1200-1920$ & 3.5 & unk. & yes & 217 int. / unk. & $\begin{array}{l}\text { (Turner and } \\
\text { Harahap, 1993) }\end{array}$ \\
\hline 5 cntr. & & & & & & & \\
\hline $\begin{array}{l}\text { Developed } \\
\text { countries }\end{array}$ & Various & $1700-2080$ & 3.5 & unk. & yes & 204 int. / unk. & $\begin{array}{l}\text { (Turner and } \\
\text { Harahap, 1993) }\end{array}$ \\
\hline $3 \mathrm{cntr}$. & & & & & & & \\
\hline
\end{tabular}

does not contain a significant share of non-motorized vehicles. However, it does contain a share of old and slow vehicles. These slow vehicles and slow responding drivers cause a $9.1 \%$ of non-following vehicles (Section 4.3). This might explain why the saturation flow in Addis Ababa fits somewhere in the middle of the range for developing countries. The large amount of differences (such as lane width and traffic composition) makes a direct comparison difficult.

\subsubsection{Slow vehicles in saturation flow}

Among others, (Lu, 2008, Li et al., 2009, Righolt and Berkhout, 2009) use multiple linear regression to calculate the saturation flow, similar to this study. However, their definition of saturation flow appears to be different than used in this research (for details see Section 3.1.3). For example, in most studies, the begin and end lag of each green phase are removed to determine the saturation flow (based on the assumptions of (Branston and van Zuylen, 1978)). (Lu, 2008, Li et al., 2009) define the saturation flow as the flow consisting of vehicles with a headway time within plus and minus two $\sigma$ (i.e., standard deviation) from the mean. Both calculation methods can result in including slow vehicles (i.e., nonfollowing vehicles) in the saturation flow. The saturation flow is an indication of the maximum flow of a junction during green phase when operating under ideal conditions (Turner and Harahap, 1993). This thesis argues that a queue discharging flow consisting only of vehicles in a car-following state will give a proper indication of the maximum flow of a junction when operating under ideal conditions.

The percentage of non-following vehicles in the saturated flow of straight through traffic of (Lu, 2008, Li et al., 2009, Righolt and Berkhout, 2009) are calculated based on the available data in their studies. The comparison of these percentages with the share of non-following vehicles in the saturation and the queue discharge flow of straight through traffic of Addis Ababa is shown in Table 4.8. It appears 
Table 4.8: International comparison of the share of non-following vehicles in saturated flow

\begin{tabular}{lllllllll}
\hline Country & City & $\begin{array}{l}\text { Flow } \\
\text { type }\end{array}$ & $\begin{array}{l}\text { NF } \\
\text { vehicles } \\
{[\%]}\end{array}$ & $\begin{array}{l}\text { Lane } \\
\text { width } \\
{[\mathbf{m}]}\end{array}$ & $\begin{array}{l}\text { Vehicle } \\
\text { composition } \\
{[\%]}\end{array}$ & $\begin{array}{l}\text { Signal } \\
\text { control }\end{array}$ & $\begin{array}{l}\text { Data } \\
\text { size }\end{array}$ & Study \\
\hline Ethiopia & Addis Ababa & queue dis. & 8.80 & $2.7-3.5$ & $c 71 \mathrm{mb27hv2}$ & yes / no & 3 int. \\
Ethiopia & Addis Ababa & sat. flow & 0 & $2.7-3.5$ & $c 71 \mathrm{mb27hv2}$ & yes / no & 3 int. \\
China & $\begin{array}{l}\text { Chengdu } \\
\text { Gangsha }\end{array}$ & sat. flow & 10.6 & $3.0-3.2$ & $c 96 \mathrm{lb} 4$ & yes & 2 int. & $\begin{array}{l}\text { (Lu, 2008, Li et } \\
\text { al., 2009) } \\
\text { (Righolt and } \\
\text { Berkhout, } \\
\text { 2009) }\end{array}$ \\
\hline
\end{tabular}

$\mathrm{NF}=$ non-following, sat. flow = saturation flow, queue dis. = queue discharge flow, int.=intersection

that all studies by (Lu, 2008, Li et al., 2009, Righolt and Berkhout, 2009) have a saturation flow with a significant share of non-following vehicles. It illustrates that the queue discharge flow fluctuates heavily, still after removing a begin and end lag. The saturation flow in these studies is not likely to give proper indication of the maximum flow of a junction when operating under ideal conditions. The method presented in this study (as defined in Section 3.1.3) is therefore recommended for flows that strongly vary during green phase.

\subsubsection{PCU value minibuses}

Public buses - both large buses and minibuses - are the common mode of public transit in most African cities, from a high of more than 70 percent of all trips in Dakar and Kigali to little more than 10 percent in Bamako and Ouagadougou. Overall, about twice as many trips are taken by minibus than by large bus (Kumar and Barret, 2008). The passenger car equivalent of minibuses has been determined in different studies, however, only Asian studies could be found. The (straight through) PCU values of the Addis Ababa study benchmarked to other studies are shown in Table 4.9. All studies, except from (Saha et al., 2009), used linear regression to determine the PCU values.

Table 4.9: International comparison of PCU values for minibuses

\begin{tabular}{|c|c|c|c|c|c|c|c|}
\hline Country & City & $\begin{array}{l}\text { PCU value } \\
\text { mini bus } \\
\text { mean/ste }\end{array}$ & $\begin{array}{l}\text { Lane } \\
\text { width } \\
\text { [m] }\end{array}$ & $\begin{array}{l}\text { Amount of } \\
\text { mini busses } \\
{[\%]}\end{array}$ & $\begin{array}{l}\text { Signal } \\
\text { control }\end{array}$ & Data size & Study \\
\hline Ethiopia & Addis Ababa & $0.90 / 0.026$ & $2.7-3.5$ & 27 & yes / no & 3 int. & \\
\hline Bangladesh & Dhaka city & $1.82 / 0.58$ & $6.8-12.7^{(*)}$ & 13 & yes & 5 int. & $\begin{array}{l}\text { (Hadiuzzaman } \\
\text { et al., 2008, } \\
\text { Hadiuzzaman } \\
\text { and Rahman, } \\
\text { 2010) }\end{array}$ \\
\hline Bangladesh & Dhaka city & 1.42/unk. & $3.1-4.2$ & $0-25$ & yes & 10 int. & $\begin{array}{l}\text { (Saha et al., } \\
\text { 2009) }\end{array}$ \\
\hline Vietnam & Hochiminh & $2.07 / 0.2$ & 3.5 & $0.2-0.3$ & yes & 3 int. & $\begin{array}{l}\text { (Minh et al., } \\
\text { 2009) }\end{array}$ \\
\hline Indonesia & Bandung & 2.18/unk. & 3.4 & unk. & yes & 57 int. & $\begin{array}{l}\text { (Turner and } \\
\text { Harahap, 1993) }\end{array}$ \\
\hline Bangladesh & Dhaka city & $\begin{array}{l}0.90 / 0.16- \\
1.27 / 0.45\end{array}$ & unk. & unk. & yes & sim. & (Hossain, 2001) \\
\hline
\end{tabular}


It appears that the PCU value determined in Addis Ababa is significantly lower than the other PCU values. The standard error is relatively small. The sample that was used to calculate the PCU value is therefore likely to be a good representation of the whole population. The only value that seems similar to the Ethiopian minibus PCU value is from the study of (Hossain, 2001). However, different simulations with the same model result in a large variety of PCU values with a relatively large standard error. The large difference between the PCU value of this thesis and the Asian PCU values can be explained by the following:

- The minibus in Asia is probably larger. The only definition that could be found was by (Minh et al., 2009). This study considers a minibus with less than 25 passengers. The Ethiopian minibus is only allowed to carry up to 12 passengers (Gebeyehu and Takano, 2007).

- (Turner and Harahap, 1993) explain that the high PCU value could be the result of the behaviour in stopping at or near junctions to ply trade. This behaviour is not observed near the stop line in Addis Ababa.

As a result, no comparable studies could be found concerning the PCU value of an Ethiopian minibus.

\subsubsection{Interference flow at conflict groups}

This study introduced the interference efficiency as an indicator of the local performance of a conflict group at an intersection (details in Section 3.1.5). The Addis Ababa interference efficiency benchmarked with both other studies is shown in Table 4.10. Based on the data presented by (Righolt and Berkhout, 2009, Lu, 2008, Li et al., 2009), the efficiency of the interfering flows is calculated. The data in Addis Ababa was collected during heavy to oversaturated traffic condition (continuous queue discharge during green phase, see Appendix I for detailed explanation) to be sure to measure the demand limited by the supply. It can be seen that the interference efficiency is the highest in Addis Ababa, despite the largest number of directions. The significant differences can be explained by the traffic mode. Although both studies were performed during peak traffic, the situation probably did not consist of heavy to oversaturated traffic. Green phases most likely consisted of both queue discharge and free flow.

In the case of ( $\mathrm{Lu}, 2008$, Li et al., 2009), there is an unbalance between the number of lanes per direction. The interference efficiency is defined as the interfering flow of the conflict group, divided by the maximum saturation flow of the involved streams (Equation 3.2). In this case, the maximum saturation flow per stream is high as a result of the stream with three lanes. The interference flow is relatively low because of the influence of the stream with only two lanes. This results in a low efficiency. The theoretical influences on the interference efficiency can be found in Section 3.1.5.

Table 4.10: International comparison of interference efficiencies

\begin{tabular}{llllllll}
\hline Country & City & $\begin{array}{l}\text { Interference } \\
\text { efficiency }\end{array}$ & $\begin{array}{l}\text { Number of } \\
\text { conflicting } \\
\text { lanes }\end{array}$ & $\begin{array}{l}\text { Number of } \\
\text { lanes per } \\
\text { direction }\end{array}$ & $\begin{array}{l}\text { Signal } \\
\text { control }\end{array}$ & $\begin{array}{l}\text { Data } \\
\text { size }\end{array}$ & Study \\
\hline Ethiopia & Addis Ababa & $74 \%$ & 3 & $2,2,2$ & No & $2 \mathrm{hr}$ & \\
$\begin{array}{l}\text { China } \\
\text { China }\end{array}$ & Nanjing & $29 \%$ & 2 & 2,2 & Yes & $6 \mathrm{hr}$ & (Righolt and Berkhout, 2009) \\
& Chendu & $46 \%$ & 2 & 2,3 & Yes & $1.5 \mathrm{hr}$ & \begin{tabular}{l} 
(Lu, 2008, Li et al., 2009) \\
\hline
\end{tabular} \\
\hline
\end{tabular}




\subsection{Conclusions}

The study area consists of the Africa Avenue corridor, a high volume route in Addis Ababa. Along this corridor, three intersections were considered: Meskel, Denbel and Wellosefer. During 9 different days, randomly chosen in November and December 2010, 9 different lanes were observed during times of congestion for at least 30 minutes per lane, resulting in a total of 20 lane-hours. In total, 6573 vehicles were counted, from which $76 \%$ consisted of passenger cars, $21 \%$ consisted of minibuses and $2 \%$ consisted of heavy vehicles. The flow rate is measured in Passenger Car Unit (PCU) per hour. Both the saturation flow and the PCU values per vehicle type are determined by means of multiple linear regression. The saturation flow rate at the corridor equaled $1517 \mathrm{PCU} / \mathrm{h}$ and the corresponding PCU values for minibuses and heavy vehicles were respectively 0.90 and 1.03 . The low PCU value for minibuses illustrates that their aggressive driving results in low time headways and therefore low PCU values. The queue discharge flow was significantly lower than the saturation flow, namely 1356 $\mathrm{PCU} / \mathrm{h}$. This is caused by $9.1 \%$ of non-following vehicles. Local (per intersection) and directional (turning and straight through) performances differ to some extent from the average.

At Wellosefer, vehicles from a conflict group existing of three conflicting streams, each consisting of two lanes, were counted during three days for a total of two hours. The traffic mode was heavy to oversaturated. The total measured flow of the conflict group was $2275 \mathrm{PCU} / \mathrm{h}$, resulting in an interference efficiency of $74 \%$.

The mean saturation flow of developing countries (1230-1950 PCU/h) is lower than the mean flow of developed countries (1710-2080 PCU/h). Besides the lower mean, the range of saturation flows of developing countries is larger than the range of flows in developed countries. The low mean can be explained by a diverse composition of traffic, consisting of a large share of old and slow vehicles, motorized and non-motorized traffic using the same lanes and high level of pedestrian interference with the vehicle flow. The large range is a result of the different traffic conditions for the different studies. The traffic in Addis Ababa does not contain a significant share of non-motorized vehicles. However, it does contain a share of old and slow vehicles. These slow vehicles and slow responding drivers cause a $9.1 \%$ of non-following vehicles in the studied corridor. This might explain why the saturation flow in Addis Ababa fits somewhere in the middle of the range for developing countries.

The saturation flow in other studies appeared to consist for a significant share of non-following vehicles. This thesis argues that a queue discharging flow consisting only of vehicles in a car-following state will give a proper indication of the maximum flow of a junction when operating under ideal conditions. The method presented in this thesis (Section 3.1.3) is therefore recommended to calculate the saturation flow during heavily fluctuating queue discharge flows during green phase. The PCU value of minibuses appeared to be low benchmarked to other studies. However, only Asian studies could be found. Asian minibuses are probably larger than the Ethiopian ones. Finally, the interference efficiency was significantly larger in Addis Ababa than calculated based on two Chinese studies. This was highly likely caused by under-saturated traffic conditions in the Chinese studies. 


\section{Chapter 5}

\section{Modeling}

The objective of the model that has to be developed is to quantify the different factors that influence the flow at conflict groups in order to suggest improvements. As defined in Equation 3.3, the interference flow is the product of the average queue discharge and the productivity of the conflict group (productivity represents the losses due to e.g., transition of right-of-way). The productivity of a signal controlled conflict group can be calculated based on the signal settings (Equation 2.3). However, the productivity of an officer controlled conflict group is harder to determine. The interference flow is therefore modeled into two different parts: model part 1 describes the queue discharging flow and model part 2 the productivity factor of an officer controlled intersection. Wellosefer was chosen as the basis for model part 2 because it is fully controlled by an officer, it has a simple layout and it has severe congestion problems. Moreover, the available video dataset of this intersection is larger than the datasets of the other intersections. As explained in Chapter 3, the interference flow of a conflict group will be modeled in a macroscopic manner.

Table 5.1: Average saturation flow per lane, combined with traffic and lane specifications

\begin{tabular}{|c|c|c|c|c|c|c|c|c|c|}
\hline $\begin{array}{l}\text { Dataset number } \\
\text { /intersection }\end{array}$ & Lane & $\begin{array}{l}\text { Control } \\
\text { type }\end{array}$ & Direction & $\begin{array}{l}\text { Sample size } \\
\text { (phas/ int) }\end{array}$ & $\begin{array}{l}\text { Lane } \\
\text { width }\end{array}$ & $\%$ MB & $\% \mathrm{HV}$ & $\% N F$ & $\begin{array}{l}\text { Q.d. flow } \\
\text { PCU/h }\end{array}$ \\
\hline 1 Wellosefer & 8 right & human & straight & $119 / 779$ & 2.7 & 52.3 & 2.17 & 9.94 & 1317 \\
\hline 2 & 8 left & human & straight & $117 / 769$ & 2.7 & 8.94 & 2.61 & 8.41 & 1410 \\
\hline 3 & 6 left & human & turn & $91 / 207$ & 3.0 & 6.62 & 1.70 & 15.8 & 1359 \\
\hline 4 & 3 left & human & turn & $130 / 603$ & 3.0 & 7.09 & 3.77 & 11.1 & 1406 \\
\hline 5 Denbel & 2 right & human & straight & $18 / 212$ & 2.7 & 43.6 & 1.60 & 6.91 & 1371 \\
\hline 6 & 2 left & human & straight & $17 / 223$ & 2.7 & 21.0 & 0.858 & 20.5 & 1221 \\
\hline 7 & 2 right & signal & straight & $13 / 212$ & 2.7 & 49.6 & 2.30 & 8.00 & 1354 \\
\hline 8 & 2 left & signal & straight & $16 / 223$ & 2.7 & 21.4 & 1.49 & 10.3 & 1384 \\
\hline 9 Meskel & $11 \mathrm{mid}$ & signal & straight & $13 / 37$ & 3.5 & 16.9 & 9.56 & 8.46 & 1578 \\
\hline 10 & 11 left & signal & straight & $14 / 43$ & 3.5 & 8.30 & 6.57 & 11.5 & 1393 \\
\hline 11 & 8 left & signal & straight & $21 / 98$ & 3.5 & 12.2 & 2.62 & 7.00 & 1452 \\
\hline
\end{tabular}


Figure 5.1: The value of POS for different lanes

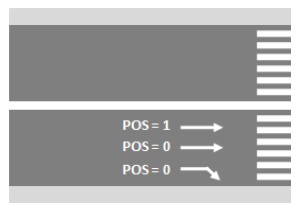

\subsection{Modeling the queue discharge flow}

The queue discharge flow is modeled based on average queue discharge flow rates per lane. To be able to quantify the effect of, e.g., an officer on flow rate, all the three considered intersections have to be included. The development of the first part of the model is subdivided into the presentation of the data, the development of a new model, the validation of the new model and the assessment of the new model.

\subsubsection{Data}

The average queue discharge flow per lane with the corresponding specifications is presented in Table 5.1. Denbel is partly controlled by signals. Signals are installed, but during specific times of the day, officers are present to overrule the signal when needed. To study the effect of the officer on the queue discharge flow, the dataset of Denbel was split into signal controlled and officer controlled flow.

\subsubsection{Model development}

With the aim to quantify the influences of the significant factors on the observed queue discharge flow, a new model is developed. The effect of the following variables on the queue discharge flow rate is studied:

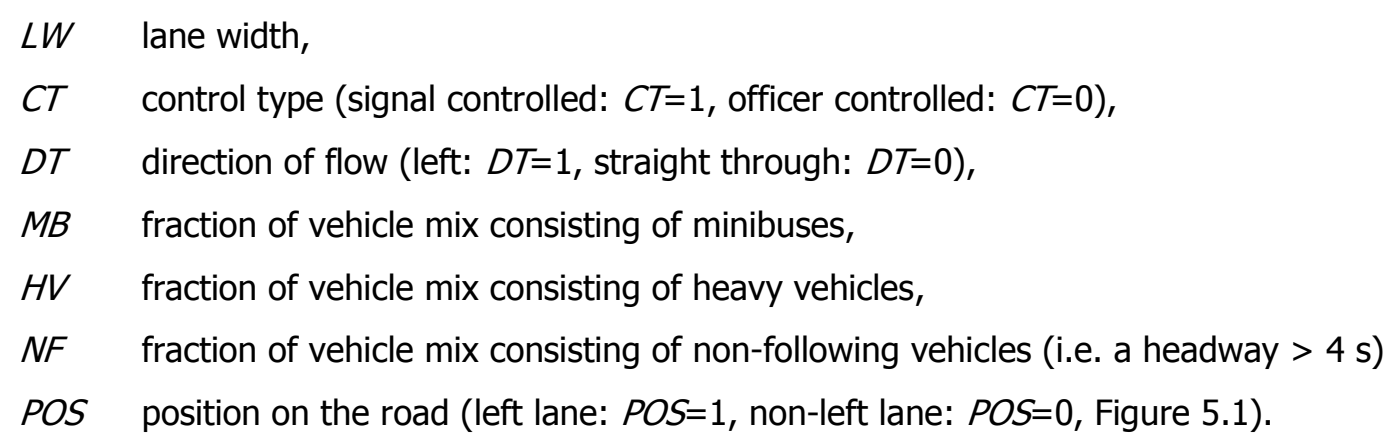

It has to be noticed that some variables are dummy variables ( $C T, D T$ and $P O S)$. These variables can have an effect on the queue discharge flow, but also on the effect of the other variables on the queue discharge flow (interaction effect) (Field, 2009). Both effects are studied.

Linear regression by means of the backwards method (for details see Section 3.2.2) was used to determine which factors have significant influence. It appeared that only the variables $M B, N F$ and $P O S$ have significant influence on the queue discharge flow rate. The regression coefficients of the model are shown in Table 5.3. Filling in the coefficients results in a model to predict the queue discharge flow rate per lane $\left(Q_{\text {ane }}\right)$ :

$$
Q_{\text {lane }}=1765-622.7 \times M B-1194 \times N F-161.6 \times P O S
$$

The model significance, the $\mathrm{R}^{2}$, the power, and the standard error are shown in Table 5.2. It can be seen that the variables MB, NF and POS explain the variation of $Q_{\text {lane }}$ for $93.2 \%$. 


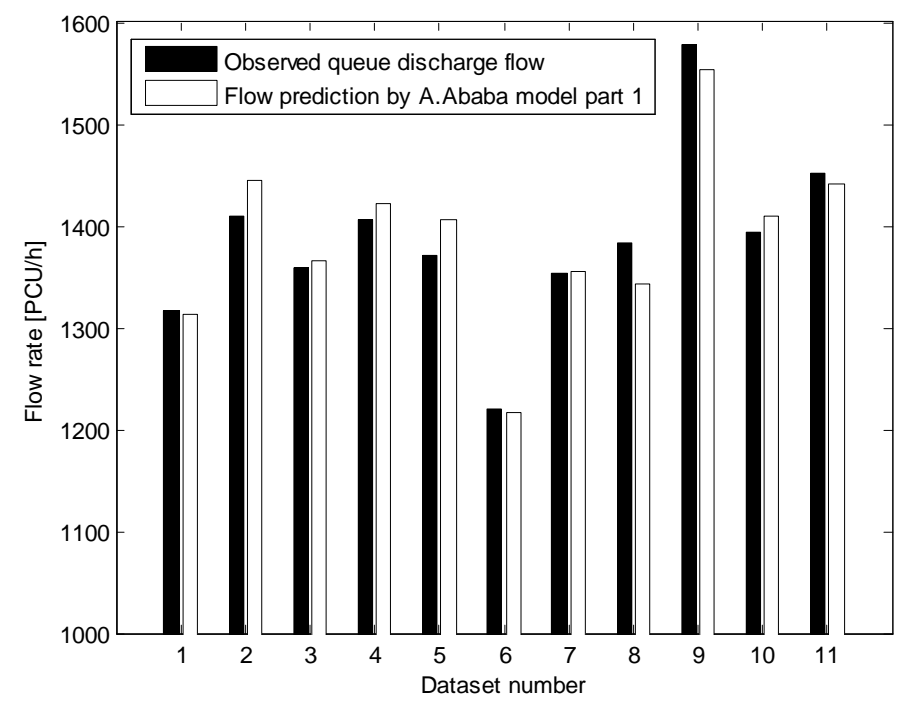

Figure 5.2: Predicted flow by the developed model versus the observed queue discharge flow. The data numbers correspond with the dataset numbers from Table 5.1.

Table 5.2: Statistical performance of the model

\begin{tabular}{llll}
\hline Model significance (a) & $\mathbf{R}^{2}$ & Power (1- $\boldsymbol{\beta})$ & Standard error \\
\hline 0.000 & 0.932 & 1.00 & 27.3 \\
\hline
\end{tabular}

Table 5.3: The regression coefficients

\begin{tabular}{llll}
\hline Coefficient & Value & Standard error & Significance \\
\hline Constant & 1765 & 40.8 & \\
$B_{\mathrm{MP}}$ & -622.7 & 86.1 & 0.000 \\
$B_{\mathrm{NF}}$ & -1194 & 240 & 0.002 \\
$B_{\mathrm{POS}}$ & -161.6 & 32.4 & 0.002 \\
\hline
\end{tabular}

The model complies with a level of significance of 0.01 . The power is larger than 0.80 , illustrating that the data size is large enough for this particular modeling process (details on statistics, see Appendix J). The observed queue discharge flow and the predicted values by means of the queue discharge model are shown in Figure 5.2. Detailed plots per variable can be found in Appendix E. It must be noticed that the model is developed within a specific range of the variables (Table 5.1) and under specific conditions (season, traffic condition, locations). Using the model outside these ranges and under different conditions might result in a less accurate prediction.

The analysis of all considered variable is listed below.

LW Lane width

- There is no significant difference in the observed queue discharge flow between lanes with different widths. 
- However, only a small range of lane widths is studied.

CT Control type (dummy variable)

- There is no significant difference in the observed queue discharge flow for lanes with different types of control. The presence of an officer does not slow down the traffic, nor does it increases the flow rate.

- There is no significant interaction effect.

DT Direction (dummy variable)

- There is no significant difference in the observed queue discharge flow for lanes with different directions.

- There is no significant interaction effect.

$M B \quad$ Fraction of vehicle mix consisting of minibuses

- There is a significant difference in the observed queue discharge flow between lanes with different percentage of minibuses.

- An increase in more minibuses will result in a decrease in queue discharge flow. Even though the aggressive driving causes a PCU value of less than one, it also results in a disturbance of the traffic flow, decreasing the total throughput.

- A large range of minibuses shares was studied.

HV Fraction of vehicle mix consisting of heavy vehicles

- There is no significant difference in queue discharge flow for lanes with different percentage of heavy vehicles.

- However, only a small range of heavy vehicle percentages is studied.

NF Fraction of vehicle mix consisting of non-following vehicles

- There is a significant difference in the observed queue discharge flow between lanes with different percentage of non-following vehicles.

- An increase of non-following vehicles will result in a decrease in queue discharge flow.

POS Position on the road (dummy variable)

- There is a significant difference in average queue discharge flow between left lanes (near the middle of the road) and non-left lanes.

- More aggressive drivers tent to drive left, resulting in a disturbed effect on the traffic flow. The left lane has therefore a lower observed queue discharge flow.

- There is no significant interaction effect.

- Only streams with two and three lanes are studied.

Furthermore, there is not a significance difference in the average queue discharge flow per intersection, nor for the effect of the other variables per intersection. Therefore, the developed queue discharge flow model is applicable to all three intersections.

\subsubsection{Cross validation}

Since the available data is very limited, the accuracy of the model could not be determined using a new dataset. Therefore, the leave-one-out cross-validation technique is applied. The method is 
described in Section 3.2.3. Applying this validation method to the developed model results in an estimated accuracy (or the average error) of $2.9 \%$. This is rather accurate. The typical crossvalidation problems of a large error and a large variation (Braga-Neto and Dougherty, 2004) did not occur. Details on the application of the validation method can be found in Appendix G.

\subsubsection{Model assessment}

Figure 5.3 shows the application of the developed linear model to predict the observed queue discharge flow in Addis Ababa. It presents both the predicted and the observed queue discharge flow rate. The maximum individual error is $2.96 \%$, and the average error is $1.25 \%$. As a benchmark, Appendix $\mathrm{F}$ shows the prediction by means of the existing HCM method, calibrated for Addis Ababa. The average error was $5.56 \%$, moreover, one individual maximum error was $16.2 \%$. The newly developed linear model (Equation 5.1) has a better fit to the observed data. Besides having a better fit to the observations, the newly developed model is able to quantify the significant effects of the share of minibuses, non-following vehicles and the position on the road. This is important, because a large share of minibuses is characterizes the traffic flow in Addis Ababa (and most Sub Saharan African cities). The calibrated Highway Capacity Manual method is not able to do the same.

\subsection{Modeling the interference productivity}

The interference productivity for signalized intersections can be calculated based on the signal settings (Equation 2.3). However, it is more complex to calculate the productivity of officer controlled intersections. No studies that described or modeled the internal lost time of officer controlled intersections could be found. Therefore, the interference productivity is modeled based on data collected at the officer controlled Wellosefer intersection. Further research is needed to test the applicability of the model on other officer controlled intersections of Addis Ababa.

The development of the second part of the model is subdivided into the presentation of the data, the development of a new model, the validation of the new model and the assessment of the new model.

\subsubsection{Data}

Two hours of vehicle counts at three conflicting streams during three days at Wellosefer are split up in 15 datasets of about the 8 minutes. After filtering on the traffic mode, 12 appeared to be usable. In these 12 datasets, the traffic mode was heavy to oversaturated traffic (Kashani and Saridis, 1983), consisting of persisting queues (see Appendix I for details on traffic modes). The total amount of observed vehicles was 3718 , from which $82 \%$ consisted of cars, $15 \%$ of minibuses and $3 \%$ of heavy vehicles.

As explained in Section 3.2.2, the interference flow is the product of the queue discharge flow rate of the involved streams and the productivity (defined in Equation 3.3). The average queue discharge per involved stream in the conflict group is $2860 \mathrm{PCU} / \mathrm{h}$ (calculation is stated in Appendix H). Dividing the measured interference flow per dataset by the average queue discharge flow results in a productivity factor per dataset. The productivity factor per dataset with corresponding flow specifications is shown 
Table 5.4: The interference flow, productivity factor and traffic specifications

\begin{tabular}{llllll}
\hline $\begin{array}{l}\text { Dataset } \\
\text { number }\end{array}$ & $\begin{array}{l}\text { Flow rate of conflict } \\
\text { group (F) }[\mathbf{P C U} / \mathbf{h}]\end{array}$ & $\begin{array}{l}\text { Productivity } \\
\text { factor }(\mathbf{P})\end{array}$ & Day & Change rate (/h) & Block ratio (\%) \\
\hline 1 & 2282 & 0.798 & 1 & 106 & 3.92 \\
2 & 2157 & 0.754 & 1 & 141 & 8.80 \\
3 & 2438 & 0.852 & 1 & 113 & 0.00 \\
4 & 2150 & 0.752 & 1 & 122 & 3.74 \\
5 & 2158 & 0.754 & 1 & 91.8 & 6.27 \\
6 & 2213 & 0.774 & 1 & 146 & 3.08 \\
7 & 2375 & 0.831 & 1 & 84.9 & 1.18 \\
8 & 2321 & 0.812 & 2 & 63.4 & 2.05 \\
9 & 2084 & 0.729 & 2 & 63.7 & 6.78 \\
10 & 2162 & 0.756 & 2 & 63.5 & 5.59 \\
11 & 2346 & 0.820 & 3 & 76.4 & 4.14 \\
12 & 2405 & 0.841 & 3 & 79.1 & 0.550 \\
\hline
\end{tabular}

in Table 5.4. The productivity factor represents the share of time that the intersection is productive. Downtime can be the result of changing the right of way or blocked lanes.

\subsubsection{Model development}

With the aim to quantify the influences of the significant factors on the productivity of an officer controlled conflict group, a new model is developed. The influence of the following variables on the productivity is studied:

$C R$ change rate, number of changes of right-of-way per hour,

$B R$ the blocking ratio, seconds of blocked stream during green time divided by the total time in seconds of dataset. E.g., an intersection consisting of 3 streams with each 2 lanes can have:

- one lane (half of the stream) blocked during green phase for 10 seconds in a dataset with a length of 500 seconds resulting in $B R=(10 / 2) / 500=0.01$, or

- two lanes (complete stream) blocked during green phase for 10 seconds in a dataset with a length of 500 seconds resulting in $B R=10 / 500=0.02$.

Using linear regression by means of the backwards method (for details see Section 3.2.2), a model for the productivity is developed. It appeared that the variable BR has a significant influence on the interference productivity. The coefficients of the model are shown in Table 5.6. Filling in the coefficients results in a model to predict the productivity $P$.

$$
P=0.840-1.311 \times B R
$$

The model significance, the coefficient of determination $\left(R^{2}\right)$, the power, and the standard error are shown in Table 5.5. It can be seen that the variable $B R$ explains the variation of $P$ for $72.1 \%$. The model complies with a level of significance of 0.01 . The power is larger than 0.80 , illustrating that the data size is large enough for this particular modeling process (details on statistics, see Appendix J). 


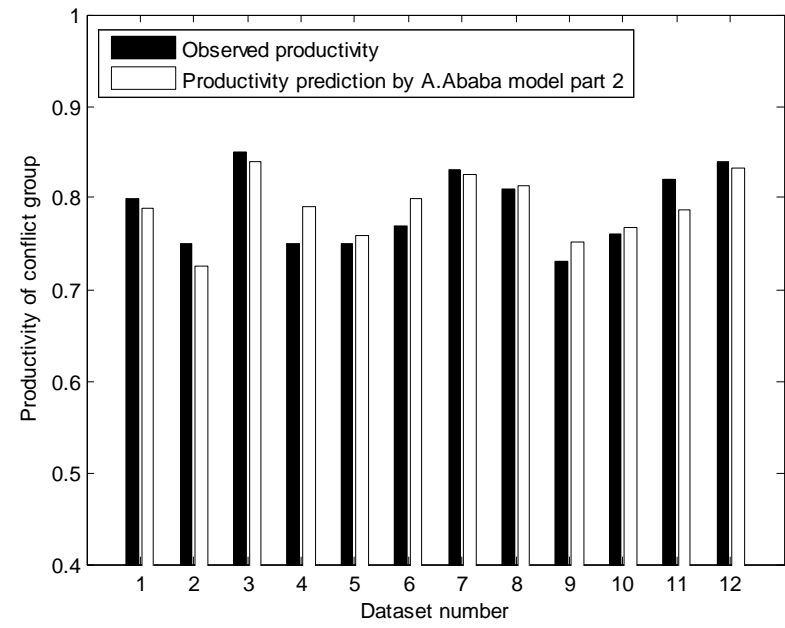

Figure 5.3: Predicted productivity by the developed model versus the observed productivity. The data numbers correspond with the data numbers from Table 5.4 .

Table 5.5: Statistical performance of the model

\begin{tabular}{llll}
\hline Model significance (a) & $\mathbf{R}^{2}$ & Power (1- $\boldsymbol{\beta})$ & Standard error \\
\hline 0.000 & 0.721 & 0.978 & 0.0229 \\
\hline
\end{tabular}

Table 5.6: The regression coefficients

\begin{tabular}{llll}
\hline Coefficient & Value & Standard error & Significance \\
\hline Constant & 0.840 & 0.012 & \\
$B_{B R}$ & -1.311 & 0.258 & 0.000 \\
\hline
\end{tabular}

The observed productivity and the predicted values by means of the productivity model are shown in Figure 5.3. Detailed plots per variable can be found in Appendix E. It must be noticed that the model is developed within a specific range of the variables (Table 5.4) and under specific conditions (season, traffic condition, location). Using the model outside these ranges and under different conditions might result in a less accurate prediction.

An increase of the blocking ratio $(B R)$ will increase the unproductive time of the intersection and therefore decreases the productivity factor. The change rate $(C R)$ appears to have no significant contribution to the variation of the queue discharge flow, even though there is a large range of change rate values studied (Table 5.4). The changes of flow direction happen so quickly that no significant productive time is lost. The inter-green-time due to changes of right-of-way is, as a result of highly efficient officer control, not significant. Furthermore, there is no significance difference in the productivity factor per considered day, nor for the effect of the $B R$ per day.

The developed model can explain $72.1 \%$ of the observed productivity. The other effects might have been too small to be quantified in this research with a strongly limited dataset. A study for a longer 
period of time is recommended to increase the $R^{2}$. However, since the model explains the majority of the variation in the productivity, it can be properly used to suggest flow improving solutions.

\subsubsection{Cross validation}

Since the available data is very limited, the accuracy of the model could not be determined using a new dataset. Therefore, the leave-one-out cross-validation technique is applied. The method is described in Section 3.2.3. Applying this validation method to the developed model, the estimated accuracy (or the average error) is $2.8 \%$. This is rather accurate. The average error is slightly lower than the first part of the model, described in Section 5.1.4. The typical cross-validation problems of a large error and a large variation (Braga-Neto and Dougherty, 2004) did not occur. Details on the application of the validation method can be found in Appendix G.

\subsubsection{Model assessment}

Figure 5.4 shows the application of the interference productivity model of the traffic flow at the Wellosefer intersection. It presents the predicted and the observed productivity. It can be seen that the individual errors of the prediction by the model are not large. The maximum individual error is $4.71 \%$ and the average error is $1.97 \%$. This is an acceptable error.

\subsection{Calculating the interference flow}

The objective of the model is to quantify the different factors that influence the interference flow of a conflict group at an intersection in order to suggest improvements. The model will be applied in the to simulate the traffic flow at Wellosefer, since this intersection has severe congestion problems and is currently only controlled by officers. This is described in the next chapter.

During heavy to over saturated traffic conditions, the interference flow is the product of the average queue discharging flow per stream and the productivity of the conflict group (Equation 3.3). Based on data of three intersections in the corridor of African Avenue, the queue discharge flow per lane was modeled (Equation 5.1). Based on data of the Wellosefer intersection, also part of the corridor, the productivity of an officer controlled conflict group at Wellosefer was modeled (Equation 5.2)

To substitute the queue discharge model and the productivity model into one model that predicts the interference flow at Wellosefer, the average queue discharge flow per stream has to be calculated. The number of lanes per stream is constant and equals 2 . Each stream has therefore one left lane and one right lane. The average queue discharge flow per stream at Wellosefer can be calculated as follows:

$$
Q=2 \times(1765-622.7 \times M B-1194 \times N F-161.6 \times 0.5)
$$

Substituting results in the overall formula for the interference flow at Wellosefer:

$$
F=2 \times(1765-622.7 \times M B-1194 \times N F-161.6 \times 0.5) \times(0.840-1.311 \times B R)
$$

The total model (Equation 5.4) will be used in the next chapter to simulate the effect of different situations on the interference flow at Wellosefer. 
For signalized intersections, the productivity can be directly calculated (Equation 2.3). The model for the interference flow for the signalized intersections Meskel and Denbel becomes:

$$
F=Q \times \frac{T_{\text {cycle }}-T_{\text {lost }}}{T_{\text {cycle }}}
$$

\subsection{Conclusions}

The objective of the model that is developed is to quantify the different factors that influence the flow of a conflict group. As a case study, this model will be applied to Wellosefer in order to suggest improvements. At an intersection, the overall flow rate of conflicting lanes is the product of the average queue discharging flow per stream and the productivity of the conflict group. The productivity represents losses for example due to changes of right-of-way. In case of signal control, the productivity can be obtained by simply dividing the effective green time by the cycle length. The effective green time is the cycle time minus the internal lost time (as defined by e.g., (Taale, 2008, Hegyi, 2008)). However, at Wellosefer, the flow is manually controlled. Therefore, the productivity cannot be directly calculated. To quantify the effects of different influences on the queue discharge flow and the productivity of a human controlled intersection, both parts are modeled separately.

The first model was developed by means of linear regression based on average queue discharge flow rates per lane at three different intersections in one corridor. The effect of the following variables on the queue discharge flow was studied:
$\angle W \quad$ lane width,
$C T$ control type (signal controlled: $C T=1$, officer controlled: $C T=0$ ),
$D T$ direction of flow (left: $D T=1$, straight through: $D T=0$ ),
$M B$ fraction of vehicle mix consisting of minibuses,
$N F \quad$ fraction of vehicle mix consisting of non-following vehicles,
$P O S$ position on the road (left lane: $P O S=1$, non-left lane: $P O S=0$ ),
$H V$ fraction of vehicle mix consisting of heavy vehicles.

Only $M B, N F$ and $P O S$ appeared to have significant influence, resulting in the following model for the queue discharge flow per lane $\left(Q_{\text {lane }}\right)$ :

$$
Q_{\text {lane }}=1765-622.7 \times M B-1194 \times N F-161.6 \times \text { POS }
$$

The model has an $\mathrm{R}^{2}$ of 0.932 and an accuracy of $2.9 \%$. Compared to the commonly used Highway Capacity Manual method (TRB, 2000), the newly developed model has a better fit to the observed data. Besides having a better fit to the observations, the newly developed model is able to quantify the significant effects of the share of African minibuses, non-following vehicles and the position on the road. This is important because a large share of minibuses is characteristic for Addis Ababa and most Sub Saharan African cities. The calibrated Highway Capacity Manual is not able to do the same.

The second model (to predict the productivity of an officer controlled conflict group) was developed by means of linear regression based on productivity observations per dataset of about 8 minutes at 
the officer controlled intersection Wellosefer. The effect of the following variables on the queue discharge flow was studied:

$C R$ change rate, number of changes of right-of-way per hour,

$B R$ the blocking ratio, seconds of blocked direction during green time divided by the total time in seconds of dataset.

The following model for the interference productivity $(P)$ was developed:

$$
P=0.840-1.311 \times B R
$$

The model has an $R^{2}$ is 0.721 and an accuracy of $2.8 \%$. Only $B R$ appeared to have significant influence. Apparently, the officer is able to change the right-of-way without resulting in a significant time loss.

Both models are developed within a specific range of the variables (Tables 5.1 and 5.4 ) and under specific conditions (season, traffic condition, locations). Using the models outside these ranges and under different conditions might result in a less accurate prediction.

Model part 1 and part 2 can be combined to calculate the interference flow $(F)$ during heavy to saturated traffic mode:

$$
F=Q \times P
$$

Where $P$ is the productivity factor from model part 2 and $Q$ is the average queue discharge flow rate per stream that is calculated as the sum of the queue discharge flow rates of the lanes (model part 1 ) of a conflict group, divided by the number of streams.

The total model will be used in the next chapter to simulate the effect of different situations on the interference flow at Wellosefer. 


\section{Chapter 6}

\section{Simulation and results}

In Chapter 5, a model is developed to describe the interference flow at Wellosefer. This model is applied to simulate the effects of vehicle composition, slow vehicles, blocked lanes and installing signals on the interference flow at Wellosefer. Based on these results, flow improvement measures are presented.

\subsection{The effect of vehicle composition}

In this study, the vehicles were classified according to three vehicle groups: passenger cars, minibuses and heavy vehicles. Concerning the vehicle mix, only the share of minibuses appeared to have significant influence on the interference flow (Section 5.1.2).

The model developed in Chapter 5 is used to simulate the effect of a varying share of minibuses on the interference flow at Wellosefer. Figure 6.1.a shows the effect of a varying share of minibuses from 0 to 50 percent. The other influences on the interference flow are kept constant and equal to the average observed value. Table 6.1 shows the average values per variable per stream (calculations can be found in Appendix $\mathrm{H}$ ).

At Wellosefer passenger transport forms the main share of the traffic. Observations show that heavy vehicle freight transport form less than two percent of the vehicle mix. The number of freight transporting vehicles will be slightly higher as a result of small scale freight transport with pick-up trucks that are part of the passenger car vehicle class, but still the majority of traffic consists of passenger transport. To study the effect of the share of minibuses on the total flow of passengers, the model has to be transformed. Assuming a capacity of 12 passengers per minibus and a capacity of 4 passengers for an average non-minibus results in the following model to calculate the

Table 6.1: The average values of the variables at Wellosefer

\begin{tabular}{ll}
\hline Variable & Average value per stream \\
\hline NF share of non-following traffic & $12.0 \%$ \\
MB share of minibuses & $14.8 \%$ \\
BR blocking ratio & $3.9 \%$ \\
\end{tabular}




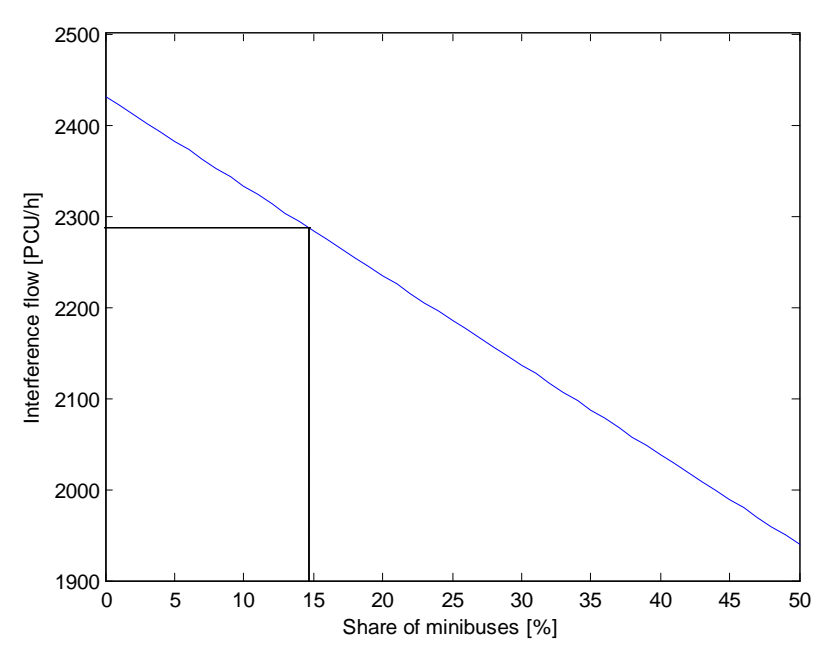

a)

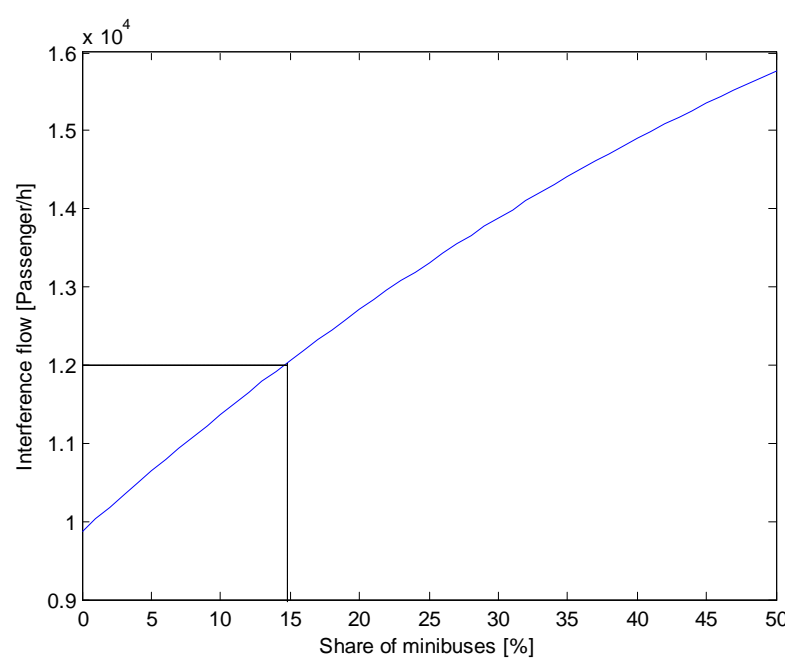

b)

Figure 6.1: The interference flow in PCU/h (a) and passenger/h (b) versus share of minibuses. The black line shows the observed current situation: a share of minibuses vehicles of $14.8 \%$

interference flow of passengers $\left(F_{\text {pass }}\right)$ :

$$
F_{\text {pass }}=\left(\frac{F}{\mathrm{PCU}_{\text {average }}}\right)(1-M B) \times 4+\left(\frac{F}{\mathrm{PCU}_{\text {average }}}\right) \times M B \times 12
$$

Where:

$\mathrm{PCU}_{\text {average }} \quad$ average $\mathrm{PCU}$ value of observed traffic.

The average PCU value is calculated according to:

$$
\mathrm{PCU}_{\text {average }}=\frac{n_{\text {car }}+n_{\text {minibus }} \times \mathrm{PCU}_{\text {minibus }}+n_{\text {heavy vehicle }} \times \mathrm{PCU}_{\text {heavy vehicle }}}{n_{\text {car }}+n_{\text {minibus }}+n_{\text {heavy vehicles }}}
$$

Where:

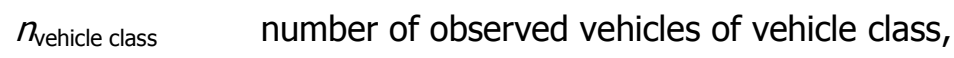

$\mathrm{PCU}_{\text {vehicle class }} \mathrm{PCU}$ value of vehicle class.

Using the PCU values per vehicle class based on both turning and straight through traffic $\left(\mathrm{PCU}_{\text {minibus }}=0.90, \mathrm{PCU}_{\text {heavy vehicle }}=1.03\right.$, Table 4.3$)$, and the number of observed vehicles during the observation of the interference flow (3039 cars, 572 minibuses, 104 heavy vehicles), the average PCU value is 0.99 .

Figure 6.1.b shows the effect of the share of minibuses on the interference flow, measured in passengers per hour. A comparison of the interference flow measured in PCU per hour and passengers per hour for specific shares of minibuses is shown in Table 6.2. It is clear that an increase

Table 6.2: The interference flow in PCU/h and passenger/hr versus share of minibuses

\begin{tabular}{lll}
\hline Share of minibuses [\%] & Interference flow [PCU/h] & Interference flow [Passenger/hr] \\
\hline 5.0 & 2384 & 10649 \\
10.0 & 2335 & 11377 \\
14.8 (observed current situation) & 2288 & 12036 \\
20.0 & 2236 & 12714 \\
25.0 & 2187 & 13323 \\
\hline
\end{tabular}


of the share of minibuses results in a decrease of vehicle flow rate, but in an increase of passenger flow rate. An increase to a share of $25.0 \%$ of minibuses would result in a decrease of the PCU flow rate of $4.4 \%$ compared to the current situation, but in an increase of passenger flow rate of $10.1 \%$. In the current situation, the interference flow consists of 1979 non-minibuses/hour. If the traffic mix would change to a situation in which $25.0 \%$ would consist of minibuses, the amount of non-minibuses would be 1665 per hour. This means that passengers of 314 non-minibuses per hour have to change to a minibus per hour to realize this increase to $25.0 \%$ of minibuses. Increasing the number of minibuses implies a shift of vehicle type for a large amount of passengers.

The share of minibuses can be increased by the following measures:

- Rerouting. However, this will decrease the share of minibuses elsewhere. Therefore, it is not a solution for the network as a whole. Moreover, it does not cause a shift from non-minibuses to minibuses.

- Promoting the minibus over passenger cars, e.g., by making public transport free. This is likely to cause a shift from car to minibus. However, it is also likely to cause a shift from walking to public transport. This results in an undesirable increase of traffic demand.

- Promoting the minibus for new passengers. In general, for every additional 1000 people in developing world cities, an increase of 350-400 public transport trips will be realized per day. (The World Bank, 2002). This measure is therefore expected to happen naturally when the city grows. Again, this does not cause a shift from non-minibus to minibus.

When economy is growing there is a risk of motorization as a result of an intense desire to own a passenger cars (Gakenheimer, 1999).

This section studied the effect of the share of minibuses on the interference flow at Wellosefer. The simulation was based on model part 1 . This part of the model is developed at the three intersections in the corridor. Similar effects as described in this section are expected to happen at the other locations in the corridor when the share of minibuses would change.

\subsection{The effect of slow vehicles}

In this study, the flow of vehicles in a discharging queue were classified into either non-following vehicles (i.e., slow vehicles with a time headway of more than 4 seconds) and following vehicles (i.e., vehicles with a time headway smaller than 4 seconds), as explained in Section 3.1.3. The share of nonfollowing vehicles appeared to have significant influence on the interference flow (Section 5.1.2).

The model developed in Chapter 5 is used to simulate the effect of varying the share of non-following vehicles on the interference flow at Wellosefer. Figure 6.2 shows the effect of a share of non-following vehicles from 0 to 20 percent on the interference flow, measured in PCU/h (a). Since passenger transport forms the main share of the transport at Wellosefer, the interference flow is also expressed in passenger/h (b). The other influences on the saturation flow are kept constant and equal to the average observed value. Table 6.1 shows the average values per variable per stream (calculations can be found in Appendix $\mathrm{H}$ ). A comparison of the interference flow measured in PCU per hour and passengers 


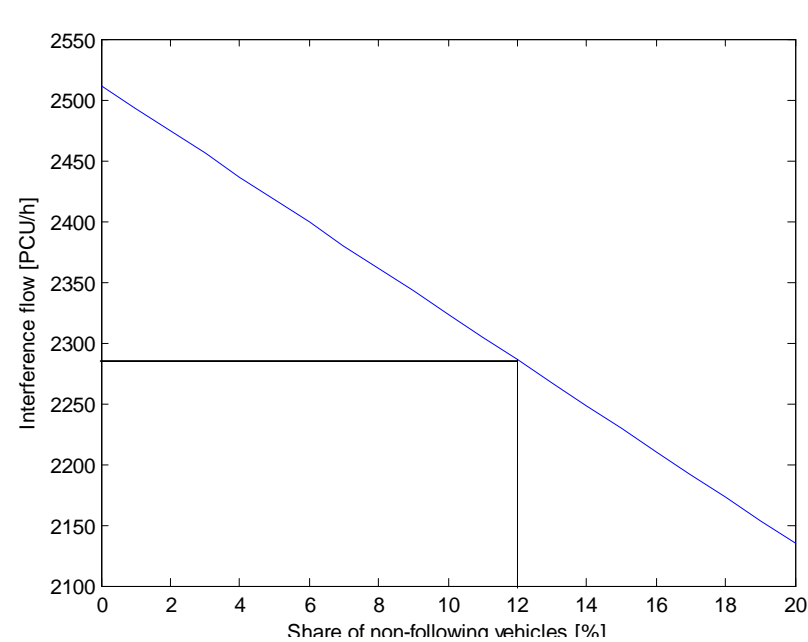

a)

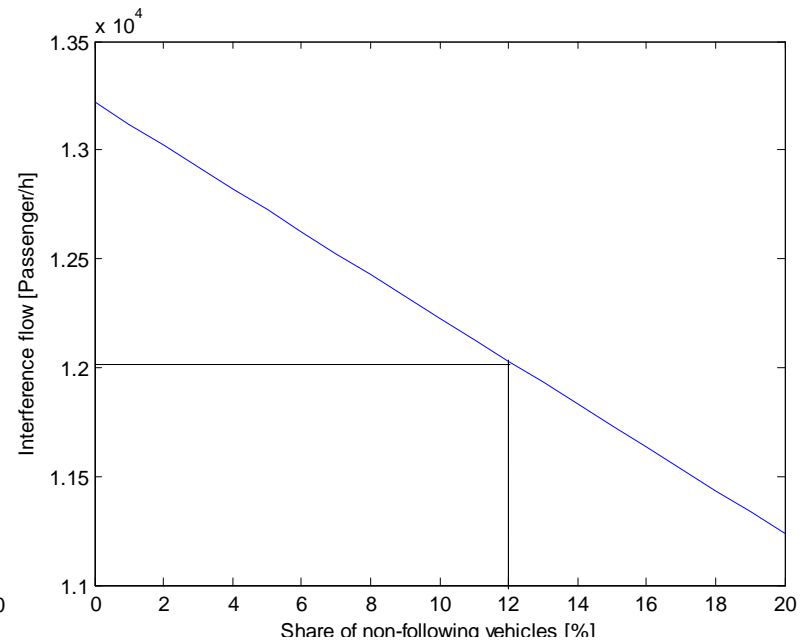

b)

Figure 6.2: The interference flow in PCU/h (a) and passenger/hr (b) versus share of non-following vehicles. The black line shows the observed current situation: a share of non-following vehicles of $12.0 \%$

per hour for specific shares of minibuses is shown in Table 6.3. It is clear that a decrease of the share of non-following vehicles results in an increase of both the vehicle flow rate and the passenger flow rate. A decrease to a share of $5 \%$ of non-following vehicles would result in an increase of the PCU flow rate and passenger flow rate of $5.8 \%$ compared to the current situation.

A detailed study showed that non-following behavior happens throughout the whole green period (beginning, middle, end) and with all considered vehicle types (cars, minibuses, heavy vehicles). Based on observations it appeared that the main reasons to cause non-following vehicles are low acceleration capacities of old vehicles and slow responding driving, two common phenomena in developing countries (Gakenheimer, 1999).

The share of non-following vehicles can be decreased by the following measures:

- Decrease the number of old vehicles with low acceleration capacities. Strict rules to remove old cars (often old implies affordable) are, especially in developing countries, immoral. The best solution is natural wastage.

- Improvement of drivers' response to changing situations. This will result less non-following vehicles. Improving the driver's education might support this measure.

Table 6.3: The interference flow in PCU/h and passenger/h versus share of non-following vehicles

\begin{tabular}{lll}
\hline Share of non-following vehicles [\%] & Interference flow [PCU/h] & Interference flow [Passengers/h] \\
\hline 0.0 & 2515 & 13230 \\
5.0 & 2420 & 12734 \\
10.0 & 2326 & 12238 \\
12.0 (observed current situation) & 2288 & 12036 \\
15.0 & 2232 & 11742 \\
\hline
\end{tabular}




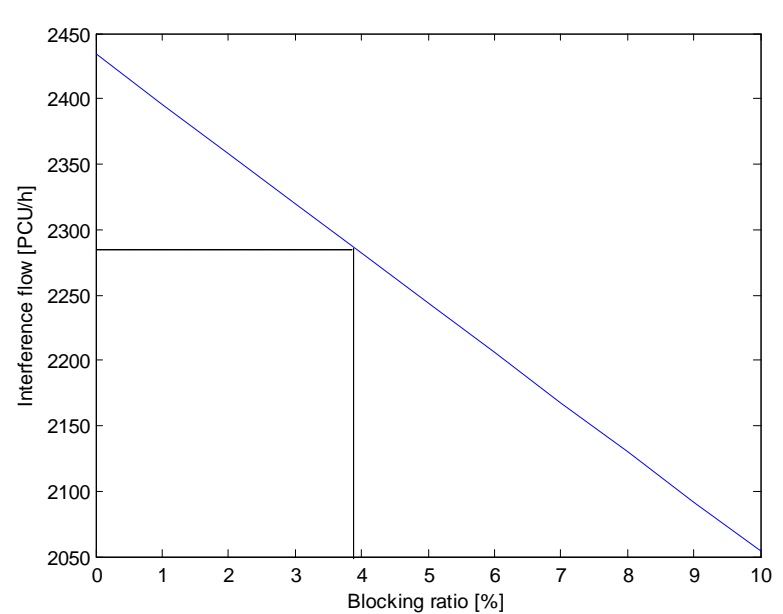

a)

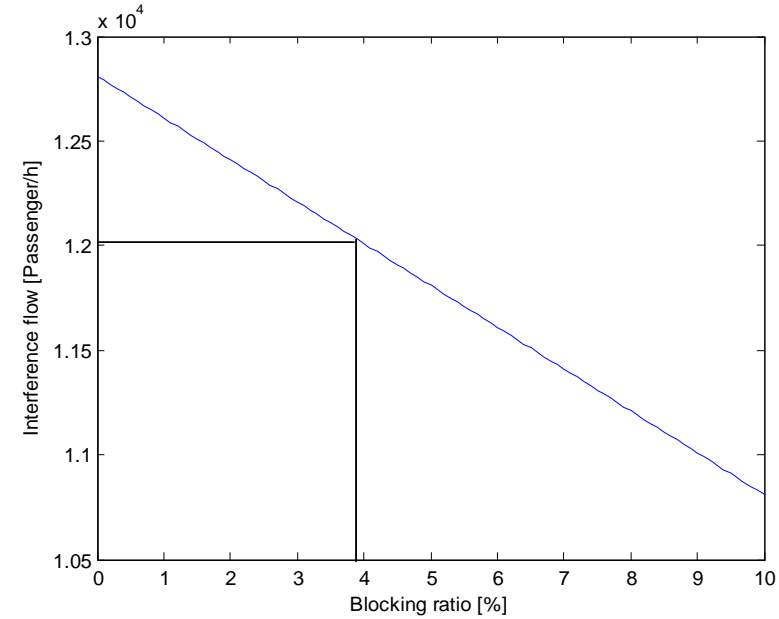

b)

Figure 6.3: The interference flow in PCU/h (a) and passenger/hr (b) versus the blocking ratio. The black line shows the observed current situation: a blocking ratio of $3.9 \%$.

This section studied the effect of the share of non-following vehicles on the interference flow at Wellosefer. The simulation was based on the queue discharge flow model. This model is developed at the three intersections in the corridor. Similar effects as described in this section are expected to happen at the other locations in the corridor when the share of minibuses would change.

\subsection{The effect of blocked lanes}

Blocked lanes appeared to have significant influence on the interference flow (Section 5.2.2). Blocking occurs when a stream with the right-of-way does not have an output of vehicles at the intersection. The amount of blocking is measured in the blocking ratio $(B R)$. The blocking ratio is the amount seconds of blocked direction during green time divided by the total time in seconds of a dataset. The conflict group at Wellosefer consists of 3 streams with each 2 lanes. An example of $B R$ values is given below:

- Case 1: one lane (half of the stream) is blocked during green phase for 10 seconds in a dataset with a length of 500 seconds: $B R=(10 / 2) / 500=0.01$

- Case 2: two lanes (complete stream) are blocked during green phase for 10 seconds in a dataset with a length of 500 seconds: $B R=10 / 500=0.02$

The model developed in Chapter 5 is used to simulate the effect of a varying blocking ratio on the

Table 6.4: The interference flow in PCU/h and passenger/hr versus the blocking ratio

\begin{tabular}{lll}
\hline Blocking ratio [\%] & Interference flow [PCU/h] & Interference flow [Passengers/hr] \\
\hline 0.0 & 2434 & 12804 \\
1.0 & 2396 & 12604 \\
2.0 & 2358 & 12404 \\
3.0 & 2320 & 12204 \\
3.9 (observed current situation) & 2288 & 12036 \\
5.0 & 2244 & 11804 \\
\end{tabular}




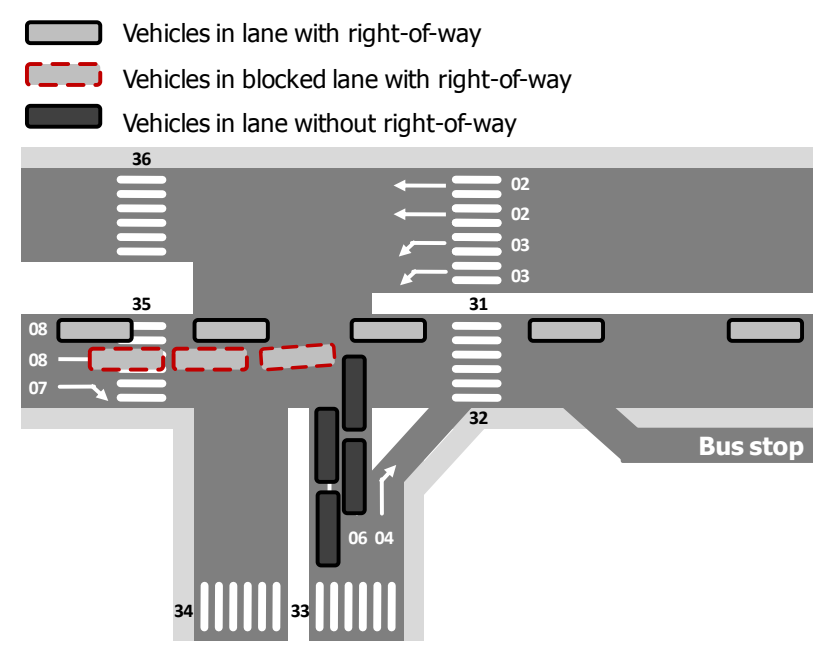

a)

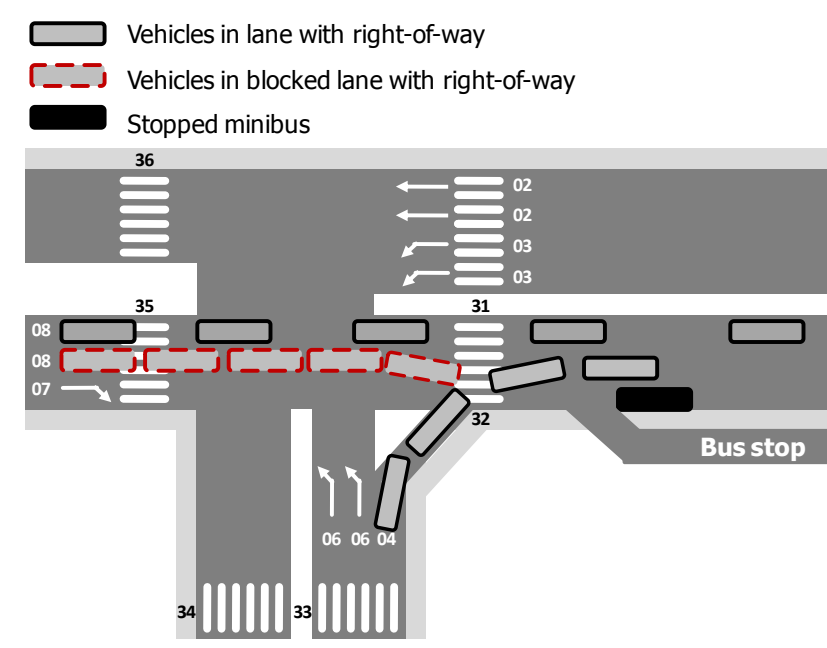

b)

Figure 6.4: Two main causes of blocked lanes: (a) pushing vehicles, (b) lane 04 and lane 08 conflict. Lane numbers according to Dutch standards.

interference flow at Wellosefer. Figure 6.3 shows the effect of the blocking ratio from 0 to 10 percent on the interference flow, measured in PCU/h (a). Since passenger transport forms the main share of the transport at Wellosefer, the interference flow is also expressed in passenger/hr (b). The other influences on the saturation flow are kept constant and equal the average observed value. Table 6.1 shows the average values per variable per stream (calculations can be found in Appendix $\mathrm{H}$ ). A comparison of the interference flow measured in PCU per hour and passengers per hour for specific shares of minibuses is shown in Table 6.4. It is clear that a decrease of the blocking ratio results in an increase of both the vehicle flow rate and the passenger flow rate. A decrease to a blocking ratio of $0.0 \%$ would result in an increase of the PCU flow rate and passenger flow rate of $6.4 \%$ compared to the current situation.

A detailed study showed that the blocked lanes are mainly caused by two phenomena:

- Pushing vehicles in a lane without the right-of-way, decreasing the lane width of flow with right-of-way (Figure 6.4.a). In some cases the total width is only allowing one lane to flow.

- Combination of the right-of-way of lanes 08 and 04 (Figure 6.4.b). There is a bus stop immediately after the intersection. However, some buses will stop on the road instead of on the separate bus stop. The flow of lane 08 will interfere with vehicles from lane 04 . This will cause a blockage.

No blockage was observed that was caused by overspill from a neighboring intersection.

The blocking ratio can be decreased by the following measures:

- Stop the vehicles at lane 04 when lanes 08 have the right of way

- Place visible stop lines and force vehicles to stop at the stop line

- Forbid to stop on the road near the intersection

Controlling stream 04 , forcing vehicles to stop at the stop line and preventing vehicles to stop on the road near the intersection can be the task of an extra officer near lane 04 . 
This section studied the effect of the blocking ratio on the interference flow at Wellosefer. The simulation was based on model part 2 , the productivity model. This part of the model is specifically developed at the offer controlled Wellosefer intersection. The results are therefore not applicable to the signal controlled intersections Denbel and Meskel.

\subsection{The effect of installing signals}

The interference flow is the product of the average interference productivity and the average queue discharge flow per stream (Equation 3.3). Linear regression, described in Section 5.1.4, showed that the control type does not have significant effect on the queue discharge flow. However, the control type does influence the productivity factor (compare Equation 2.3 for signal control with Equation 5.2 for officer control). Based on model part 2 (see Section 5.2.3) it can be concluded that the maximum productivity at Wellosefer with officer control is 0.84 . This section will study the effect of both traffic responsive signal control and fixed cycle signal control.

\subsubsection{Traffic responsive signal control}

Different types of traffic responsive signal control exist (Papageorgiou et al., 2003). One of the simplest strategies is the vehicle-interval method. Minimum-green durations are assigned to each direction. Depending on the demand of the traffic, the green duration is prolongated with a new critical time interval to enable more cars to cross the intersection. However, at Wellosefer, as a result of an unbalance in demand, no standard order of lanes during green phase is favorable. In some cases, lanes 03 have no queue, while lanes 08 are oversaturated. In this case, it is better to shift directly from 08 to 06 , instead of going from 08 to 03 to 06 .

The inductive loop detectors in the road can also be used to only turn the signal light to green only when traffic is queued. Assuming no loss of productivity due to 'lost green time', the only productivity loss is caused by transition of directions with the right of way. The internal lost time due to lane transition is defined in Equation 2.1. Using the internal lost time, the productivity $(P)$ is defined in Equation 2.3.

Using a comparable conflict group with three lanes at a Dutch intersection of the same size as a maximum performance benchmark, the internal lost time ( $T_{\text {internal_loss }}$ ) equals 12 seconds (Hegyi, 2008) (Table 6.5). The longer the cycle length, the higher the productivity. A maximum acceptable cycle

Table 6.5: Internal lost time at the Kruithuisweg-Provinciale weg in Delft, the Netherlands of a comparable conflict group (Hegyi, 2008)

\begin{tabular}{llllll}
\hline Right-of-way & $\mathbf{T}_{\text {amber }}$ [s] & $\mathbf{T}_{\text {amber_used }}$ [s] & $\mathbf{T}_{\text {clear }[\mathbf{s}]}$ & $\mathbf{T}_{\text {start_up_delay }}$ [s] & $\mathbf{T}_{\text {internal_lost }}$ [s] \\
\hline Transition 02-09 & 3 & 2 & 1 & 2 & 4 \\
Transition 09-12 & 3 & 2 & 2 & 2 & 5 \\
Transition 12-02 & 3 & 2 & 0 & 2 & 3 \\
Sum & 9 & 6 & 3 & 6 & 12 \\
\hline
\end{tabular}


length of 120 seconds is generally used. A longer period would result in weak law compliance due to impatience. Currently, the average cycle length is 115 seconds at Wellosefer. Using a cycle length of 120 seconds, the maximum productivity becomes 0.90 . However, this is only under the following conditions:

- Signals are only green when a queue of cars exists (there is no minimum green phase length)

- The conductors are located some 40 meters upstream to result in a direct red signal when the queue is dissolved

- The transition losses are comparable to Dutch traffic

These conditions are realistic for a Dutch intersection, however, almost certainly not for the Addis Ababa traffic situation. Both the startup delay and the clearance time would probably be higher due to lower drivers' response, wider vehicle mix and lower law obedience. Therefore, 0.90 is practically not possible. An increase of the start-up delay from 2 to 3 seconds and an increase of clearance time with 2 seconds extra per transition will result in a productivity of $1-(21 / 120)=0.83$. This is lower than the productivity of 0.84 at Wellosefer with officer control in case of no blocking. However, if an increase of productivity is realized to 0.90 , the interference flow at Wellosefer would increase with $12.5 \%$ compared to the current situation. If the productivity reaches the more realistic 0.83 , the interference flow would increase with $3.1 \%$. As discussed before, only removing the blocking ratio at an officer controlled intersection results in an increase of interference flow of $6.4 \%$. By installing signals, the blocking ratio will probably reduce to zero, however, the signals result in additional losses due to the signal settings. Therefore, the realistic improvement with signals of $3.1 \%$ is lower than the improvement with optimal officer control of $6.4 \%$.

\subsubsection{Fixed cycle signal control}

Fixed cycle signal control is the most basic type of signal control. It is currently installed at Denbel and Meskel. With fixed time signal control, the signal settings are split into phases to minimize the delay or to maximize the capacity. During these phases, each of the streams has a fixed period of right-of-way.

In the case of the Wellosefer intersection, fixed cycle signal control is likely to result in a decrease of the productivity. The internal lost time of fixed cycle control equals the internal lost time of responsive control plus the extra losses due to unused green phase. The traffic mode at the 08 lanes is heavy to oversaturated (traffic modes: Appendix I), however, the flows at the 03 and 06 lanes are not. Therefore, the green signal has to turn into red as soon as the queue of lanes 03 and 06 are discharged to prevent a decrease of productivity. Deeper observations showed that the queue lengths at lanes 03 and 06 are not constant; therefore, a fixed cycle time is likely to result in a loss of productivity. Assuming the idealistic internal lost time of 12 seconds, as presented in Section 6.4.1, an increase with an unused green phase of only 7 seconds per cycle would result in a productivity of 0.84 . This is the same productivity as at Wellosefer with officer control in case of no blocking. Assuming the more realistic internal loss time of 21 seconds (Section 6.4.1) combined with an unused phase of 7 seconds will result in a productivity of only 0.76 . This might explain why fixed signal control is overruled by officers 
during peak hours at Denbel. If fixed time signal control is cheaper than officer control, then fixed time control during off-peak hours combined with officer control during peak hours would be an option.

\subsection{Recommendations for flow improvement}

As described in Chapter 5, the interference flow at Wellosefer is significantly influenced by the share of minibuses and non-following vehicles, the position of the lane and the amount of time a stream is blocked.

These variables can be influenced by the following actions:

- Promoting the minibus over passenger cars. This will result in a larger share of minibuses and therefore in an increase of interference flow measured in passengers per hour. However, it will decrease the interference flow measured in PCU/h. An increase of the current $14.8 \%$ to $25.0 \%$ of minibuses will result a $10.1 \%$ increase in passenger flow but a $4.4 \%$ decrease of PCU flow.

- Proper education is likely to increase drivers' response to changing situations. On the long term, this might reduce the number of non-following vehicles. Reducing the current share of $12.0 \%$ non-following vehicles to $5.0 \%$ will result in a $5.8 \%$ increase of both passenger and PCU flow at the conflict group of Wellosefer. Changing the driving education is a comprehensive project and the effects on the Addis Ababa traffic are uncertain.

- The blocking ratio can be reduced by the following set of actions (Figure 6.5):

- Stop the vehicles at lane 04 when lanes 08 have the right of way to prevent interference.

- Place visible stop lines and force vehicles to stop at the stop line to prevent lane width reduction due to pushing. The dashed lines in Figure 6.5 can be used both as stop lines and to mark the streams. Figure 6.6 shows one control cycle with stop positions.

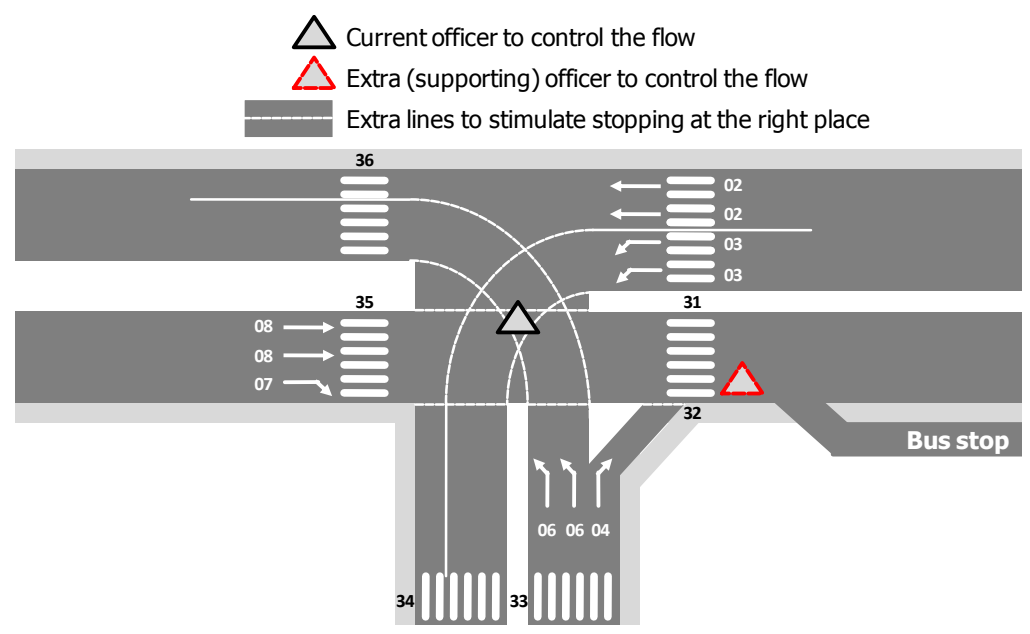

Figure 6.5: Graphical representation of recommended improvements. Lane numbers according to Dutch standards 


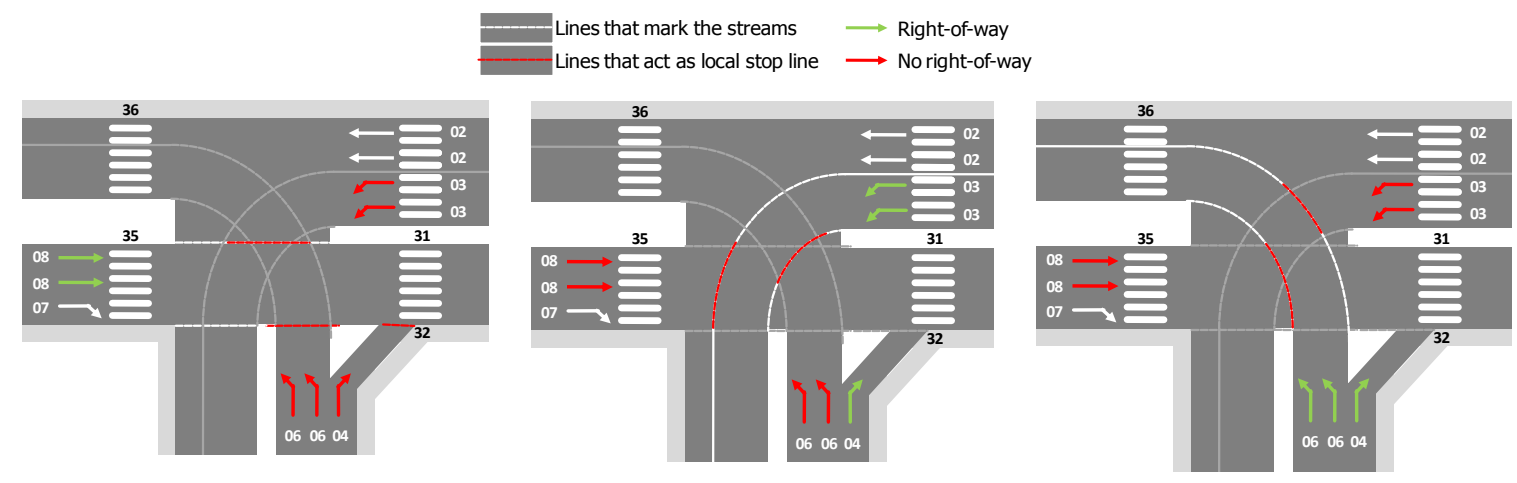

Figure 6.6: Graphical representation of stop lines during one green cycle. When not having the right-of-way, vehicles can drive up to dashed line of the lane with the right-of-way (illustrated in red). Lane numbers according to Dutch standards

- Forbid to stop on the road near the intersection to prevent lane width reduction as a result of lane-blocking vehicles.

Controlling stream 04, forcing vehicles to stop at the stop line and enforcing the rule that forbids vehicles to stop on the road near the intersection can be the task of an extra supporting officer near lane 04. All together, these low-cost measures are expected to significantly reduce the blocking ratio. Reducing the current blocking ratio of $3.9 \%$ to zero will result in a $6.4 \%$ increase in both passenger and PCU flow at the conflict group of Wellosefer.

- Section 5.1 showed that the control type (signals or officer) do not influence the queue discharge flow. However, installing signals will influence the productivity (compare Equation 5.5 for officer control with 2.3 for signal control). Based on a Dutch example, adaptive control is able to result in a productivity of 0.90 . This is higher than the productivity with officer control in case of no blocked lanes of 0.84 . Installing such a system is expensive and complex, especially to tune the settings in such a way that a high productivity of 0.90 is reached. This confirms the study by (Marsh, 1927). He argues that thorough research by traffic experts is needed before and during installation to secure a high efficiency. As a result of the slow response of some drivers to changing situations and the wide vehicle mix, it is not sure whether a high productivity will be reached. If the needed clearance time or response time is slightly larger than the ideal situation, then signal control will not outperform officer control. Fixed cycle signals are less expensive and less complex than adaptive control; however, also less sure to result in a higher productivity than officer control.

Reducing the blocking ratio by means of the presented measures is a low-cost and effective solution with a high certainty. Installing signals will also result in a reduction of blocked lanes, however, signals itself will introduce extra productivity loss compared to officer control. Figure 6.5 shows an overview of the recommended improvements. Observations at Denbel and Meskel show that most drivers comply with stopping at the stop line. Controlling one intersection with two officers is also proven to work: Denbel is currently controlled from two points of view during peak hours. The efficiency is assured because the extra officer at Wellosefer has only a supporting task compared to the first officer. 
However, if future research shows that traffic responsive signal control can be tuned in Addis Ababa to result in a productivity higher than officer control (at Wellosefer higher than 0.84 ), then installing traffic responsive signals have to be reconsidered. Also, if in further research appears that coordinated traffic response control strategies result in a significant decrease of waiting time in the network, installing signals have to be reconsidered. However, coordinated control is beyond the scope of this study. Fixed time control during off-peak hours -only when traffic cannot regulate itself- combined with officer control during peak hours would be an option if fixed time signal control is cheaper than officer control.

\subsection{Conclusions}

The effects of vehicle composition, slow vehicles, blocked lanes and signals on the interference flow at the officer controlled intersection Wellosefer were studied. Concerning vehicle composition, only the share of minibuses appeared to have significant influence. Increasing the share of minibuses would result in a decrease of interference flow measured in PCU/h. However, it results in an increase of interference flow measured in passenger/h. Reducing the share of slow vehicles (i.e., non-following vehicles) would result in an increase of interference flow, both for passengers as for PCUs. Reducing the amount of blocked lanes would also result in an increase of interference flow, both for passengers as for PCUs. Installing signals has the potential to improve the interference flow of a conflict group. A comparable Dutch intersection reaches a productivity of 0.90 . However, as a result of the Addis Ababa traffic characteristics, it is not likely whether the signal settings that determine the length of the transition periods can be tuned at Wellosefer in such a way that signal control results in an improvement compared to officer control. According to model part 2 (the productivity model), the maximum possible productivity with officer control is 0.84 . Responsive control is more likely to result in an flow improvement compared to current situation than fixed signal control; on the other hand, responsive control is also more complex and more expensive.

A simple, low-cost and effective solution with a high certainty is to reduce the amount of blocked lanes by drawing stop lines, preventing interference between lanes 08 and lane 04 and preventing vehicles to stop on the road after the intersection. To enable this, an extra (supporting) officer located near lane 04 is needed (Figure 6.5). If all blockages will be solved, the interference flow is expected to increase with $6.4 \%$.

The current urbanization rate in Ethiopia is $4.3 \%$ (CIA, 2010). The urban growth is directly related to the increase of number of trips by public transport (The World Bank, 2002). To cope with a large expected growth in traffic demand, maximizing the use of existing infrastructure will not be enough soon. As a result of the basic state of the economy, Western solutions such as home-working and flexible working hours to prevent congestion are not likely to be successful. A combination of maximizing the use of infrastructure with broader solutions - such as extra infrastructure, coordinated traffic control and new mobility concepts - is in general in Sub Saharan African countries difficult to realize (Gakenheimer, 1999) but essential. 


\section{Chapter 7}

\section{Conclusions and further research}

As stated in the introduction, the goal of this research is the development of a simulation model that describes the traffic flows at the intersections of Addis Ababa. The aim of the model is to perform ex ante assessment of different flow improvement strategies. The research objectives of this thesis are the following:

Determine the different factors that significantly influence the traffic flow rate at the intersections of Addis Ababa

Build a model of the traffic flow rate at the intersections of Addis Ababa

Assess different strategies to improve the traffic flow rate at one specific intersection in Addis Ababa

The research objectives are translated into four research questions. Based on the results of the study, as described in Chapter 2 to 6 , the answers to the four research questions are discussed in this chapter.

1. What are the saturation flow rates and the queue discharge flow rates of different lanes at different intersections during congestion in Addis Ababa?

The average saturation flow rate at the studied lanes at intersections in Addis Ababa equaled 1517 Passenger Car Units per hour (PCU/h) and the corresponding PCU values for minibuses and heavy vehicles were respectively 0.90 and 1.03 . The PCU value of a passenger car is always normalized to 1 . The low PCU value for minibuses illustrates that their aggressive driving results in low time headways and therefore low PCU values. The saturation flow at intersections is an indication of the maximum flow of a junction during green phase when operating under ideal conditions (Turner and Harahap, 1993). The saturation flow is a well described performance indicator for intersections worldwide. However, when one wants to improve the actual flow at an intersection, the flow under actual conditions is needed, not the flow under ideal conditions. Therefore, this study also considers the actual occurring queue discharge flow. The queue discharge flow rate was significantly lower than the saturation flow 
rate, namely $1356 \mathrm{PCU} / \mathrm{h}$. This is caused by $9.1 \%$ of non-following vehicles (i.e., vehicles with a headway time of more than 4 seconds). Local (per intersection) and directional (turning and straight through) performance differed to some extent from the average.

The study area consisted of the Africa Avenue corridor, a high volume route in Addis Ababa. Along this corridor, three intersections were considered: Meskel, Denbel and Wellosefer. During 9 different days, randomly chosen in November and December 2010, 9 different lanes were studied during times of congestion for at least 30 minutes per lane, resulting in a total of 20 lane-hours. The observed vehicles were grouped in three vehicle types: passenger cars, minibuses and heavy vehicles. In total, 6573 vehicles were counted, from which $76 \%$ were passenger cars, $21 \%$ were minibuses and $2 \%$ were heavy vehicles. Both the saturation flow and the PCU values per vehicle type were determined by means of multiple linear regression.

At Wellosefer, vehicles from a conflict group existing of three conflicting streams, each consisting of two lanes, were counted during three days for a total of two hours. The traffic mode was heavy to oversaturated. The total flow of vehicles at all lanes in the conflict group was 2275 PCU/h.

\section{What are the differences between the saturation flow rate at intersections in Addis Ababa compared to developing and developed cities?}

Based on different studies around the world, it can be concluded that the mean saturation flow of developing countries (1230-1950 PCU/h) is lower than the mean flow of developed countries (1710-2080 $\mathrm{PCU} / \mathrm{h}$ ). Besides the lower mean, the range of saturation flows of developing countries is larger than the range of flows in developed countries. The low mean can be explained by a diverse composition of traffic, consisting of a large share of old and slow vehicles, motorized and non-motorized traffic using the same lanes and high level of pedestrian interference with the vehicle flow. The large range is a result of the different traffic conditions for the different studies. However, no traffic flow studies about Sub Sahara African cities could be found. The traffic in Addis Ababa does not contain a significant share of nonmotorized vehicles. On the other hand, it does contain a share of old and slow vehicles. These slow vehicles and slow responding drivers cause a $9.1 \%$ of non-following vehicles (Section 4.3). This might explain why the saturation flow in Addis Ababa fits somewhere in the middle of the range for developing countries.

The saturation flow in some other studies in developing cities appeared to consist for a significant share of slow (non-following, i.e., headway larger than 4 seconds) vehicles. This thesis argues that a queue discharging flow consisting only of vehicles in a car-following state (i.e., headway smaller than 4 seconds) will give a proper indication of the maximum flow of a junction when operating under ideal conditions. The method presented in this thesis is therefore recommended to calculate the saturation flow in case of heavily fluctuating queue discharge flows during green phase.

The PCU value of minibuses appeared to be low compared to other developing countries. However, only Asian studies could be found. Asian minibuses are most likely larger than the Ethiopian ones. 


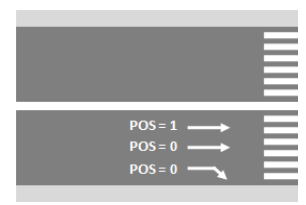

Figure 7.1: The value of POS for different lanes

3. What are the significant factors that influence the flow rate at the intersections of Addis Ababa and what are the quantitative contributions of these factors?

At an intersection, the overall flow rate of conflicting lanes is the product of the average queue discharging flow per stream and the productivity of the conflict group. The productivity represents losses for example due to changes of right-of-way. In case of signal control, the productivity can be obtained by simply dividing the effective green time by the cycle length. The effective green time is the cycle time minus the internal lost time (as defined by e.g., (Taale, 2008, Hegyi, 2008)). However, at Wellosefer, the flow is manually controlled by officers. Therefore, the productivity cannot be easily calculated. To quantify the effects of different factors on the queue discharge flow and the productivity of a human controlled intersection, both parts are modeled separately. Part 1 will be the queue discharge flow model, part 2 will be the productivity model.

The queue discharge flow model was developed by means of linear regression based on average queue discharge flow rates per lane at three different intersections in one corridor. The effect of the following variables on the queue discharge flow was studied:

$\angle W \quad$ lane width,

$C T$ control type (signal controlled: $C T=1$, officer controlled: $C T=0$ ),

$D T$ direction of flow (left: $D T=1$, straight through: $D T=0$ ),

$M B$ fraction of vehicle mix consisting of minibuses,

$N F$ fraction of vehicle mix consisting of non-following vehicles,

$P O S$ position on the road (left lane: $P O S=1$, non-left lane: $P O S=0$, Figure 7.1),

$H V \quad$ fraction of vehicle mix consisting of heavy vehicles.

Only $M B, N F$ and $P O S$ appeared to have significant influence, resulting in the following model for the queue discharge flow per lane $\left(Q_{\text {lane }}\right)$ :

$$
Q_{\text {lane }}=1765-622.7 \times M B-1194 \times N F-161.6 \times \text { POS }
$$

The model has a coefficient of determination $\left(R^{2}\right)$ of 0.932 , a level of significance of 0.01 and an accuracy of $2.9 \%$. The flow can also be predicted by a the commonly used Highway Capacity Manual method (TRB, 2000), calibrated on the Addis Ababa traffic conditions. The linear model (Equation 7.1) has a better fit to the observed data. Besides having a better fit to the observations, the newly developed model is able to quantify the significant effects of the share of minibuses, non-following vehicles and the position on the road. This is important, because a large share of minibuses is characterizes the traffic flow in Addis Ababa (and most Sub Saharan African cities). The calibrated Highway Capacity Manual method is not able to do the same.

The productivity model was developed based on observations the officer controlled intersection Wellosefer. Per dataset of about 8 minutes, the productivity was determined. Linear regression was 
used to determine the quantitative influence of different factors. The effect of the following factors on the productivity was studied:

$C R$ change rate, number of changes of right-of-way per hour,

$B R$ the blocking ratio, seconds of blocked direction during green time divided by the total time in seconds of dataset.

The following model for the interference productivity $(P)$ at Wellosefer was developed:

$$
P=0.840-1.311 \times B R
$$

The model has a coefficient of determination $\left(R^{2}\right)$ of 0.721 , a level of significance of 0.01 and an accuracy of $2.8 \%$. Only $B R$ appeared to have significant influence. As a result of efficient flow control by the officer, the change rate did not have significant influence

Both models are developed within a specific range of the variables and under specific conditions (season, traffic condition, locations). Using the models outside these ranges and under different conditions might result in a less accurate prediction.

Model part 1 (the queue discharge model) and part 2 (the productivity model) can be combined to calculate the interference flow $(F)$ for heavy to saturated traffic modes:

$$
F=Q \times P
$$

Where $Q$ is the average queue discharge flow rate per stream that is calculated as the sum of the queue discharge flow rates of the lanes (calculated by means of model part 1) of a conflict group, divided by the number of streams. $P$ is the productivity factor. For signalized intersections (such as Meskel and Denbel), $P$ can be calculated based on the signal settings. This results in the following model for the interference flow:

$$
F=Q \times \frac{T_{\text {cycle }}-T_{\text {lost }}}{T_{\text {cycle }}}
$$

Where:

$T_{\text {cycle }}$ the length of a control cycle,

$T_{\text {lost }}$ the internal lost time due to transitions and unused green and amber phase.

For the officer controlled intersections Wellosefer, the productivity can be determined by using the productivity model (Equation 7.2). This results in the following model for the interference flow:

$$
F=Q \times(0.840-1.311 \times B R)
$$

\section{Case study: how can the traffic flow at one specific intersection in Addis Ababa be improved?}

In order to combine the queue discharge model and the productivity model to predict the interference flow at Wellosefer, the average queue discharge flow per stream has to be calculated. Wellosefer has one conflict group consisting of 3 streams. The number of lanes per stream is constant and equals 2 . Each stream has therefore one left lane and one right lane. The average queue discharge flow per stream at Wellosefer can be calculated as follows:

$$
Q=2 \times(1765-622.7 \times M B-1194 \times N F-161.6 \times 0.5)
$$


Substituting Equation 7.5 and 7.2 in 7.3 results in the overall formula for the interference flow at Wellosefer:

$$
F=2 \times(1765-622.7 \times M B-1194 \times N F-161.6 \times 0.5) \times(0.840-1.311 \times B R)
$$

The effects of vehicle composition, slow vehicles, blocked lanes and signals on the interference flow at Wellosefer were studied. Concerning vehicle composition, only the share of minibuses appeared to have significant influence. Increasing the share of minibuses resulted in a decrease of interference flow measured in $\mathrm{PCU} / \mathrm{h}$, however, it resulted in an increase of interference flow measured in passenger/hr. Reducing the share of slow vehicles (i.e., non-following vehicles) would result in an increase of interference flow, both for passengers as for PCUs. Reducing the amount of blocked lanes would also result in an increase of interference flow, both for passengers as for PCUs. Installing signals has the potential to improve the interference flow. A comparable Dutch intersection reaches a productivity of 0.90 . However, it is not sure whether the signal settings that determine the length of the transition periods can be tuned at Wellosefer in such a way that signal control results in an improvement compared to officer control. According to model part 2, the maximum possible productivity with officer control is 0.84 . Responsive control is more likely to result in a flow improvement compared to current situation than fixed signal control; on the other hand, responsive control is also more complex and more expensive.

A simple, low-cost and effective solution with a high certainty is to reduce the amount of blocked lanes by (1) preventing pushing vehicles (Figure 7.2.a), by (2) avoiding interference between lanes 08 and lane 04 and by (3) preventing vehicles to stop on the road after the intersection (Figure 7.2.b). To enable this, lines have to be put on the intersection. Stopping stream 04 when stream 08 has the right-of-way, forcing vehicles to stop at the stop line and preventing vehicles to stop on the road near the intersection can be the task of an extra officer near lane 04 (Figure 7.3). If all blockages will be solved, the interference flow is expected to increase with $6.4 \%$. The blockages will also be solved when signals would be installed. However, signals introduce extra productivity losses due to signal settings, resulting in a lower increase than $6.4 \%$. Observations at Denbel and Meskel show that most drivers comply with stopping at a stop line. Controlling one intersection with two officers is also proven to work: Denbel is currently controlled from two points of view during peak hours.

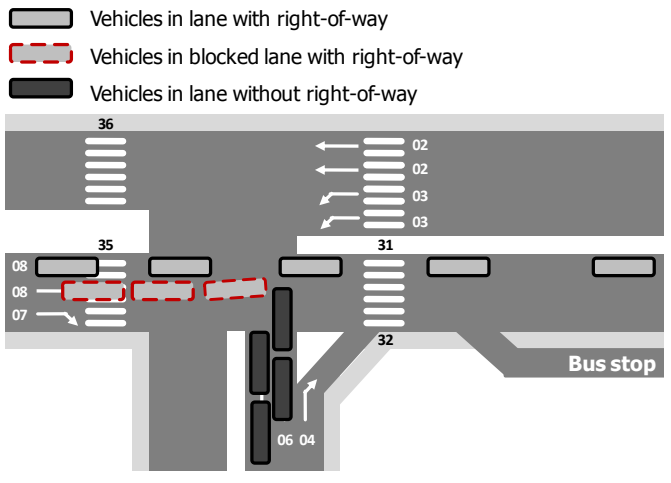

a)

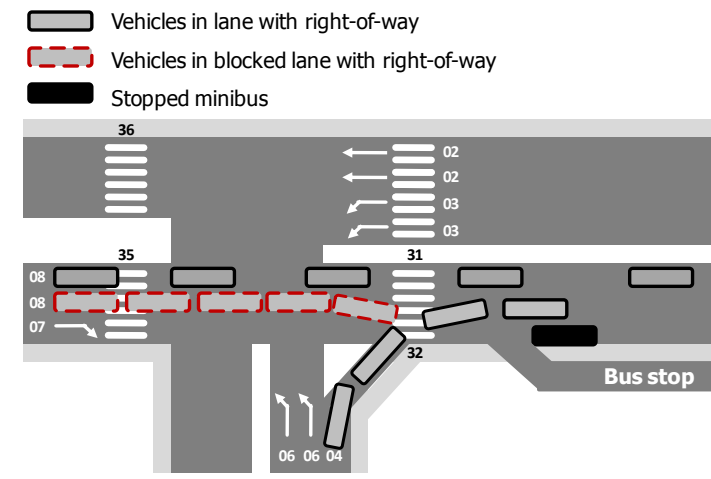

b)

Figure 7.2: Two main causes of blocked lanes: (a) pushing vehicles, (b) lane 04 and lane 08 conflict. Lane numbers according to Dutch standards. 


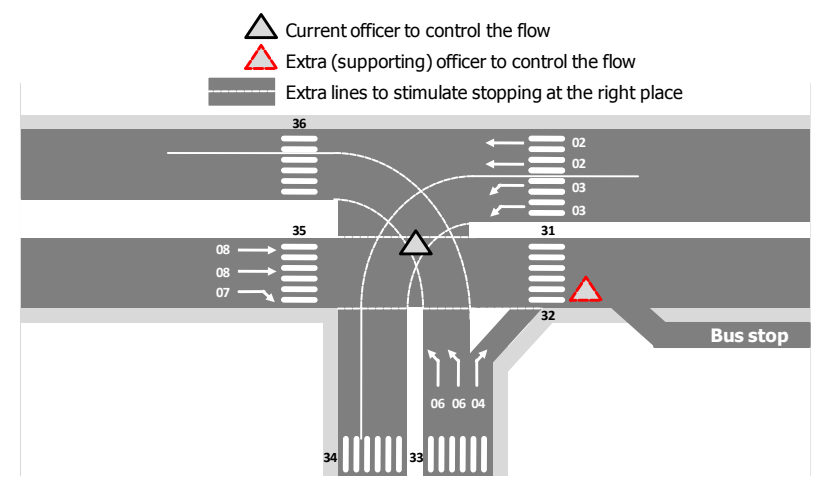

Figure 7.3: Graphical representation of recommended improvements. When not having the right-of-way, vehicles can drive up to dashed line of the lane with the right-of-way. Lane numbers according to Dutch standards

However, if future research shows that traffic responsive signal control can be tuned in Addis Ababa to result in a productivity higher than officer control (at Wellosefer higher than 0.84 ), then installing traffic responsive signals have to be reconsidered. Also, if in further research appears that coordinated responsive signal control strategies result in a significant decrease of waiting time in the network, installing signals has to be reconsidered. However, coordinated control is beyond the scope of this study. Fixed time control during off-peak hours - only when traffic cannot regulate itself - combined with officer control during peak hours would be an option, only if fixed time signal control is cheaper then officer control.

Overall, further research is recommended in the following fields:

- Installing traffic responsive signal control has the potential to improve the total interference flow. However, illustrated by this study, tuning the signals to the chaotic traffic situation in Addis Ababa to result in a higher productivity than officer control is not simple. It is recommended to study the feasibility of an increase of productivity by tuning traffic responsive signals.

- The models are developed within a specific range of variables and in a specific area in Addis Ababa. It is recommended to test the applicability of the developed models outside this range of variables and in other parts of Addis Ababa and other cities in Sub Saharan Africa.

- There is an obvious gap in literature concerning urban traffic performance in Sub Saharan Africa. To fill this gap, it is recommended to extend this study by determining the traffic flow characteristics for other urban areas in Sub Saharan Africa.

- The used dataset was small. If better reliability needed, it is recommended to use larger and richer datasets. However, for the purpose of flow improvement, small datasets appeared to be sufficient in this case to determine the most important factors that influence the flow.

- The current urban growth in Ethiopia is $4.3 \%$ (CIA, 2010). The urban growth is directly related to the increase of the number of trips by public transport (The World Bank, 2002). To cope with a large expected growth in traffic demand, maximizing the use of existing infrastructure will not be enough soon. A combination of maximizing the use of infrastructure with broader solutions such as extra infrastructure, coordinated traffic control and new mobility concepts - is difficult to realize (Gakenheimer, 1999) but essential. Further research is needed to determine what the effects of broader solutions will be and how these measures can be implemented successfully. 


\section{References}

AKCELIK, R. 1981. Traffic signals: capacity and timing analysis. ARRB Research record 123. Melbourne: Australian road research board.

ALEMU,H. 2010. INSA installing street surveillance cameras. Addis Fortune, March 21, 2010.

BARCELO, J. 2003. AIMSUN User manual v 4.1.3.

BARRETT, C., BERKBIGLER, K., SMITH, L., LOOSE, V., BECKMAN, R., DAVIS, J., ROBERTS, D. \& WILLIAMS, M. 1995. An operational description of TRANSIMS. Los Alamos, USA: Los Alamos National Laboratory.

BHATTACHARYA, P. G. \& BHATTACHARYA, A. K. 1982. Observation and analysis of saturation flow through signalised intersections in Calcutta. Indian Highways, 11-33.

BRACKSTONE, M. \& MCDONALD, M. 1999. Car-following: a historical review. Transportation Research Part F: Traffic Psychology and Behaviour, 2, 181-196.

BRAGA-NETO, U. M. \& DOUGHERTY, E. R. 2004. Is cross-validation valid for small-sample microarray classification. Bioinformatics, 20, 374-380.

BRANSTON, D. 1979. Some factors affecting the capacity of signalised intersections. Traffic Engineering and Control, 20, 390-396.

BRANSTON, D. \& GIPPS, P. 1981. Some experience with a multiple linear regression method of estimating parameters of the traffic signal departure process. Transportation Research Part A: General, 15, 445-458.

BRANSTON, D. \& VAN ZUYLEN, H. 1978. The estimation of saturation flow, effective green time and passenger car equivalents at traffic signals by multiple linear regression. Transportation research, 12, 47-53.

CIA 2010. CIA The world factbook. 2010 ed.: CIA.

COHEN, B. 2004. Urban growth in developing countries: a review of current trends and a caution regarding existing forecasts. World Development, 32, 23-51.

COHEN, B. 2006. Urbanization in developing countries: current trends, future projections, and key challenges for sustainability. Technology in Society, 28, 63-80.

CUDDON, A. P. \& OGDEN, K. W. 1992. The effect of heavy vehicles on saturation flows at signalised intersections. 16th Australian road research board conference. Perth, Australia. 
DE ANDRADE, J. P. 1988. The performance of urban intersections in Brazil. PhD thesis, University of Southampton.

DE JONGH SCHREUDER, H. \& VENTER, C. 2005. Implementation of traffic control measures systems as an interim labour-based alternative to intelligent transport systems. 24th Southern African Transport Conference. Pretoria, South Africa.

DEMOGRAPHIA 2006. World urban population density by country and area. 2006 ed.: Demographia.

DEMOGRAPHIA 2010. Demographia world urban areas and population projections. Demographia.

DURNING, A. T. 1992. How much is enough? The consumer society and the future of the earth, New York, Norton.

ERDFELDER, E., FAUL, F. \& BUCHNER, A. 1996. GPOWER: A general power analysis program. Behavior Research Methods Instruments \& Computers, 28, 1-11.

EVANS, L. \& WASIELEWSKI, P. 1983. Risky driving related to driver and vehicle characteristics. Accident Analysis \& Prevention, 15, 121-136.

FELLENDORF, M. \& VORTISCH, P. 2001. Validation of the microscopic traffic flow model VISSIM in different real-world situations. In: 80th meeting of the Transportation Research Board, 012001 Washington D.C., 1-9.

FHWA 2003. CORSIM User's Manual. McLean, VA: Department of transportation, office of safety and traffic operations.

FIELD, A. P. 2009. Discovering statistics using SPSS (and sex, drugs and rock ' $n$ ' roll), Los Angeles, SAGE Publications.

FILARSKI, R. 2004. The rise and decline of transport systems : changes in a historical context, Rotterdam, Rijkswaterstaat.

GAKENHEIMER, R. 1999. Urban mobility in the developing world. Transportation Research Part A: Policy and Practice, 33, 671-689.

GEBEYEHU, M. \& TAKANO, S. 2007. Diagnostic evaluation of public transportation mode choice in Addis Ababa. Journal of Public Tranportation, 10, 27-50.

GREENSHIELDS, B. D., SHAPIRO, D. \& ERICKSON, E. L. 1947. Traffic performance at urban intersections. Technical Report. New Haven: Bureau of highway traffic.

GWILLIAM, K. 2003. Urban transport in developing countries. Transport Reviews: A Transnational Transdisciplinary Journal, 23, 197-216.

HADIUZZAMAN, RAHMAN \& KARIM 2008. Saturation flow model at signalized intersection for non-lane based traffic. Canadian journal of transportation 2, 77-90.

HADIUZZAMAN, M. \& RAHMAN, M. M. 2010. Capacity analysis for fixed time signalized intersection for non-lane based traffic condition. Advanced Materials Research, 83-86, 904-913.

HEGYI, A. 2004. Model predictive control for integrating traffic control measures. PhD thesis, Delft University of Technology.

HEGYI, A. 2008. Dynamic traffic management: traffic control. Delft: Delft University of Technology. 
HOLROYD, E. M. 1963. Effect of motorcycles and pedal cycles on saturation flow at traffic signals. Roads Road Construction, 41, 315-316.

HOOGENDOORN, S. P. \& BOVY, P. H. L. 2001. State-of-the-art of vehicular traffic flow modelling. Proceedings of the Institution of Mechanical Engineers Part I-Journal of Systems and Control Engineering, 215, 283-303.

HOSSAIN, M. 2001. Estimation of saturation flow at signalised intersections of developing cities: a micro-simulation modelling approach. Transportation Research Part A: Policy and Practice, 35, $123-141$

HUSSAIN, A. M. 1990. Determination of saturation flows at signalised intersections in Malaysian urban areas. In: 6th REAAA conference, 1990 Kuala Lumpur.

HUZAYYIN, A. S. \& SHOUKRY, W. S. 1986. Saturation flow and effective approach width at signalised intersections in greater Cairo. In: 6th African Highway IRF conference, 1986 Cairo.

INDEXMUNDI 2010. Country facts. 2010 ed.

JOHN, G. H., KOHAVI, R. \& PFLEGER, K. 1994. Irrelevant features and the subset selection problem. In: Machine learning: proceedings of the 11th international conference, 1994 San Francisco, USA. 121-129.

KASHANI, H. R. \& SARIDIS, G. N. 1983. Intelligent control for urban traffic systems. Automatica, 19, 191-197.

KESSIDES, C. 2007. The urban transition in Sub-Saharan Africa: challenges and opportunities. Environment and Planning C-Government and Policy, 25, 466-485.

KHAN, S. 2007. Automated versus human traffic control for Dhaka and cities of developing countries. In: 10th international conference on computer and information technology, 2007 Dhaka. 1-4.

KIMBER, R. M., MCDONALD, H. \& HOUNSELL, N. B. 1986. The prediction of saturation flow for road junctions controlled by traffic signals. Research report 67. Berkshire: Transport Research Laboratory.

KIMBER, R. M., MCDONALD, M. \& HOUNSELL, N. B. 1985. Passenger car units in saturation flow: concept, definition, derivation. Transportation Research B, 19B, 39-61.

KLDASSOCIATES 1996. WATSim Model: user guide.

KOCKELMAN, K. M. \& SHABIH, R. A. 2000. Effect of vehicle type on capacity of signalized intersections. Journal of Transportation Engineering, 126, 506-512.

KUMAR, A. \& BARRET, F. 2008. Stuck in traffic: urban transport in Africa. The World Bank group.

LI, J. 2008. Comparison of saturation flow and headway between China and the Netherlands. Delft: Delft University of Technology.

LI, J., VAN ZUYLEN, H. J., CHEN, Y. \& LU, R. 2009. Comparison of driver behavior and saturation Flow between China and the Netherlands. In: Second international conference on transportation engineering, 2009 Chengdu, China. 643-655.

LO, H. K., CHANG, E. \& CHAN, Y. C. 2001. Dynamic network traffic control. Transportation Research Part a-Policy and Practice, 35, 721-744. 
LU, R. 2008. International comparison of driver behavior and simulation model applicability. MSc thesis, Delft University of Technology.

MARSH, B. W. 1927. Traffic Control. Annals of the American Academy of Political and Social Science, $133,90-113$.

MATHEW, T. V. \& RADHAKRISHNAN, P. 2010. Calibration of microsimulation models for nonlanebased heterogeneous traffic at signalized intersections. Journal of urban planning and development, 136, 59-66.

MAY, A. D. 1990. Traffic flow fundamentals, Englewood Cliffs, N.J., Prentice Hall.

MEADOWS, D. H. 1972. The limits to growth; a report for the Club of Rome's project on the predicament of mankind, New York, Universe Books.

MILLER, A. J. 1968. The capacity of signalised intersections in Australia. ARRB Bulletin. Melbourne: Australian road research board.

MINH, C. C., BINH, T. H., MAI, T. T. \& SANO, K. 2009. The delay estimation under heterogeneous traffic conditions. Journal of the Eastern Asia Society for Transportation Studies, 7, 1-13.

NELSON, J. D., BLUNDELL, S., PETTITT, P. \& THOMPSON, S. 2001. Intelligent transport systems solutions in transitional countries: the case of Korea. Transport Reviews, 21, 51-74.

NIITTYMAKI, J. \& PURSULA, M. 1992. Saturation flows at signal-group-controlled traffic signals. Transportation Research Record, 1572, 24-32.

OKTECH, T. 2003. Modeled performance characteristics of heterogeneous traffic streams containing non-motorized vehicles. In: 86nd TRB 2003 Annual Meeting, Jan 12-16 2003 Washington. 114.

PANWAI, S. \& DIA, H. 2005. Comparative evaluation of microscopic car following behaviour. Transactions on intelligent transportation systems, 6, 314-325.

PAPAGEORGIOU, M., DIAKAKI, C., DINOPOULOU, V., KOTSIALOS, A. \& WANG, Y. B. 2003. Review of road traffic control strategies. Proceedings of the Ieee, 91, 2043-2067.

PARK, B. \& QI, H. 2005. Development and evaluation of a procedure for the calibration of simulation models. Journal of the Transporation Research Board, 1934, 208-217.

PARK, B. \& SCHNEEBERGER, J. D. 2003. Microscopic simulation model calibration and validation: case study of VISSIM simulation model for a coordinated actuated signal system. Transportation Research Record 1856, 185-192.

PARK, B. \& WON, J. 2006. Microscopic simulation model calibration and validation handbook. Richmond: Traffic Operations Laboratory for Transportation Studies University of Virginia.

PTV 2003. VISSIM version 3.70 user manual.

QUADSTONE LIMITED 2002. PARAMICS model version 3.0 user guide and reference manual. Edinburgh, U.K.

RIGHOLT, J. \& BERKHOUT, A. 2009. Chinese driving behaviour in Nanjing, calibrating VISSIM parameters. Delft: Delft University of Technology. 
RUST, F. C., VAN WYK, L., ITTMANN, H. W. \& KISTAN, K. 2008. The role of R\&D in transport infrastructure in South Africa. In: 27th Annual Southern African Transport Conference 2008, 7-11 July, 20082008 Pretoria. SATC, 1-12.

SAHA, P., HOSSAIN, Q. S., MAHMUD, H. M. I. \& ISLAM, M. Z. 2009. Passenger Car Equivalent (PCE) of through vehicles at signalized intersections in Dhaka metropolitan city, Bangladesh. IATSS Research, 33, 99-204.

SALTER, R. J. 1974. Highway traffic analysis and design, London, Macmillan.

SCHAFER, A. \& VICTOR, D. G. 1999. Global passenger travel: implications for carbon dioxide emissions. Energy, 24, 657-679.

SCRAGGS, D. A. 1964. Determination of passenger car equivalent of goods vehicle in single lane flow at traffic signals. Report LN/573/DAS. Crowtorne: Road Research Laboratory.

SLOP, P. 1972. Criteria voor het aanbrengen van verkeerslichten (Criteria for installing traffic signals). Verkeerskunde 23.

SLOP, P. 1975. Criteria voor het aanbrengen van verkeerslichten (Criteria for installing traffic signals). Verkeerskunde, 26.

SUTANDI, A. C. 2008. Comparative analysis of advance and fixed time traffic control systems in increasing traffic performance. Media Teknik Sipil, 8, 51-58.

TAALE, H. 2008. Integrated anticipatory control of road networks. PhD, Delft University of Technology.

TARKO, A. P. \& TRACZ, M. 2000. Uncertainty in saturation flow predictions. In: BOARD, T. R. (ed.) Fourth international symposium on highway capacity. Hawaii.

TEPLY, S. 1984. Canadian capacity guide for signalized intersections. Institute of transportation engineers, District 7-Canada and the University of Alberta.

THE WORLD BANK 2002. Urban mobility in three cities, Addis Ababa, Dar es Salaam, Nairobi. SubSaharan Africa Transport Policy Program, The World Bank, Economic Commission for Africa.

THE WORLD BANK 2010. World databank, world development indicators and global development finance. The World Bank.

THE WORLD BANK 2011. Data Ethiopia. The World Bank.

TIWARI, G., FAZIO, J. \& PAVITRAVAS, S. 2000. Passenger car units for heterogeneous traffic using a modified density method. In: Fourth international symposium on highway capacity, June 27 July 12000 Maui, Hawaii.

TRAFFICWARE 2003. SimTraffic 6 traffic simulation software user guide. Albany, USA.

TRANSPORT AND ROAD RESEARCH LABORATORY 1963. A method of measuring saturation flow at traffic signals. Road note London: HMSO.

TRB 2000. Highway Capacity Manual 2000. Washington.

TURNER, J. \& HARAHAP, G. 2003. Simplified saturation flow data collection methods. In: CODATU VI Conference on the development and planning of urban transport, 1993 Tunis, Tunisia. 1-12.

UNITED NATIONS 2002. World urbanization prospects, the 2001 revision. New York: United Nations. 
UNITED NATIONS 2004. World urbanization prospects: the 2003 revision data tables and highlights. New York: United Nations.

UNITED NATIONS 2008. World urbanization prospects: the 2007 revision population database. 2008 ed.

VAN AERDE, M. 2005. INTEGRATION release 2.30 user's guide. M. Van Aerde \& Assoc.

VAN LINT, H. 2009. Innovations in dynamic traffic management. Intelligent transport systems and services for road transport. Delft: Delft University of Technology.

VANDERSCHUREN, M. 2007. Calibrating microscopic simulation models. In: 26th Southern African Transport Conference, 9-12 July 2007 Pretoria, South Africa. 610-620.

VIEN, L. L., IBRAHIM, W. H. W. \& SADULLAH, A. F. M. 2006. Passenger car equivalents and saturation flow rates for through vehicles at signalized intersections in Malaysia. In: ARRB conference - Research into Practice, 2006 Canberra, Australia. 1-9.

VIVIER, J. \& MEZGHANI, M. 2001. The millennium cities database: a tool for sustainable mobility. In: ECEEE 2001, Further than ever from Kyoto? Rethinking energy efficiency can get us there, 2001 Mandelieu, France. 474-479.

WANG, F. Y. 2003. Integrated intelligent control and management for urban traffic systems. 2003 Ieee Intelligent Transportation Systems Proceedings, Vols. 1 \& 2, 1313-1317.

WASIELEWSKI, P. 1979. Car-following headways on freeways interpreted by the semi-poisson headway distribution model. Transportation Science, 13, 36-54.

WEBSTER, F. V. 1958. A controlled experiment on the capacity of junctions with traffic signals. Road research Laboratory Research Note.

WEBSTER, F. V. 1964. Experiment on saturation flow of right-turning vehicles at traffic signals. Traffic Eng. Control, 11, 427-434.

WEBSTER, F. V. \& COBBE, B. M. 1966. Traffic Signals. Technical paper 56. London: HMSO.

WESTERMAN, M., BERGHOUT, L., VAN KONINGSBRUGGEN, P., EBBEN, M. \& MIDDELHAM, F. 2001. Verkeerskundige Architectuur, Architectuur voor verkeersbeheersing (Traffic Architecture, Architecture for Traffic Management). Ministerie van verkeer en waterstaat, Nederland.

WU, J., BRACKSTONE, M. \& MCDONALD, M. 1999. Car-following: a historical review. Transportation Research Part F: Traffic Psychology and Behaviour, 6, 165-184.

YANG, Q. A. 1997. A simulation laboratory for evaluation of dynamic traffic management systems. $\mathrm{PhD}$ Thesis, Massachusetts Institute of Technology. 


\section{Appendix A}

\section{Summary in paper format}

This appendix contains a summary of the study, using a format of a scientific paper. 


\title{
Urban traffic flow modeling in Addis Ababa
}

\author{
J.W.Zwarteveen ${ }^{\mathrm{a}}$, S.K.Zegeye ${ }^{\mathrm{b}}$, J.Hellendoorn ${ }^{\mathrm{c}}$ \\ ${ }^{a}$ Faculty of Mechanical, Maritime and Materials Engineering, Department of Transportation Engineering, Delft University of Technology, \\ Mekelweg 2, 2628 CD, Delft, the Netherlands, J.W.Zwarteveen@ student.tudelft.nl \\ ${ }^{b}$ Faculty of Mechanical, Maritime and Materials Engineering, Delft Centre for Systems and Control, Delft University of Technology \\ ${ }^{c}$ Faculty of Mechanical, Maritime and Materials Engineering, Department of Transportation Engineering, Delft University of Technology
}

\begin{abstract}
World's largest urbanization is taking place in Sub Saharan Africa. As a result the demand for mobility is increasing. However, the supply of infrastructure is low. This study modeled the flow of vehicles in at several intersections in Addis Ababa in order to simulate different strategies to improve the use of infrastructure. It appeared that the share of minibuses, the share of slow vehicles, the number of lanes per stream and the productivity of the type of control have significant influences on the total flow of conflict groups at intersections. Manual intersection control appeared to result in a relatively high productivity. Simple solutions to improve the vehicle throughput exist.
\end{abstract}

Keywords: Urban mobility, Traffic flow modeling, Saturation flow, Interference flow, PCU minibus

\section{Introduction}

Worldwide urbanization is stimulating a new global economy and vice versa. This interactive process will literally change the face of the planet (Cohen, 2004). More than half of world's population is currently living in cities. This share is expected to grow to almost 70 percent in 2050. The total world population growth in the same period (2010-2050) is estimated to be 33 percent; therefore, the prognosis for the absolute urban growth is 86 percent over the next 40 years (United Nations, 2008).

A significant share of the urban growth is taking place in large cities. Especially the number of conglomerates with more than 5 million inhabitants will grow. Middle and low income countries show the highest urban population increase, especially in Sub Saharan Africa (Gwilliam, 2003). Despite some economic benefits, the rapid urban growth in these developing countries is outstripping the capacity of most cities to provide adequate services for their citizens (Cohen, 2004). A high urbanization rate in combination with the intense desire for car ownership in developing countries causes a rapid growth of motorization (Gakenheimer, 1999). In other countries where public transport plays an dominant role, urban population growth goes hand in hand with a significant increase in public transport trips (The World Bank, 2002). On the other hand, a lack of infrastructure and weak maintenance put extra stress on these growing traffic flows with congestion, pollution and a low road safety level as a result (Rust et al., 2008, Cohen, 2004, Gakenheimer, 1999, Gwilliam, 2003).

Improved mobility in urban areas in developing countries is possible by building new infrastructure. However, this is a long term and expensive solution. A short term solution is to improve the traffic management to rationalize the use of existing infrastructure (Gakenheimer, 1999). The current traffic control and management in developing cities is underdeveloped (Gwilliam, 2003).

Urban traffic flows interfere at intersections. The intersections can be considered as the bottlenecks of the urban traffic flows. Severe congestion takes place when the demand of traffic outnumbers the supply of infrastructure. Optimizing the flow at intersections would result a decrease of congestion. In order to maximize the use of existing infrastructure, the influence of the different factors that influence the intersection flow have to be quantified. This can be done by modeling. Simulation can be used to assess flow-improving concepts. Commonly used intersection flow models are developed for Western traffic conditions, or are tailor made for specific cities in developing countries. The specific characteristics of chaotic urban traffic in developing countries result in different models per city.

Numerous scientists have studied the traffic flow at intersections in both developed countries and developing countries. However, no intersection flow study about a city in Sub Saharan Africa could be found. Since the largest urban growth worldwide is taking place in this area (Gwilliam, 2003), significant mobility related problems are to be expected. According to forecasts, African society is will be predominantly urban by 2025 (United Nations, 2004). Research on the urban intersection traffic flow in Sub Saharan Africa is needed in order to prevent large scale congestion problems. The Sub Saharan traffic has specific characteristics, such as a large share of minibuses and intersections controlled by officers. The effects of both characteristics on today's traffic in the considered area are not well-described in literature yet. This research will study several intersections in Addis Ababa, Ethiopia, as a start to fill this gap in scientific literature and to be able to quickly respond to the emerging mobility problems.

The goal of this research is the development of a simulation model that describes the traffic flows at intersections in Addis Ababa. The aim of the model is to perform ex ante assessment of different flow improvement strategies to maximize the use of existing infrastructure.

\section{Methods}

\subsection{Method of data generation}

Based on video images of traffic surveillance cameras, nine lanes at three intersections in Addis Ababa are studied. Per intersection, the geometry is determined using Google Earth. All lanes are part of conflict groups. Per vehicle, the vehicle 
Table 1: Definitions of the different vehicle classes

\begin{tabular}{lll}
\hline Class & Includes & Details \\
\hline \multirow{3}{*}{ Car } & Passenger car, taxi, SUV, pick-up & $2-7$ passengers \\
Minibus & Minibus & 12 passengers ${ }^{[1]}$ \\
Heavy vehicle & Medium bus, large bus & $>12$ passengers \\
& Light truck, heavy truck, trailer & Freight transport
\end{tabular}

[1] In Ethiopia a minibus is allowed to carry up to 12 passengers (Gebeyehu and Takano, 2007)

type and the time when the front axis crosses the stop line are manually registered, using a data log program. The observed vehicles are grouped into three vehicle categories: passenger cars, minibuses and heavy vehicles (Table 1). Motorbikes and non-motorized vehicles are not considered, since preliminary observations showed that these vehicles form a negligible share of the total vehicle composition. To be sure to measure the demand limited by the supply of the network and not the demand of the traffic during free flow, only queue discharging flows are studied. The output of the data log program consists of a list with vehicle types and their corresponding times of crossing the stop line. The total flow of a conflict group is measured as the total amounts of vehicles leaving the zone of interference per unit of time.

Two of the considered intersections are controlled by policemen. As a result, the stop position of vehicles before crossing the intersection differs heavily. In most cases, stop line is ignored since it is located far away from the intersection or simply because a stop line does not exist. Therefore, a virtual stop line is defined as the front of the last stop position of the first vehicle in a queue before it crosses the intersection.

\subsection{Calculation method PCU value and saturation flow}

The saturation flow is used as a macro performance measure of a lane at intersections and is applied extensively in intersection and control design. It is an indication of the maximum flow of a junction during green phase when operating under ideal conditions (Turner and Harahap, 1993). (Branston and van Zuylen, 1978) argue that it is a well-know property of signals that when the light turns green on an approach gaining right-of-way, the flow across the stop line quickly rises to a steady value, the saturation flow, of the approach. Removing the begin and end delay is enough to determine the saturation flow. However, preliminary analysis showed that the queue discharge flow in Addis Ababa does not reach a steady value. The flow is heavily fluctuating, as illustrated in Figure 1. Even during queue discharge large time headways occur as a result of significant differences in acceleration behavior and slow responding traffic (both observations confirm the traffic characteristics described by (Gakenheimer, 1999)). Therefore, removing only a begin and end lag will not result in an indication of the maximum flow of a junction when operating under ideal conditions.

(Lu, 2008) therefore uses a different method to determine the saturation flow. In this study, the saturation flow is defined as the vehicles with a headway time within plus and minus two $\sigma$ (i.e. standard deviation) from the mean. In the study of $\mathrm{Lu}$, this resulted in a maximum time headway of 6 seconds. All traffic with headways lower than 6 seconds was considered as being part of the saturation flow. However, including such large headway times, it is not likely to get a proper indication of the maximum flow of a junction when operating under ideal conditions.

The third method is to introduce a fixed threshold for the saturation flow, either measured by a maximum headway distance or a minimum number of vehicles per time interval. The latter was applied by (Minh et al., 2009). The problem with the study by Minh et al is that the threshold is defined for non-lane based traffic. This cannot be compared to the lane based traffic of Addis Ababa.

Traffic flows consist of both car following vehicles and nonfollowing vehicles. Non-following vehicles have such a large distance to the preceding vehicle that the driving behavior is not depending on the preceding vehicle. A study by (Wasielewski, 1979) concluded that vehicles with a time headway of larger than 4 seconds cannot be described as carfollowing vehicles. Concerning the traffic in Addis Ababa, this study assumes that a queue discharging flow consisting only of vehicles in a car-following state will give a proper indication of the maximum flow during green phase of a junction when operating under ideal conditions. Therefore, the upper limit of the time headway of 4 seconds is used as a threshold to define the saturation flow. An upper limit of the time headway will result in a lower boundary for the saturation flow. As a result, in this thesis the saturation flow is not a constant value as assumed by (Branston and van Zuylen, 1978), but consists of a range of values with a minimum threshold, as illustrated in Figure 1.

To compensate for vehicle differences, in this study the saturation flow is expressed in Passenger Car Units (PCU) per hour. The PCU value is the ratio between the time headway of a vehicle of a specific type and the time headway of a passenger car. As a result of different traffic behavior, the PCU values differ heavily for vehicle classes worldwide. Therefore, it is preferred to determine the PCU values in the same area where the saturation flow is measured. Different methods to calculate the saturation flow and the PCU values exist.

This research will use the multiple linear regression method for a combined calculation of the saturation flow and PCU value. It makes the results comparable to numerous studies worldwide (Lu, 2008, Li et al., 2009, Righolt and Berkhout, 2009, Hadiuzzaman et al., 2008, Turner and Harahap, 1993). Based on vehicle counts per vehicle type per time interval of 5 seconds, the PCU values and saturation flow value are determined by means of linear regression.

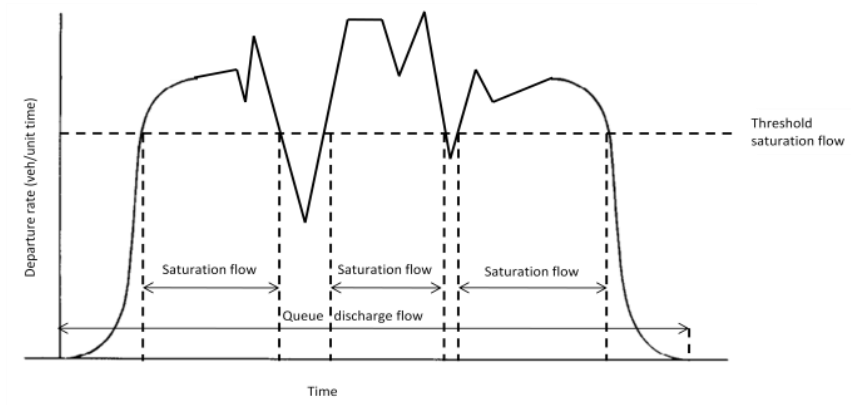

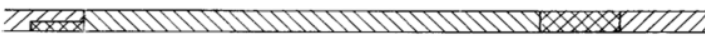

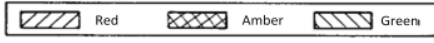

Figure 1: Representation of the saturation flow definition with a minimum threshold, adapted from (Kimber et al., 1985) 


\subsection{Calculation method queue discharge flow}

In this study, the saturation flow is determined to enable international comparison and to be able to calculate the PCU values. However, the queue discharge flow is needed to model the actual flow at conflicting streams at intersections. The difference between the saturation flow and the queue discharge flow is illustrated in Figure 1. The queue discharge flow is based on the overall amount of observed vehicles of a discharging flow during green phase per unit of time; therefore, it does include vehicles with a headway time of larger than 4 seconds. The conversion from vehicles per hour to PCU per hour is made by using the previously determined PCU values per vehicle class.

\subsection{Method of model development}

The objective of the model is to quantify the different factors that influence the flow of a conflict group at an intersection in order to suggest improvements. The total flow of a conflict group equals the average queue discharge flow of the involved lanes, minus losses for example due to transition of the rightof-way. The losses are expressed in the productivity factor.

\section{Where:}

$$
F=Q \times P
$$

$F$ total flow rate of conflict group (also called: interference flow),

$P \quad$ average productivity factor of the conflicting group,

$Q \quad$ average queue discharge flow rate per stream.

The productivity of signal controlled conflict groups can be calculated based on the signal settings. However, the productivity of officer controlled conflict groups are harder to determine. Both the productivity factor of officer controlled conflict groups and the queue discharge flow rate are functions of different influencing factors. Therefore, the productivity and the queue discharge rate will be modeled separately.

Nine different lanes at three different intersections are studied. Based on the average observed queue discharge flow rate per lane, a model is developed that quantifies the effects of different factors on the queue discharge rate by means of multiple linear regression (method also be used by e.g. (Kimber et al., 1986, Turner and Harahap, 1993, Hadiuzzaman et al., 2008, Hossain, 2001)). As a result of differences between the studied lanes, numerous factors can be studied. Examples of factors are: lane with, type of control (officer or signals) and traffic composition.

Furthermore, two hours of flow at a conflicting group at one intersection during heavy to oversaturated traffic conditions were studied. Based on these observations, the total flow rate of the conflict group $(F)$ can be determined. Combining this with the average queue discharge flow rate of the involved lanes enables the modeling of the productivity factor. The dataset is split into several groups and multiple linear regression is applied to determine the influence of different factors, such as the transition rate of the right-of-way and the amount of time the intersection is blocked.

The accuracy of the models is determined by leave-one-out cross-validation (e.g. used by (John et al., 1994)). A significance level of 0.01 is considered. Post hoc analysis using GPOWER (Erdfelder et al., 1996) is applied to determine whether the sample size is large enough for sufficient power.
Based on the developed models, simulation is used to suggest improvements to increase the total flow at a conflict group.

\section{Results}

\subsection{Area of data collection}

Addis Ababa consists of a basic road network. A network exists of links and nodes (or intersections). Three intersections in one corridor in Addis Ababa are considered. The African Avenue is the main road between the international airport and the city center; it is one of the major routes of Addis Ababa (Figure 2). Cameras are positioned at several intersections on the corridor. The available video images are from cameras positioned at the following intersections:

- Meskel: intersection at the Meskel Square

- Denbel: intersection with the Dem. Rep. Congo Street

- Wellosefer: intersection with the Ethio-China Street

Different lanes at all three intersections are studied to model the queue discharge flow. An overview of the specifications of the intersections is shown in Table 2. During 9 different days, randomly chosen in November and December 2011, 9 different lanes were studied during times of congestion for at least 30 minutes per lane, resulting in a total of 20 lane-hours. The Wellosefer intersection is particularly interesting since the traffic is completely regulated by policemen. No signals are installed. On the other hand, the Denbel and Meskel intersection are currently already (partially) controlled by signals. The Wellosefer intersection causes large delays and shows potential for improvement by simply replacing the manual controllers by signals. It offers the opportunity to study and model the interference flow. Wellosefer is a unique location to be able to estimate the improvements of signal control verses manual control in case of the Addis Ababa traffic situation.

\subsection{Flow characteristics}

In total, 6573 vehicles were counted, from which $76 \%$ were passenger cars, $21 \%$ were minibuses and $2 \%$ were heavy vehicles. The flow rate is measured in Passenger Car Unit (PCU) per hour. The saturation flow rate for straight through traffic at the corridor equaled $1522 \mathrm{PCU} / \mathrm{h}$ and the corresponding PCU values for minibuses and heavy vehicles were respectively 0.90 and 1.09 . The low PCU value for minibuses illustrates that their aggressive driving result in low time headways and therefore low PCU values. The queue discharge flow was significantly lower than the saturation flow, namely $1356 \mathrm{PCU} / \mathrm{h}$. This is caused by $9.1 \%$ of nonfollowing vehicles. Local (per intersection) and directional (turning and straight through) performances differ to some extent from the average.

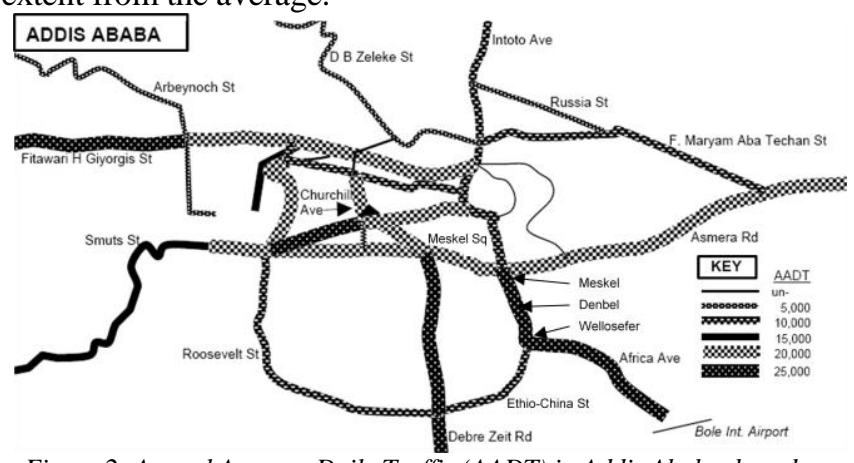

Figure 2: Annual Average Daily Traffic (AADT) in Addis Ababa, based on (The World Bank, 2002) 
Table 2: Average saturation flow per lane, combined with traffic and lane specifications, lane numbers according to Dutch standards

\begin{tabular}{|c|c|c|c|c|c|c|c|c|c|}
\hline $\begin{array}{l}\text { Dataset number } \\
\text { /intersection }\end{array}$ & Lane & $\begin{array}{l}\text { Control } \\
\text { type }\end{array}$ & Direction & $\begin{array}{l}\text { Sample size } \\
\text { (phas/int) }\end{array}$ & $\begin{array}{l}\text { Lane } \\
\text { width }\end{array}$ & $\% \mathrm{MB}$ & $\% \mathrm{HV}$ & $\% \mathrm{NF}$ & Q.d. flow PCU/h \\
\hline 1 Wellosefer & 8 right & human & straight & $119 / 779$ & 2.7 & 52.3 & 2.17 & 9.94 & 1317 \\
\hline 2 & 8 left & human & straight & $117 / 769$ & 2.7 & 8.94 & 2.61 & 8.41 & 1410 \\
\hline 3 & 6 left & human & turn & $91 / 207$ & 3.0 & 6.62 & 1.70 & 15.8 & 1359 \\
\hline 4 & 3 left & human & turn & $130 / 603$ & 3.0 & 7.09 & 3.77 & 11.1 & 1406 \\
\hline 5 Denbel & 2 right & human & straight & $18 / 212$ & 2.7 & 43.6 & 1.60 & 6.91 & 1371 \\
\hline 6 & 2 left & human & straight & $17 / 223$ & 2.7 & 21.0 & 0.858 & 20.5 & 1221 \\
\hline 7 & 2 right & signal & straight & $13 / 212$ & 2.7 & 49.6 & 2.30 & 8.00 & 1354 \\
\hline 8 & 2 left & signal & straight & $16 / 223$ & 2.7 & 21.4 & 1.49 & 10.3 & 1384 \\
\hline 9 Meskel & $11 \mathrm{mid}$ & signal & straight & $13 / 37$ & 3.5 & 16.9 & 9.56 & 8.46 & 1578 \\
\hline 10 & $11 \mathrm{left}$ & signal & straight & $14 / 43$ & 3.5 & 8.30 & 6.57 & 11.5 & 1393 \\
\hline 11 & 8 left & signal & straight & $21 / 98$ & 3.5 & 12.2 & 2.62 & 7.00 & 1452 \\
\hline
\end{tabular}

phas: green phases, int: time intervals, MB: minibuses, HV: heavy vehicles, NF:non-following vehicles, Q.d.: queue discharge

\subsection{Queue discharge modeling}

With the aim to quantify the influences of the significant factors on the queue discharge flow, a new model is developed. The effect of the following variables on the queue discharge flow rate was studied:

$L W \quad$ lane width,

$C T$ control type (signal controlled: $C T=1$, officer controlled: $C T=0)$,

$D T$ direction of flow (left: $D T=1$, straight through: $D T=0)$,

$M B$ fraction of vehicle mix consisting of minibuses,

$H V$ fraction of vehicle mix consisting of heavy vehicles $N F$ fraction of vehicle mix consisting of nonfollowing vehicles,

$P O S$ position on the road (left lane: $P O S=1$, non-left lane: $P O S=0$, figure 3).

It has to be noticed that some variables are dummy variables $(C T, D T$ and $P O S)$. These variables can have an effect on the queue discharge flow, but also on the effect of the other variables on the queue discharge flow (interaction effect) (Field, 2009). Both effects are studied.

Using linear regression, it appeared that the variables $M B, N F$ and $P O S$ have a significant influence on the queue discharge flow rate. Filling in the regression coefficients results in the following model to predict the queue discharge flow rate per lane $\left(Q_{\text {lane }}\right)$ :

$$
Q_{\text {lane }}=1765-622.7 \times M B-1194 \times N F-161.6 \times P O S
$$

The model has a R2 of 0.932 , a standard error of 27.3 and an accuracy of $2.9 \%$. The model complies with a level of significance of 0.01 . The power is sufficient (i.e. larger than 0.80 ), illustrating that the data size is large enough. Predicting the flow by using the HCM method (calibrated for Addis Ababa conditions) resulted in an average error of 5.56\% and a maximum individual maximum error of $16.2 \%$. Predicting the flow by using the newly developed model resulted in an

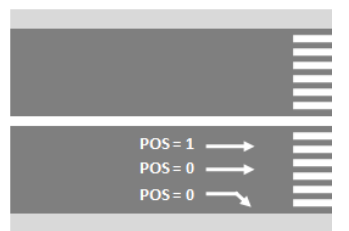

Figure 3: The value of POS for different lanes average error of $1.25 \%$ and a maximum individual error of $2.96 \%$. Besides a better fit to the observations, the newly developed model is also able to quantify the significant effects of the share of minibuses and non-following vehicles. Since a large share of minibuses is characteristic for Addis Ababa and most Sub Saharan African cities, the use of the Addis Ababa model is preferred over the existing HCM method.

The analysis of all considered variables is listed below:

Lane width $(L W)$

- There is no significant difference in the observed queue discharge flow between lanes with different widths.

- However, only a small range of lane widths is studied.

Control type (dummy variable) (CT)

- There is no significant difference in the observed queue discharge flow for lanes with different types of control. The presence of an officer does not slow down the traffic, nor does it increases the flow rate.

- There is no significant interaction effect

Fraction of vehicle mix consisting of minibuses $(M B)$

- There is a significant difference in the observed queue discharge flow between lanes with different percentage of minibuses.

- An increase in more minibuses will result in a decrease in queue discharge flow. Even though the aggressive driving causes a PCU value of less than one, it also results in a disturbance of the traffic flow, decreasing the total throughput.

- A large range of minibuses shares was studied.

Direction (dummy variable) (DT)

- There is no significant difference in the observed queue discharge flow for lanes with different directions.

- There is no significant interaction effect.

Percentage of vehicle mix consisting of heavy vehicles $(H V)$

- There is no significant difference in queue discharge flow for lanes with different percentage of heavy vehicles.

- However, only a small range of heavy vehicle percentages is studied.

Fraction of vehicle mix consisting of non-following vehicles $(N F)$

- There is a significant difference in the observed queue discharge flow between lanes with different percentage of non-following vehicles. 
Table 3: The interference flow, productivity factor and traffic specifications

\begin{tabular}{|c|c|c|c|c|c|}
\hline Dataset number & $\begin{array}{l}\text { Flow rate of conflict } \\
\text { group (F) }[\text { PCU/h] }\end{array}$ & Productivity factor (P) & Day & Change rate (/h) & Block ratio $(\%)$ \\
\hline 1 & 2282 & 0.798 & 1 & 106 & 3.92 \\
\hline 2 & 2157 & 0.754 & 1 & 141 & 8.80 \\
\hline 3 & 2438 & 0.852 & 1 & 113 & 0.00 \\
\hline 4 & 2150 & 0.752 & 1 & 122 & 3.74 \\
\hline 5 & 2158 & 0.754 & 1 & 91.8 & 6.27 \\
\hline 6 & 2213 & 0.774 & 1 & 146 & 3.08 \\
\hline 7 & 2375 & 0.831 & 1 & 84.9 & 1.18 \\
\hline 8 & 2321 & 0.812 & 2 & 63.4 & 2.05 \\
\hline 9 & 2084 & 0.729 & 2 & 63.7 & 6.78 \\
\hline 10 & 2162 & 0.756 & 2 & 63.5 & 5.59 \\
\hline 11 & 2346 & 0.820 & 3 & 76.4 & 4.14 \\
\hline 12 & 2405 & 0.841 & 3 & 79.1 & 0.550 \\
\hline
\end{tabular}

- An increase of non-following vehicles will result in a decrease in queue discharge flow.

Position on the road (dummy variable) (POS)

- There is a significant difference in average queue discharge flow between left lanes (near middle of the road) and non-left lanes.

- $\quad$ More aggressive drivers tent to drive left, resulting in a disturbed effect of the traffic flow. The left lane has therefore a lower observed queue discharge flow.

- There is no significant interaction effect.

- Only streams with two and three lanes are studied.

Furthermore, there is not a significance difference in the average queue discharge flow per intersection, nor for the effect of the other variables per intersection.

It must be noticed that the model is developed within a specific range of the variables (Table 2) and under specific conditions (season, traffic condition, locations). Using the model outside these ranges and under different conditions might result in a less accurate prediction.

\subsection{Queue discharge modeling}

With the aim to study the influence of different factors on the variation in productivity of the officer controlled intersection Wellosefer, a new model is developed. The effect of the following variables on the productivity was studied:

$C R$ Change rate, number of changes of right-of- way/h

$B R$ The blocking ratio, seconds of blocked direction during green time divided by the total time in seconds of dataset.

E.g. an intersection consists of 3 streams with each 2 lanes:

Case 1, one lane (half of the stream) is blocked during green phase for 10 seconds in a dataset with a length of 500 seconds:

$B R=(10 / 2) / 500=0.01$ Case 2, two lanes (complete stream) are blocked during green phase for 10 seconds in a dataset with a length of 500 seconds: $B R=10 / 500=0.02$

Using linear regression it appeared that only the variable BR has a significant influence on the interference productivity.

Filling in the regression coefficients results in the following model to predict the productivity $P$ :

$$
P=0.840-1.311 \times B R
$$

The model has a $\mathrm{R}^{2}$ of 0.721 , a standard error of 0.0229 and an accuracy of $2.8 \%$. The model complies with a level of significance of 0.01 . The power is sufficient (i.e. larger than $0.80)$, illustrating that the data size is large enough.

An increase of the blocking ratio will increase the unproductive time of the intersection and therefore decreases the productivity factor. The change rate $(C R)$ appears not to have a significant contribution to the variation of the queue discharge flow. The changes of flow direction happen so quickly that no significant productive time is lost. The intergreen-time due to changes of right-of-way is, as a result of highly efficient officer control, not significant. Furthermore, there is not a significance difference in the productivity factor per considered day, nor for the effect of the $B R$ per day.

The developed model can explain $72.1 \%$ of the observed productivity. The other effects might have been too small to be quantified in this research with a strongly limited dataset. A study for a longer period of time is recommended to increase the $\mathrm{R}^{2}$. However, since the model explains the majority of the variation productivity, it is well fit to be able to suggest flow improving solutions. It must be noticed that the model is developed within a specific range of the variables (Table 3) and under specific conditions (season, traffic condition, locations). Using the model outside these ranges and under different conditions might result in a less accurate prediction.

\subsection{Simulation}

An officer controlled conflict group at the Wellosefer intersection is used as a case study for flow improvement. The considered conflict group consists of 3 streams with each 2 lanes. Substituting results in the overall formula for the interference flow at Wellosefer:

$$
\begin{gathered}
F=2 \times(1765-622.7 \times M B-1194 \times N F-161.6 \times 0.5) \\
\times(0.840-1.311 \times B R)
\end{gathered}
$$

The total model will be used to simulate the effect of different situations on the interference flow Wellosefer.

The effects of vehicle composition, slow vehicles, blocked lanes and signals on the interference flow at Wellosefer were studied. Concerning vehicle composition, only the share of minibuses appeared to have a significant influence. Increasing the share of minibuses would result in a decrease of interference flow measured in PCU/h, however, it resulted in 


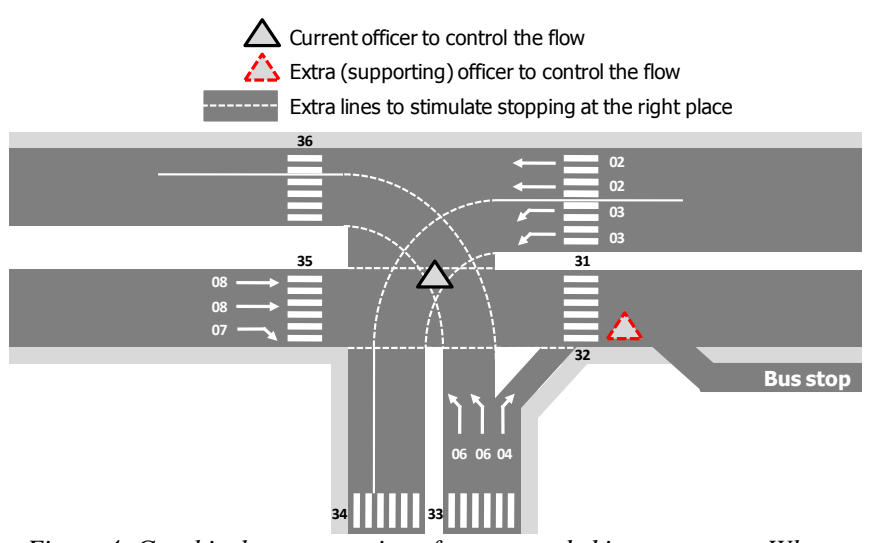

Figure 4: Graphical representation of recommended improvements. When not having the right-of-way, vehicles can drive up to dashed line of the lane with the right-of-way Lane numbers according to Dutch standards

an increase of interference flow measured in passenger $/ \mathrm{h}$. Reducing the share of slow vehicles (i.e. non-following vehicles) would result in an increase of interference flow, both for passengers and for PCUs. Reducing the amount of blocked lanes would also result in an increase of interference flow, both for passengers and for PCUs. Installing signals has the potential to improve the interference flow. A comparable Dutch intersection reaches a productivity of 0.90 (Hegyi, 2008). However, it is not sure whether the signal settings that determine the length of the transition periods can be tuned at Wellosefer in a way that results in an improvement compared to officer control. According to productivity model, the maximum possible productivity with officer control is 0.84 . Responsive control is more likely to result in an improvement than fixed signal control; on the other hand, responsive control is also more complex and more expensive.

A simple, low-cost and effective solution with a high certainty is to reduce the amount of blocked lanes by drawing stop lines, preventing interference between lanes 08 and lane 04 and preventing vehicles to stop on the road after the intersection. To enable this, an extra officer located near lane 04 is needed (Figure 4). If all blockages will be solved, the interference flow is expected to increase with $6.4 \%$.

This section described the simulation at the officer controlled intersection Wellosefer. The interference flow at the signal controlled intersections Meskel and Denbel can be predicted using the following format:

$$
F=Q \times \frac{T_{\text {cycle }}-T_{\text {lost }}}{T_{\text {cycle }}}
$$

Where:

$T_{\text {cycle }} \quad$ length of a complete control cycle,

$T_{\text {lost }} \quad$ total lost time per cycle.

\section{Discussion and conclusion}

The characteristics of vehicle flows at intersections in Addis Ababa are not well-described in literature. This study provides an insight in the characteristics of vehicle flows at intersections in Addis Ababa, Ethiopia. The saturation flow at the studied intersections for straight through traffic equals $1522 \mathrm{PCU} / \mathrm{h}$. This is comparable to the average of the range of saturation flows for developing countries presented by (Turner and Harahap, 1993). The PCU value of minibuses at the studied area was 0.90 for straight through vehicle flows. The low value represents the aggressive driving behavior. No comparable study could be found.

It appeared that the total flow at the studied conflict groups depends on the share of minibuses, the share of slow vehicles, the number of lanes per approach and the productivity of the type of control. Current officer control shows a relatively high productivity. It is unsure whether signal control is able to reach the same productivity. (Marsh, 1927) argues that thorough research by traffic experts is needed before and during installation to secure a high efficiency. Further research is needed to determine the feasible productivity of traffic responsive control at intersections in Addis Ababa.

The models are developed within a specific range of variables and in a specific area in Addis Ababa. It is recommended to test the applicability of the developed models outside this range of variables and in other parts of Addis Ababa and other cities in Sub Saharan Africa.

There is an obvious gap in literature concerning urban traffic performance in Sub Saharan Africa. It is recommended to extend this study by determining the traffic flow characteristics in terms of PCU values, saturation flow and flow modeling for other urban areas in Sub Saharan Africa to fill this gap.

The used dataset was small. If a higher reliability is needed, it is recommended to use larger datasets than used in this research. However, for the purpose of flow improvement, small datasets appeared to result in models that explained the majority of the variation, sufficient for flow improvement suggestions.

Simple solutions to prevent blocked lanes at one studied intersection with officer control are expected to result in a flow increase of $6.4 \%$. However, the current urbanization rate in Ethiopia is 4.3\% (CIA, 2010). The urban growth is directly related to the increase of number of trips by public transport (The World Bank, 2002). To cope with a large expected growth in traffic demand, maximizing the use of existing infrastructure will not be enough soon. As a result of the basic state of the economy, Western solutions such as homeworking and flexible working hours to prevent congestion are not likely to be successful. A combination of maximizing the use of infrastructure with larger solutions - such as extra infrastructure, coordinated traffic control and new mobility concepts - is difficult to realize (Gakenheimer, 1999) but essential. Further research is needed to determine what the effects of larger solutions will be and how these measures can be implemented successfully.

\section{Acknowledgements}

This study would not have been possible without the data that was generously provided by the INSA in Addis Ababa. The authors would like to express their gratitude towards all who made the fruitful cooperation possible.

\section{References}

BRANSTON, D. \& VAN ZUYLEN, H. 1978. The estimation of saturation flow, effective green time and passenger car equivalents at traffic signals by multiple linear regression. Transportation research, $12,47-53$

CIA 2010. CIA The world factbook. 2010 ed.: CIA

COHEN, B. 2004. Urban growth in developing countries: a review of current trends and a caution regarding existing forecasts. World Development, 32, 23-51. 
ERDFELDER, E., FAUL, F. \& BUCHNER, A. 1996. GPOWER: A general power analysis program. Behavior Research Methods Instruments \& Computers, 28, 1-11.

FIELD, A. P. 2009. Discovering statistics using SPSS (and sex, drugs and rock ' $n$ ' roll), Los Angeles, SAGE Publications.

GAKENHEIMER, R. 1999. Urban mobility in the developing world. Transportation Research Part A: Policy and Practice, 33, 671-689.

GEBEYEHU, M. \& TAKANO, S. 2007. Diagnostic evaluation of public transportation mode choice in Addis Ababa. Journal of Public Tranportation, 10, 27-50.

GWILLIAM, K. 2003. Urban transport in developing countries. Transport Reviews: A Transnational Transdisciplinary Journal, 23, 197-216.

HADIUZZAMAN, RAHMAN \& KARIM 2008. Saturation flow model at signalized intersection for non-lane based traffic. canadian journal of transportation 2, 77-90.

HEGYI, A. 2008. Dynamic Traffic Management: Traffic Control. Delft: Delft University of Technology.

HOSSAIN, M. 2001. Estimation of saturation flow at signalised intersections of developing cities: a micro-simulation modelling approach. Transportation Research Part A: Policy and Practice, 35, $123-141$.

JOHN, G. H., KOHAVI, R. \& PFLEGER, K. 1994. Irrelevant features and the subset selection problem. In: Machine learning: proceedings of the 11th international conference, 1994 San Francisco, USA. 121 129.

KIMBER, R. M., MCDONALD, H. \& HOUNSELL, N. B. 1986. The prediction of saturation flow for road junctions controlled by traffic signals. Research report 67. Berkshire: Transport Research Laboratory.

KIMBER, R. M., MCDONALD, M. \& HOUNSELL, N. B. 1985. Passenger car units in saturation flow: concept, definition, derivation. Transportation Research B, 19B, 39-61.

LI, J., VAN ZUYLEN, H. J., CHEN, Y. \& LU, R. 2009. Comparison of driver behavior and saturation flow between China and the Netherlands. In: Second international conference on transportation engineering, 2009 Chengdu, China. 643-655.
LU, R. 2008. International comparison of driver behavior and simulation model applicability. MSc thesis, Delft University of Technology.

MARSH, B. W. 1927. Traffic Control. Annals of the American Academy of Political and Social Science, 133, 90-113.

MINH, C. C., BINH, T. H., MAI, T. T. \& SANO, K. 2009. The delay estimation under heterogeneous traffic conditions. Journal of the Eastern Asia Society for Transportation Studies, 7, 1-13.

RIGHOLT, J. \& BERKHOUT, A. 2009. Chinese driving behaviour in Nanjing, calibrating VISSIM parameters. Delft: Delft University of Technology.

RUST, F. C., VAN WYK, L., ITTMANN, H. W. \& KISTAN, K. 2008. The role of R\&D in transport infrastructure in South Africa. In 27th Annual Southern African Transport Conference 2008, 7-11 July, 20082008 Pretoria. SATC, 1-12.

THE WORLD BANK 2002. Urban mobility in three cities, Addis Ababa, Dar es Salaam, Nairobi. Sub-Saharan Africa Transport Policy Program, The World Bank, Economic Commission for Africa.

TRB 2000. Highway Capacity Manual 2000. Washington.

TURNER, J. \& HARAHAP, G. 1993. Simplified saturation flow data collection methods. In: CODATU VI Conference on the development and planning of urban transport, 1993 Tunis, Tunisia. 1-12.

UNITED NATIONS 2004. World urbanization prospects: the 2003 revision data tables and highlights. New York: UN.

UNITED NATIONS 2008. World urbanization prospects: the 2007 revision population database. 2008 ed.

WASIELEWSKI, P. 1979. Car-following headways on freeways interpreted by the semi-poisson headway distribution model. Transportation Science, 13, 36-54. 


\section{Appendix B}

\section{Data}

The data can be found on the attached CD. The data is based on the output of TrafficLog and is categorized per intersection. Both the data files for saturated and queue discharge flow are available. The vehicle counts that form the basis of the interference flow are also enclosed. The format given below is used to save the saturation and queue discharge flow data. The first column shows the moment in time when the front axis of a vehicle crosses the stop line. Per green phase, the timer starts at 0 . The green phase starts when the first vehicle in the queue crosses the stop line. The second column is the time between two vehicles, i.e., the headway. The third column shows the vehicle type. Passenger cars, minibuses and heavy vehicles are represented by respectively the number 1,2 and 3 . The fourth column shows the number of the green cycle. The fifth column shows the number of the 5-seconds time interval. Vehicle counts per time interval of 5 seconds are used as a basis for the saturation flow calculation. The last column shows the name of the lane, using Dutch standardized numbering.

Table B.1: A sample of the flow data

\begin{tabular}{|c|c|c|c|c|c|}
\hline $\begin{array}{l}\text { Green time } \\
\text { (seconds) }\end{array}$ & $\begin{array}{l}\text { Headway } \\
\text { (seconds) }\end{array}$ & $\begin{array}{l}\text { Vehicle } \\
\text { type }\end{array}$ & Number of cycle & $\begin{array}{l}\text { Number of time interval } \\
\text { (per } 5 \mathrm{~s} \text { ) }\end{array}$ & Lane \\
\hline 0 & 0 & 1 & 1 & 1 & $11 \_2$ \\
\hline 3,817 & 3,817 & 3 & 1 & 1 & \\
\hline 9,692 & 5,875 & 3 & 1 & 2 & \\
\hline 12,212 & 2,52 & 1 & 1 & 3 & \\
\hline 14,527 & 2,315 & 2 & 1 & 3 & \\
\hline 16,423 & 1,896 & 1 & 1 & 4 & \\
\hline 19,961 & 3,538 & 1 & 1 & 4 & \\
\hline 0 & 0 & 2 & 2 & 1 & \\
\hline 3,184 & 3,184 & 1 & 2 & 1 & \\
\hline 5,45 & 2,266 & 1 & 2 & 2 & \\
\hline 6,826 & 1,376 & 2 & 2 & 2 & \\
\hline 8,641 & 1,815 & 1 & 2 & 2 & \\
\hline 11,395 & 2,754 & 1 & 2 & 3 & \\
\hline 12,811 & 1,416 & 2 & 2 & 3 & \\
\hline 15,15 & 2,339 & 2 & 2 & 4 & \\
\hline 17,23 & 2,08 & 1 & 2 & 4 & \\
\hline 18,702 & 1,472 & 1 & 2 & 4 & \\
\hline 19,681 & 0,979 & 2 & 2 & 4 & \\
\hline 21,832 & 2,151 & 1 & 2 & 5 & \\
\hline 0 & 0 & 2 & 3 & 1 & \\
\hline 3,234 & 3,234 & 1 & 3 & 1 & \\
\hline 5,346 & 2,112 & 1 & 3 & 2 & \\
\hline 7,253 & 1,907 & 1 & 3 & 2 & \\
\hline 9,828 & 2,575 & 1 & 3 & 2 & \\
\hline 11,776 & 1,948 & 1 & 3 & 3 & \\
\hline 14,199 & 2,423 & 1 & 3 & 3 & \\
\hline 15,655 & 1,456 & 1 & 3 & 4 & \\
\hline
\end{tabular}




\section{Appendix C}

\section{Measurement error}

A measurement error consists of a structural error (bias) and a variable error. The measurement error as a result of manual data logging using the program TrafficLog is a result of manual observation errors. It is expected to exist mainly of variable errors. The variable error is estimated by repetitive analysis of one cycle of traffic flows at one lane. To get an indication of the magnitude of the error introduced by manually logging the different vehicles using video data, the observation of this cycle was repeated for thirty times. It is assumed that the calculated variable error gives a good indication of the total measurement error.

Video images of the traffic flow at one lane during one green phase at Wellosefer, at 10-22-2010, from 17:11:18-17:12:11 were studied. During this green phase, 20 vehicles were observed.

\section{Time headway}

The time headway is one of the measurement units used in this thesis. The figure below shows the time headway on the vertical axis, the different vehicles that passed the stop line during green phase are shown on the horizontal axis (19 vehicles, since the first vehicle does not have a time headway). The time headway has been observed for 30 repetitions (Figure C.1). The boxplots per vehicle represent the different measured time headways for the individual vehicles during all repetitions. It can be seen that the difference between the first and the third percentile is lower than $0.25 \mathrm{~s}$. The largest variation between the minimum and maximum value can be witnessed at vehicle number 16 , the difference is $0.64 \mathrm{~s}$. The measurement error per vehicle is calculated according to the following formula:

$$
\epsilon_{h, i}=\frac{1}{n} \sum_{n} \frac{H_{\text {observed }, n, i}-H_{\text {mean observed }, i}}{H_{\text {mean observed }, i}}
$$

Where:

$\varepsilon_{h, i} \quad$ measurement error of the time headway of vehicle $i$,

$\mathrm{H}_{\mathrm{observed}, \mathrm{n}, \mathrm{i}} \quad$ observed time headway during repetition $\mathrm{n}$ of vehicle $i$, 


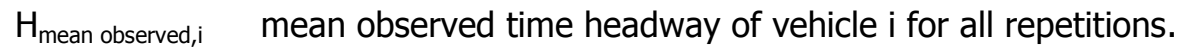

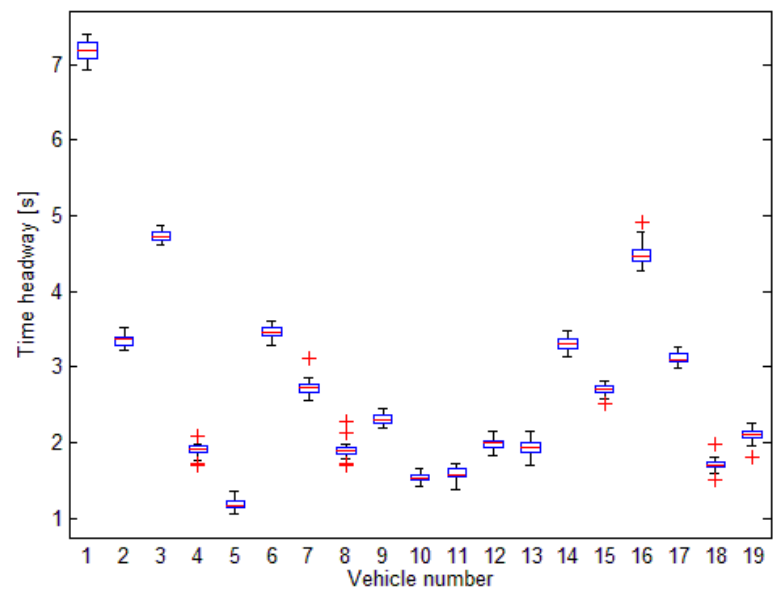

Figure C.1: The time headway per vehicle of one green phase with 19 vehicles, measured 30 repetitive times. The boxplot shows the first percentile, the mean and the third percentile. The red crosses are the outliers according to standard Matlab settings.

The average error of all 19 vehicles is $2.78 \%$ and is used as an indication of the measurement error for the headway time.

\section{Vehicle counts}

Besides the time headway, vehicle counts per time interval of 5 seconds is also used as a measurement unit in this thesis The same dataset is used to determine the measurement error for the time headway is used to determine the measurement error of vehicle counting method. In total, vehicles were counted for 30 times, during 11 time intervals. The measurement error per time interval is calculated according to the following formula:

$$
\epsilon_{v, i}=\frac{1}{n} \sum_{n} \frac{V_{\text {observed }, n, i}-V_{\text {mean observed }, i}}{V_{\text {mean observed }, i}}
$$

Where:

$\varepsilon_{v, i} \quad$ measurement error of vehicle counts of interval $i$,

$\mathrm{V}_{\text {observed,n,i }} \quad$ observed number of vehicles during repetition $\mathrm{n}$ of time interval $i$,

$\mathrm{V}_{\text {mean observed,i }}$ mean observed number of vehicles during time interval $i$ for all repetitions.

The average error of all 11 time intervals is $1.70 \%$ and is used as an indication of the measurement error for the vehicle count method. 


\section{Appendix D}

\section{Saturation flow model comparison}

(Transport and Road Research Laboratory, 1963) developed the Road Note 34 method. The numbers of vehicles of a queue discharging flow passing the stop line are recorded during successive short time intervals. The data has to be filtered in order to get the saturation flow, usually by removing the start and end delay per green phase. Saturation flows obtained by this method are expressed in vehicles/unit time. This method does not allow the calculation of PCU values of different vehicle types from observed data.

A commonly used alternative to the counting method is the average headway method (e.g., applied by (Greenshields et al., 1947, Scraggs, 1964, Miller, 1968, Webster, 1964)). The average headway method is based on time headways between vehicles. The time headway of a vehicle is usually measured as the time between the crossings of the stop line by the rears of two successive vehicles during queue discharging flow. The PCU value of a vehicle class is the average headway of its class divided by the average headway of passenger cars. The saturation flow in PCU per hour is calculated as the reciprocal of the average headway of straight on passenger cars. The data has to be filtered in order to get the saturation flow, usually by removing the start and end delay per green phase. However, this method can only be applied under specific conditions. (Scraggs, 1964, Salter, 1974, Kimber et al., 1985) describe the following condition for application:

$$
H_{\mathrm{cc}}+H_{\mathrm{bb}}=H_{\mathrm{cb}}+H_{\mathrm{bc}}
$$

Where:

$H_{c c} \quad$ headway of a car behind a car,

$H_{\mathrm{bb}} \quad$ headway of a bus behind a bus,

$H_{\mathrm{cb}} \quad$ headway of a car behind a bus,

$H_{b c} \quad$ headway of a bus behind a car.

If this condition holds for every considered vehicle class, than the headway ration can be used. However, preliminary analysis of a small set of data showed that the Addis Ababa traffic observations do not comply with the condition. The headway method can therefore not be used. This might be explained by the measurement method that has been used. In this study, as a result of limited 
camera angles, the headway is measured between the fronts of vehicles. Ideally, one would like to measure it between the rears of vehicles, taking only the own vehicle length into account.

In an attempt to obtain simultaneous estimations of all relevant properties of the discharge process, multiple linear regression was applied (Branston and van Zuylen, 1978, Branston and Gipps, 1981, Holroyd, 1963). The number of vehicles that pass the stop line in consecutive time periods of $n$ seconds is measured. A vehicle is counted when the front axis of the vehicle passes the stop line. In this estimation method, different classes of vehicles are distinguished. The saturation flow is defined as the number of passenger car units that cross the stop line per hour. Per measurement of length $T$, the following equation can be formulated.

$$
n_{\mathrm{c}}+n_{1} \times p c u_{1}+n_{2} \times p c u_{2}+\cdots+n_{i} \times p c u_{i}=S \times T
$$

Where:

$n_{\mathrm{c}} \quad$ number of passenger cars,

$n_{\mathrm{i}} \quad$ number of vehicles from class $i$,

$p c u_{i} \quad$ PCU value of vehicles from class $i$,

$S$ saturation flow measured in PCU/h,

$T \quad$ length of time interval.

After having observed the traffic flows for a period of time, a large number of equations per small time interval can be formulated. Linear regression with all these equations will result in the saturation flow measured in PCU/h and corresponding PCU values for the previously defined vehicle classes.

For this study, both the linear regression method and the Note 34 method combined with an alternative method to calculate the PCU value (e.g., as described by (Webster, 1958, Tiwari et al., 2000)) can be used to determine the saturation flow and the PCU values. Since the multiple linear regression combines the calculation of the saturation flow and PCU value in on, this thesis will use linear regression. It makes the results also comparable to numerous studies worldwide (Lu, 2008, Li et al., 2009, Righolt and Berkhout, 2009, Hadiuzzaman et al., 2008, Turner and Harahap, 1993).

Similar to other studies, the length of the time interval is chosen to be 5 seconds. However, since the length of the green phase differs significantly with officer control, the last interval will almost never be complete. For example, a green phase with the length of 38 seconds will result in 7 time intervals of 5 seconds. The last three seconds will be removed from the dataset. To be sure to measure only complete time intervals, the last time interval of each green cycle will not be considered. 


\section{Appendix E}

\section{Model calculations versus observations}

Sections 5.1.2 and 5.2.2 describe the development of respectively the queue discharge model and the intersection productivity model. Figures below show the different plots of the predicted and observed values. The observed data correspond with the data presented in Tables 5.1 and 5.4.
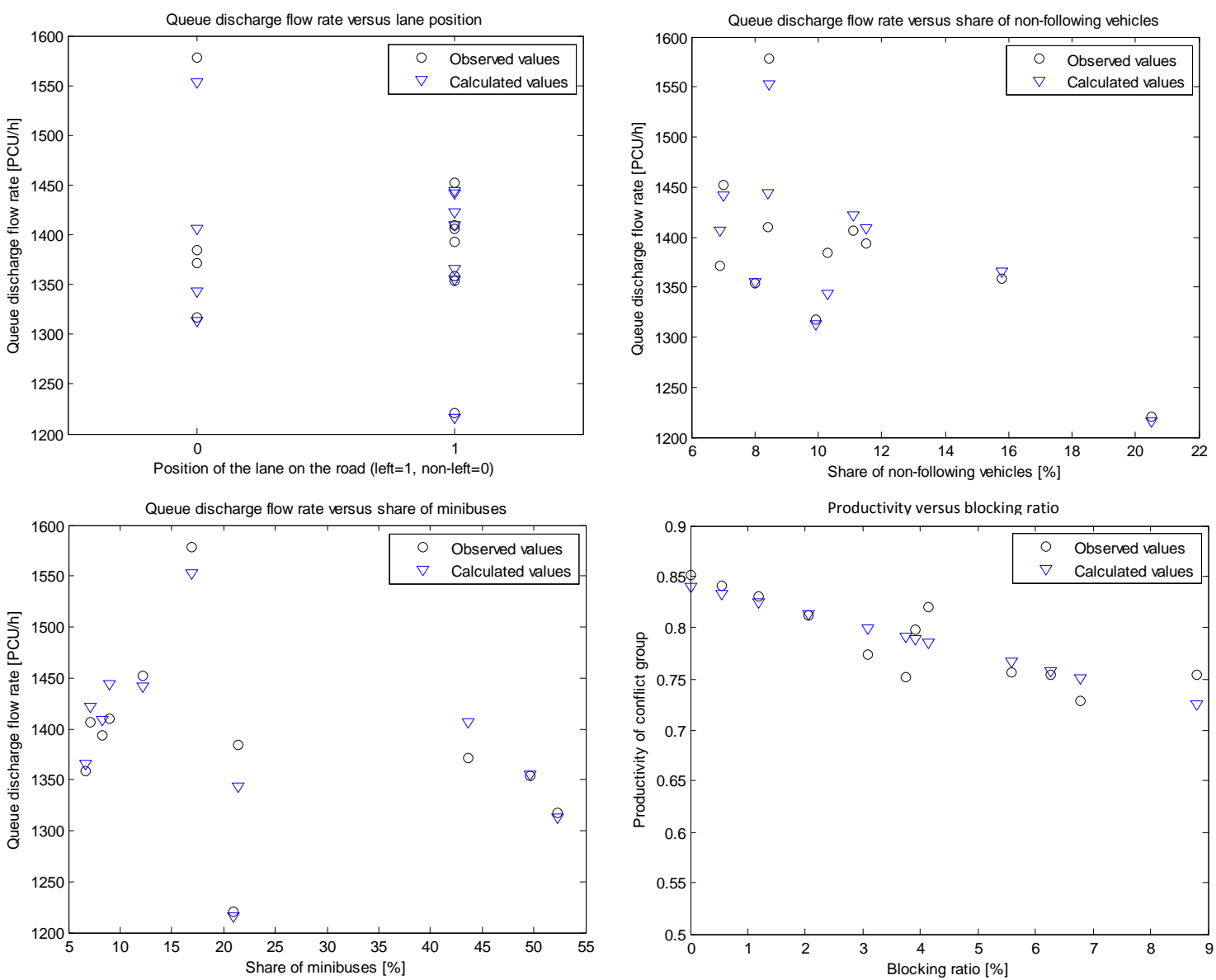

Figure E.1: Observed and calculated values of the queue discharge flow versus the lane position (top left), the share of non-following vehicles (top right) and the share of minibuses (bottom left). Bottom right shows the observed and calculated values of the productivity of a conflict group versus the blocking ratio. Per observed data point there is one calculated data point with the same $x$-axis value (clearly visible in bottom left figure). 


\section{Appendix F}

\section{Prediction of queue discharge flow by HCM method}

No model to predict the actual occurring queue discharge flow based on lane and traffic specifications could be found, however, numerous methods to predict the saturation flow are well-used. One of the most common methods to predict the saturation flow can be found in the Highway Capacity Manual (HCM) (TRB, 2000). It is to be expected that a model to predict the saturation flow will overestimate the queue discharge flow. This appendix describes the application of the calibrated HCM method to predict the queue discharge flow.

The expression that is used in the HCM method for the saturation flow $\mathrm{S}$ is:

$$
S=f \times S_{0}
$$

Where:

$S_{0} \quad$ the basic saturation flow (1800 PCU/hr),

$f \quad$ the adjustment factor for intersection and traffic specifications.

Factor $\mathrm{f}$ is a product of the following factors:

$$
f=n_{\text {lanes }} \times f_{\mathrm{w}} \times f_{\text {hv }} \times f_{\mathrm{g}} \times f_{\mathrm{p}} \times f_{\mathrm{bb}} \times f_{\mathrm{a}} \times f_{\mathrm{rt}} \times f_{\text {lt }}
$$

Where:

$n_{\text {lanes }}$ number of lanes; for all datasets presented in Table $5.1, n_{\text {lanes }}=1$,

$f_{\mathrm{w}} \quad$ adjustment factor for lane width; for lane widths of $2.7,3.0$ and 3.5 meter, $f_{\mathrm{w}}$ is respectively $0.88,0.94$ and 0.99 ,

$f_{\text {hv }}$ adjustment factor for heavy vehicles; for a share of heavy vehicles of $0 \%, 2 \%, 4 \%, 6 \%, 8 \%$ and $10 \%, f_{\mathrm{hv}}$ is respectively $1.00,0.99,0.98,0.97,0.96$ and 0.96 ,

$f_{\mathrm{g}} \quad$ adjustment factor for grade; for all datasets presented in Table 5.1, $f_{\mathrm{g}}=1$,

$f_{\mathrm{p}} \quad$ adjustment factor for parking facilities; for all datasets presented in Table 5.1, $f_{\mathrm{p}}=1$,

$f_{\mathrm{bb}} \quad$ adjustment factor for bus blockage; for all datasets presented in Table 5.1, $f_{\mathrm{bb}}=1$,

$f_{\mathrm{a}} \quad$ adjustment factor for area type; for all situations presented in Table 5.1, $f_{\mathrm{a}}=0.90$,

$f_{\mathrm{rt}} \quad$ adjustment factor for right turning movements; for all datasets presented in Table 5.1, $f_{\mathrm{rt}}=1$,

$f_{\mathrm{tt}} \quad$ adjustment factor for left turning movements; for left turning lanes, $f_{\mathrm{t}}=0.92$. 
Figure F.1 shows the flow predicted using the calibrated HCM model to the data presented in Table 5.1. The predicted flow values are compared to the observed flow values. As expected, the HCM model results in most of the cases in an overestimation of the queue discharge flow. The average error is $5.56 \%$, with an individual maximum of $16.2 \%$. The main disadvantages of the HCM model are that it does not take the type of intersection control, the share of minibuses and the share of nonfollowing vehicles (i.e., vehicles with a headway larger than 4 seconds, see Section 3.1.3) into account.

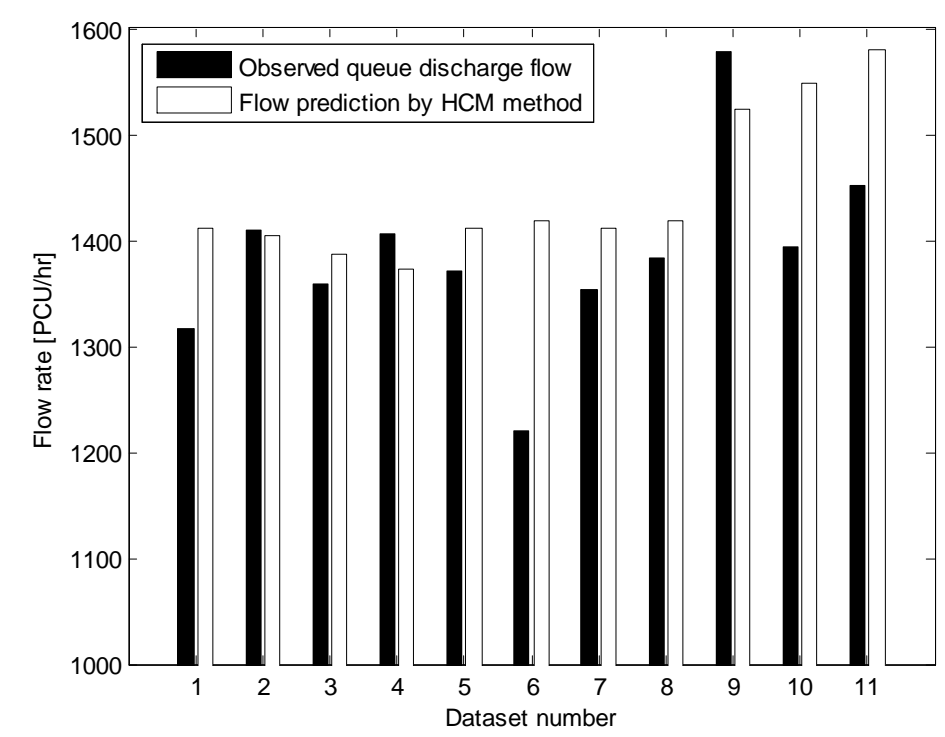

Figure F.1: Predicted flow by the HCM method versus the observed queue discharge flow. The dataset numbers on the $x$-axis correspond with the dataset numbers from Table 5.1. 


\section{Appendix G}

\section{Cross-validation of the models}

The calculations of the cross-validation (Section 5.1.4) of the queue discharge model are described in the table below. The numbers of the dataset refer to Table 5.1. The average error is $2.9 \%$

Table G.1: Cross validation of the queue discharge model

\begin{tabular}{|c|c|}
\hline Step & Details \\
\hline $\begin{array}{l}\text { Include dataset } 1-10 \text {, } \\
\text { test on dataset } 11\end{array}$ & $\begin{array}{ll}\text { - } & \text { Model: } 1598.8-284,2 * \mathrm{MB}-1371.2 * \mathrm{NF}-23.14 * \mathrm{POS}=\mathrm{QD} \\
\text { - } & \text { Calculated value } \mathrm{QD}=1441 \mathrm{PCU} / \mathrm{h} \text {, observed value } \mathrm{QD}=1578 \mathrm{PCU} / \mathrm{h} \\
\text { - } & \text { Error: } 8.7 \%\end{array}$ \\
\hline $\begin{array}{l}\text { Include dataset } 2-11 \text {, } \\
\text { test on dataset } 1\end{array}$ & $\begin{array}{ll}\text { - } & \text { Model: } 1758,8-630,0 * \mathrm{MB}-1198,1 * \mathrm{NF}-161,8 * \mathrm{POS}=\mathrm{QD} \\
\text { - } & \text { Calculated value } \mathrm{QD}=1311 \mathrm{PCU} / \mathrm{h} \text {, observed value } \mathrm{QD}=1317 \mathrm{PCU} / \mathrm{h} \\
\text { - } & \text { Error: } 0.46 \%\end{array}$ \\
\hline $\begin{array}{l}\text { Include dataset } 1,3-11 \text {, } \\
\text { test on dataset } 2\end{array}$ & $\begin{array}{l}\text { - } \quad \text { Model: } 1757.5-630.0 * \mathrm{MB}-1162.1 * \mathrm{NF}-163.5 * \mathrm{POS} \\
\text { - } \quad \text { Calculated value QD=1364 PCU/h, observed value QD=1359 PCU/h } \\
\text { Error: } 0.37 \%\end{array}$ \\
\hline $\begin{array}{l}\text { Include dataset } 1-2,4- \\
11 \text {, test on dataset } 3\end{array}$ & $\begin{array}{l}\text { - } \quad \text { Model: } 1760,5-629,4 * \mathrm{MB}-1200,8 * \mathrm{NF}-161,1 * \mathrm{POS} \\
\text { - } \quad \text { Calculated value } \mathrm{QD}=1423 \mathrm{PCU} / \mathrm{h} \text {, observed value } \mathrm{QD}=1406 \mathrm{PCU} / \mathrm{h} \\
\text { - }\end{array}$ \\
\hline $\begin{array}{l}\text { Include dataset } 1-3,5- \\
11 \text {, test on } 4\end{array}$ & $\begin{array}{l}\text { - } \quad \text { Model: } 1768,1-628,4 * \mathrm{MB}-1297,4 * \mathrm{NF}-153,8 * \mathrm{POS} \\
\text { - } \quad \text { Calculated value } \mathrm{QD}=1454 \mathrm{PCU} / \mathrm{h} \text {, observed value } \mathrm{QD}=1410 \mathrm{PCU} / \mathrm{h} \\
\text { - }\end{array}$ \\
\hline $\begin{array}{l}\text { Include dataset } 1-4,6- \\
11 \text {, test on dataset } 5\end{array}$ & $\begin{array}{l}\text { - Model: } 1758,8-623,8 * \mathrm{MB}-1207,9 * \mathrm{NF}-161,7 * \mathrm{POS} \\
\text { - } \quad \text { Calculated value } \mathrm{QD}=1116 \mathrm{PCU} / \mathrm{h} \text {, observed value } \mathrm{QD}=1221 \mathrm{PCU} / \mathrm{h} \\
\text { - } \quad \text { Error: } 8.6 \%\end{array}$ \\
\hline $\begin{array}{l}\text { Include dataset } 1-5,7- \\
11 \text {, test on dataset } 6\end{array}$ & $\begin{array}{l}\text { - } \quad \text { Model: } 1757,3-624,3 * \mathrm{MB}-1192,3 * \mathrm{NF}-161,7 * \mathrm{POS} \\
\text { - } \quad \text { Calculated value } \mathrm{QD}=1350 \mathrm{PCU} / \mathrm{h} \text {, observed value } \mathrm{QD}=1354 \mathrm{PCU} / \mathrm{h} \\
\quad \text { Error: } 0.30 \%\end{array}$ \\
\hline $\begin{array}{l}\text { Include dataset } 1-6,8- \\
11 \text {, test on dataset } 7\end{array}$ & $\begin{array}{l}\text { - } \quad \text { Model: } 1766,1-606,5 * \mathrm{MB}-1248,2 * \mathrm{NF}-166,0 * \mathrm{POS} \\
\text { - } \quad \text { Calculated value } \mathrm{QD}=1412 \mathrm{PCU} / \mathrm{h} \text {, observed value } \mathrm{QD}=1371 \mathrm{PCU} / \mathrm{h} \\
\quad \text { Error: } 3.0 \%\end{array}$ \\
\hline $\begin{array}{l}\text { Include dataset } 1-7,9- \\
11, \text { test on dataset } 8\end{array}$ & $\begin{array}{l}\text { - } \quad \text { Model: } 1772,6-683,4 * \mathrm{MB}-1083,2 * \mathrm{NF}-191,7 * \mathrm{POS} \\
\text { - } \quad \text { Calculated value } \mathrm{QD}=1329 \mathrm{PCU} / \mathrm{h} \text {, observed value } \mathrm{QD}=1384 \mathrm{PCU} / \mathrm{h} \\
\text { - }\end{array}$ \\
\hline $\begin{array}{l}\text { Include dataset } 1-8,10- \\
11 \text {, test on dataset } 9\end{array}$ & $\begin{array}{l}\text { - } \quad \text { Model: } 1759,8-628,5 * \mathrm{MB}-1197,7 * \mathrm{NF}-160,8 * \mathrm{POS} \\
\text { - } \quad \text { Calculated value } \mathrm{QD}=1405 \mathrm{PCU} / \mathrm{h} \text {, observed value } \mathrm{QD}=1393 \mathrm{PCU} / \mathrm{h} \\
\text { - }\end{array}$ \\
\hline $\begin{array}{l}\text { Include dataset } 1-9,11 \text {, } \\
\text { test on dataset } 10\end{array}$ & $\begin{array}{l}\text { - } \quad \text { Model: } 1751,5-628,8 * \mathrm{MB}-1096,4 * \mathrm{NF}-170,5 * \mathrm{POS} \\
\text { - } \quad \text { Calculated value } \mathrm{QD}=1429 \mathrm{PCU} / \mathrm{h} \text {, observed value } \mathrm{QD}=1452 \mathrm{PCU} / \mathrm{h} \\
\text { - }\end{array}$ \\
\hline
\end{tabular}


The calculations of the cross-validation (Section 5.2.4) of the interference productivity model are described in the following table. The numbers of the dataset refer to Table 5.4. The average error is $2.8 \%$

Table G.2: Cross validation of the productivity model

\begin{tabular}{|c|c|}
\hline Step & Details \\
\hline $\begin{array}{l}\text { Include dataset } 1-11 \text {, } \\
\text { test on dataset } 12\end{array}$ & $\begin{array}{l}\text { - } \text { Model: } 0.837-1.266 * \mathrm{BR}=\mathrm{P} \\
\text { - } \quad \text { Calculated value } \mathrm{P}=0.83 \text {, observed value } \mathrm{P}=0.84 \\
\text { Error: } 1.2 \%\end{array}$ \\
\hline $\begin{array}{l}\text { Include dataset } 2-12 \text {, } \\
\text { test on dataset } 1\end{array}$ & $\begin{array}{l}\text { - } \quad \text { Model: } 0.839-1.312 * B R=P(R 2=0,725) \\
\text { - } \quad \text { Calculated value } P=0.79 \text {, observed value } P=0.80 \\
\text { Error: } 1.6 \%\end{array}$ \\
\hline $\begin{array}{l}\text { Include dataset } 1,3-12 \text {, } \\
\text { test on dataset } 2\end{array}$ & $\begin{array}{ll}\text { - } & \text { Model: } 0.848-1.622 * B R=P(R 2=0,784) \\
\text { - } & \text { Calculated value } \mathrm{P}=0.71 \text {, observed value } \mathrm{P}=0.75 \\
\text { - } & \text { Error: } 6.0 \%\end{array}$ \\
\hline $\begin{array}{l}\text { Include dataset } 1-2,4- \\
12 \text {, test on dataset } 3\end{array}$ & $\begin{array}{l}\text { - } \quad \text { Model: } 0.835-1.227 * \mathrm{BR}=\mathrm{P}(\mathrm{R} 2=0,653) \\
\text { - } \quad \text { Calculated value } \mathrm{P}=0.84 \text {, observed value } \mathrm{P}=0.85 \\
\text { - } \text { Error: } 1.8 \%\end{array}$ \\
\hline $\begin{array}{l}\text { Include dataset } 1-3,5- \\
12 \text {, test on dataset } 4\end{array}$ & $\begin{array}{ll}\text { - } & \text { Model: } 0.844-1.317 * \mathrm{BR}=\mathrm{P}(\mathrm{R} 2=0,792) \\
\text { - } & \text { Calculated value } \mathrm{P}=0.79 \text {, observed value } \mathrm{P}=0.75 \\
\text { - } & \text { Error: } 6.0 \%\end{array}$ \\
\hline $\begin{array}{l}\text { Include dataset } 1-4,6- \\
12 \text {, test on dataset } 5\end{array}$ & $\begin{array}{ll}\text { - } & \text { Model: } 0.840-1.299 * \mathrm{BR}=\mathrm{P}(\mathrm{R} 2=0,700) \\
\text { - } & \text { Calculated value } \mathrm{P}=0.76 \text {, observed value } \mathrm{P}=0,75 \\
\text { - } & \text { Error: } 1.2 \%\end{array}$ \\
\hline $\begin{array}{l}\text { Include dataset } 1-5,7- \\
12 \text {, test on dataset } 6\end{array}$ & $\begin{array}{ll}\text { - } & \text { Model: } 0.843-1.338 * \mathrm{BR}=\mathrm{P}(\mathrm{R} 2=0,756) \\
\text { - } & \text { Calculated value } \mathrm{P}=0.80 \text {, observed value } \mathrm{P}=0.77 \\
\text { - } & \text { Error: } 4.1 \%\end{array}$ \\
\hline $\begin{array}{l}\text { Include dataset } 1-6,8- \\
12 \text {, test on dataset } 7\end{array}$ & $\begin{array}{ll}- & \text { Model: } 0.838-1.285^{*} \mathrm{BR}=\mathrm{P}(\mathrm{R} 2=0,693) \\
\text { - } & \text { Calculated value } \mathrm{P}=0.81 \text {, observed value } \mathrm{P}=0.83 \\
\text { - } & \text { Error: } 1.8 \%\end{array}$ \\
\hline $\begin{array}{l}\text { Include dataset } 1-7,9- \\
12 \text {, test on dataset } 8\end{array}$ & $\begin{array}{ll}\text { - } & \text { Model: } 0.840-1.314 * B R=P(R 2=0,713) \\
\text { - } & \text { Calculated value } P=0.81 \text {, observed value } P=0.81 \\
\text { - } & \text { Error: } 0.0 \%\end{array}$ \\
\hline $\begin{array}{l}\text { Include dataset } 1-8,10 \text { - } \\
12 \text {, test on dataset } 9\end{array}$ & $\begin{array}{ll}\text { - } & \text { Model: } 0.838-1.209 * B R=P(R 2=0,686) \\
\text { - } & \text { Calculated value } P=0.76 \text {, observed value } P=0.73 \\
\text { Error: } 3.6 \%\end{array}$ \\
\hline $\begin{array}{l}\text { Include dataset } 1-9,11- \\
12 \text {, test on dataset } 10\end{array}$ & $\begin{array}{l}\text { - } \quad \text { Model: } 0.840-1.284 * B R=P(R 2=0,709) \\
\text { - } \quad \text { Calculated value } P=0.77 \text {, observed value } P=0.76 \\
\text { - } \quad \text { Error: } 1.1 \%\end{array}$ \\
\hline $\begin{array}{l}\text { Include dataset } 1-10,12 \text {, } \\
\text { test on dataset } 11\end{array}$ & $\begin{array}{l}\text { - } \quad \text { Model: } 0.837-1.326 * \mathrm{BR}=\mathrm{P}(\mathrm{R} 2=0,779) \\
\text { - } \quad \text { Calculated value } \mathrm{P}=0.78 \text {, observed value } \mathrm{P}=0.82 \\
\text { - }\end{array}$ \\
\hline
\end{tabular}




\section{Appendix H}

\section{Calculation of specifications simulation}

During the simulation of the traffic flows at Wellosefer, only one factor is variable per simulation. The other influencing factors are kept constant at the average observed value. The average values per stream of the conflict group based on all observations at Wellosefer (Table 6.1) are calculated in Table H.1.

Table H.1: The average values for the variables for the streams of the conflict group at Wellosefer

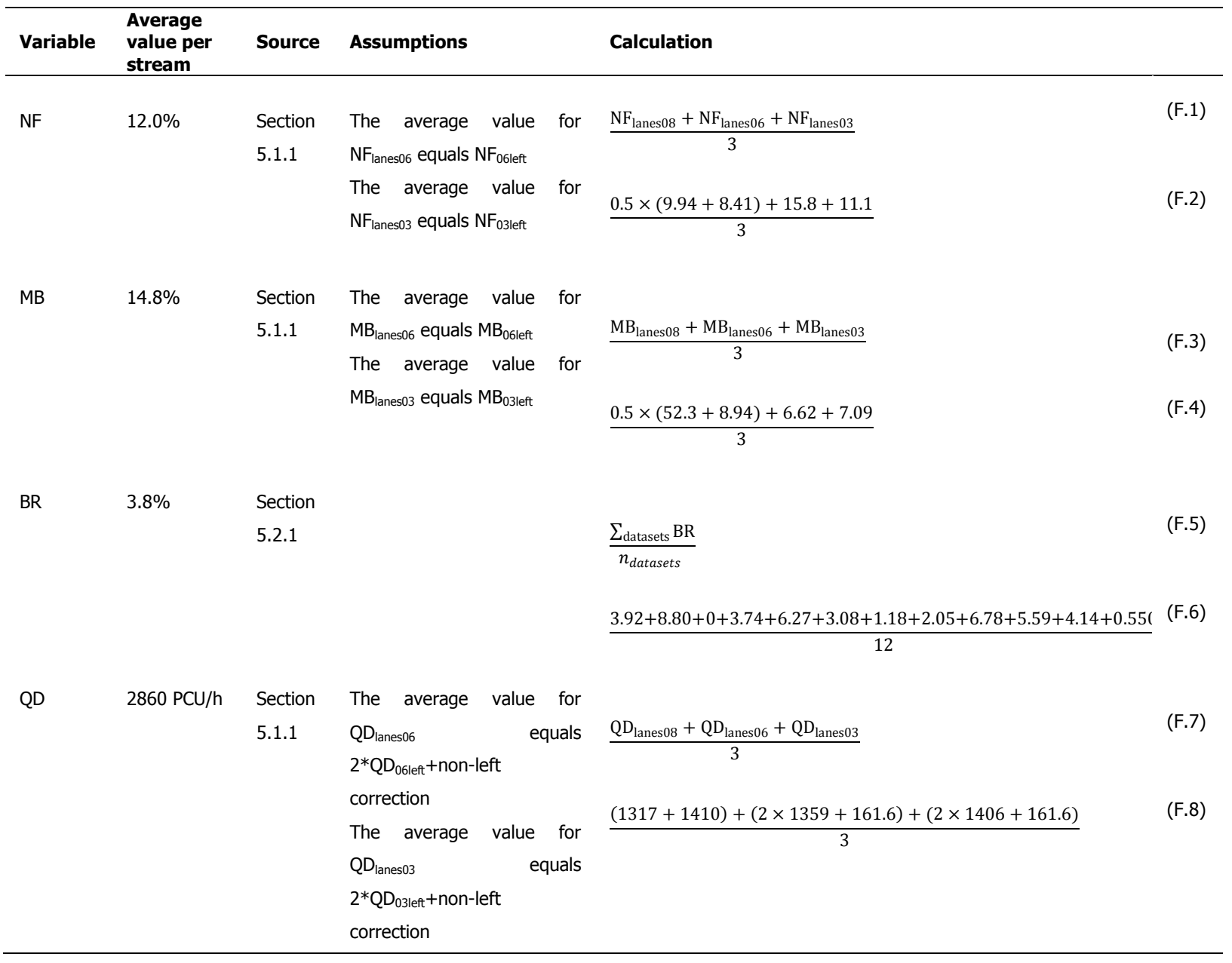


Furthermore, the average queue discharge flow rate at Wellosefer based on all observations at Wellosefer is determined to calculate the productivity factor. This value is also presented in Table H.1. An alternative manner to calculate the queue discharge flow rate is by means of model part one for a stream consisting of one left and one non-left lane:

$$
Q D=2 \times(1765-622.7 \times \mathrm{MB}-1194 \times \mathrm{NF}-0.5 \times 161.6)
$$

Filling in the average values of the variables results in:

$$
\begin{gathered}
Q D=2 \times(1765-622.7 \times 0.148-1194 \times 0.120-0.5 \times 161.6) \\
Q D=2898 \mathrm{PCU} / \mathrm{h}
\end{gathered}
$$

Both methods result in comparable answers (error 1.3\%). The value of $2860 \mathrm{PCU} / \mathrm{h}$ will be used. 


\section{Appendix I}

\section{Traffic modes}

The following definitions of traffic modes are based on (Kashani and Saridis, 1983). The various traffic situations which may be experienced are partitioned to five categories: sparse traffic, light traffic, heavy traffic, oversaturated traffic, and immobile traffic/incident.

1. Sparse traffic mode is declared when there is a very low flow of traffic. Control is based on the intuitive argument that a road accommodating more traffic (larger S) shall have greater discharge time. The demand of traffic is lower than the supply of the infrastructure.

2. Light traffic mode is recognized when the arrival rates are low and queues are short. Hence, a goal to allow all vehicles in the queues plus those arriving during the green phase to leave the intersection would be feasible. The demand of traffic is lower than the supply of the infrastructure.

3. Heavy traffic mode is identified by two characteristics: persisting queues and high arrival rates. The demand of traffic equals the level of supply of infrastructure.

4. Oversaturated traffic mode is recognized by very long queues, just about to overspill. The demand of traffic is equal to or slightly larger than the level of supply of infrastructure.

5. Immobile traffic/incident mode is declared whenever immobility is caused due to an incident or other unpredictable events. The solution will be handled through the higher levels in the hierarchy. The demand of traffic is larger than the level of supply of infrastructure.

Category 1 and 2 can also be considered as under-saturated traffic. 


\section{Appendix J}

\section{Significance and power}

An explanation of the statistical concepts of significance and power is described in this Appendix.

Assume a null hypothesis $\mathrm{H}_{0}: \mathrm{P}=1$. A sample from the population can either confirm or reject the null hypothesis. However, there is a chance of confirming $\mathrm{H}_{0}$ based on the sample, while the hypothesis in the population is false. This is called a type 2 error. There is also a chance of rejecting the hypothesis based on the sample, while the hypothesis in the population is true. This is called a type 1 error (see table below).

The probability of a type 1 error is a. The significance level is a. In general, results with a significance level of $<0.05$ or $<0.01$ are considered to be significant. This study uses a significant level of 0.01 to minimize differences between the sample and the observation.

The probability of a type 2 error is $\beta$. The power is $(1-\beta)$ and depends on data size, significance, the coefficient of determination $\left(R^{2}\right)$ and the number of predictors. In general, results with a power $>0.80$ are considered to be adequate. Post hoc analysis, using GPower (Erdfelder et al., 1996) is performed to determine whether the sample size was appropriate enough to realize sufficient power.

Table J.1: type 1 and type 2 error

\begin{tabular}{c|l|l|l|}
\multicolumn{2}{c|}{} & \multicolumn{2}{c|}{ Population } \\
\cline { 2 - 4 } \multicolumn{1}{c|}{} & $\mathbf{H}_{\mathbf{0}}=$ true & $\mathbf{H}_{\mathbf{0}}=$ false \\
\cline { 2 - 4 } Sample & $\mathbf{H}_{0}=$ false & Type I error & \\
\cline { 2 - 4 } & $\mathbf{H}_{\mathbf{0}}=$ true & & Type II error \\
\cline { 2 - 4 } & &
\end{tabular}




\section{Appendix K}

\section{Definitions of frequently used words}

\begin{tabular}{|c|c|}
\hline Word & Definition \\
\hline Conflict group & $\begin{array}{l}\text { A group of streams at an intersection from which only one stream at the time can have the right-of- } \\
\text { way in order to prevent collisions or blocked lanes (see also Figure H.2). }\end{array}$ \\
\hline Conflicting streams & Streams belonging to a conflict group (see also Figure H.2) \\
\hline Control cycle & $\begin{array}{l}\text { The length of the period in which each of the streams of a conflict group has received the right-of- } \\
\text { way at least once }\end{array}$ \\
\hline Demand of traffic & The amount of vehicles that want to make use of the infrastructure \\
\hline Departure flow & Synonym for queue discharge flow \\
\hline Direction & A stream can have different directions: straight through and turning \\
\hline Flow / flow rate & The flow rate is the flow expressed per hour \\
\hline Green phase & The time that a stream has the right-of-way \\
\hline Interference efficiency & $\begin{array}{l}\text { Indication of performance of a conflict group. Ratio of realized interference flow and the maximum } \\
\text { saturation flow of involved streams }\end{array}$ \\
\hline Interference flow & $\begin{array}{l}\text { The total output of a conflict group. It is the sum of the flows of the streams that are part of the conflict } \\
\text { group, taking losses into account due to transition of the right-of-way }\end{array}$ \\
\hline Interfering streams & Synonym for conflicting streams \\
\hline Intersection & The place where different streams meet \\
\hline Junction & Synonym for intersection \\
\hline Lane & A piece of road that allows a one-vehicle-width flow of traffic (see also Figure H.1) \\
\hline Queue discharge flow & $\begin{array}{l}\text { The actual flow of a junction during green time when operating under normal conditions, usually } \\
\text { expressed per lane or stream. Measured in vehicles or Passenger Car Units. }\end{array}$ \\
\hline Right-of-way & Streams at an intersection that are allowed to drive have the right-of-way \\
\hline Saturation flow & $\begin{array}{l}\text { An indication of the maximum flow of a junction during green time when operating under ideal } \\
\text { conditions, usually expressed per lane or stream. Measured in vehicles or Passenger Car Units. }\end{array}$ \\
\hline Stream & A combination of lanes with one-directional flow (see also Figure H.1) \\
\hline Supply of infrastructure & The amount of vehicles the infrastructure can process \\
\hline (Time) headway & $\begin{array}{l}\text { The headway is an indication of the distance between vehicles. In this thesis, the headway of a } \\
\text { vehicle is defined as the moment in time when the front axis of the preceding vehicle crosses the } \\
\text { stop line minus the moment in time when its own front axis crosses the same stop line. }\end{array}$ \\
\hline
\end{tabular}

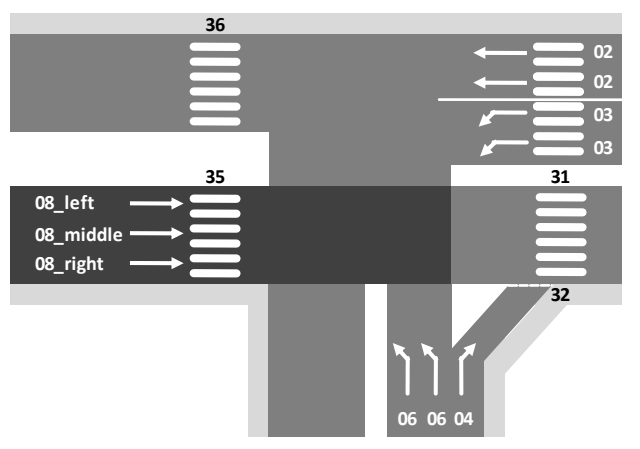

Figure H.1: One stream consisting of three lanes. Lane numbers according to Dutch standards.

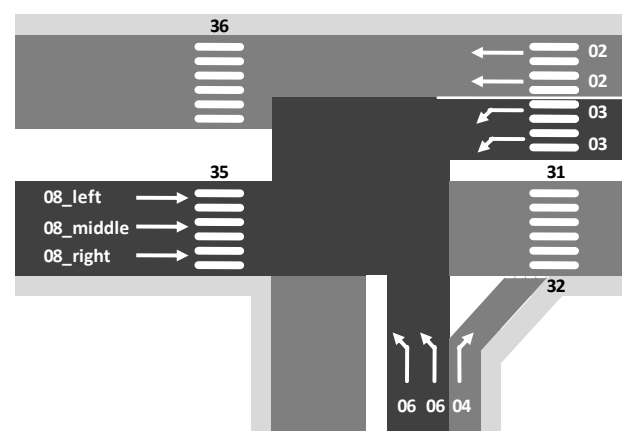

Figure H.2: One conflict group consisting of three conflicting streams. Lane numbers according to Dutch standards. 